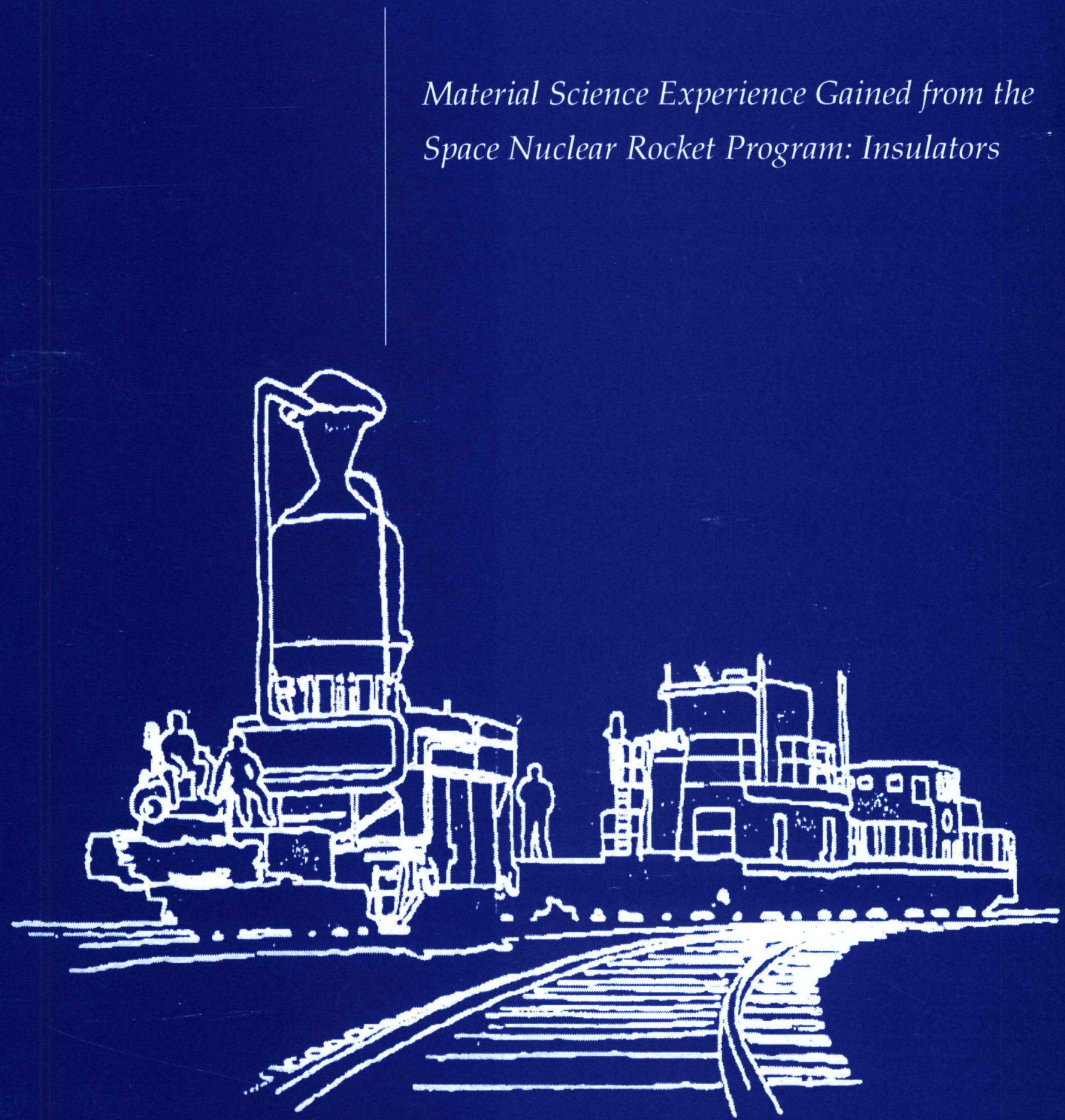




\section{DISCLAIMER}

This report was prepared as an account of work sponsored by an agency of the United States Government. Neither the United States Government nor any agency Thereof, nor any of their employees, makes any warranty, express or implied, or assumes any legal liability or responsibility for the accuracy, completeness, or usefulness of any information, apparatus, product, or process disclosed, or represents that its use would not infringe privately owned rights. Reference herein to any specific commercial product, process, or service by trade name, trademark, manufacturer, or otherwise does not necessarily constitute or imply its endorsement, recommendation, or favoring by the United States Government or any agency thereof. The views and opinions of authors expressed herein do not necessarily state or reflect those of the United States Government or any agency thereof. 


\section{DISCLAIMER}

Portions of this document may be illegible in electronic image products. Images are produced from the best available original document. 


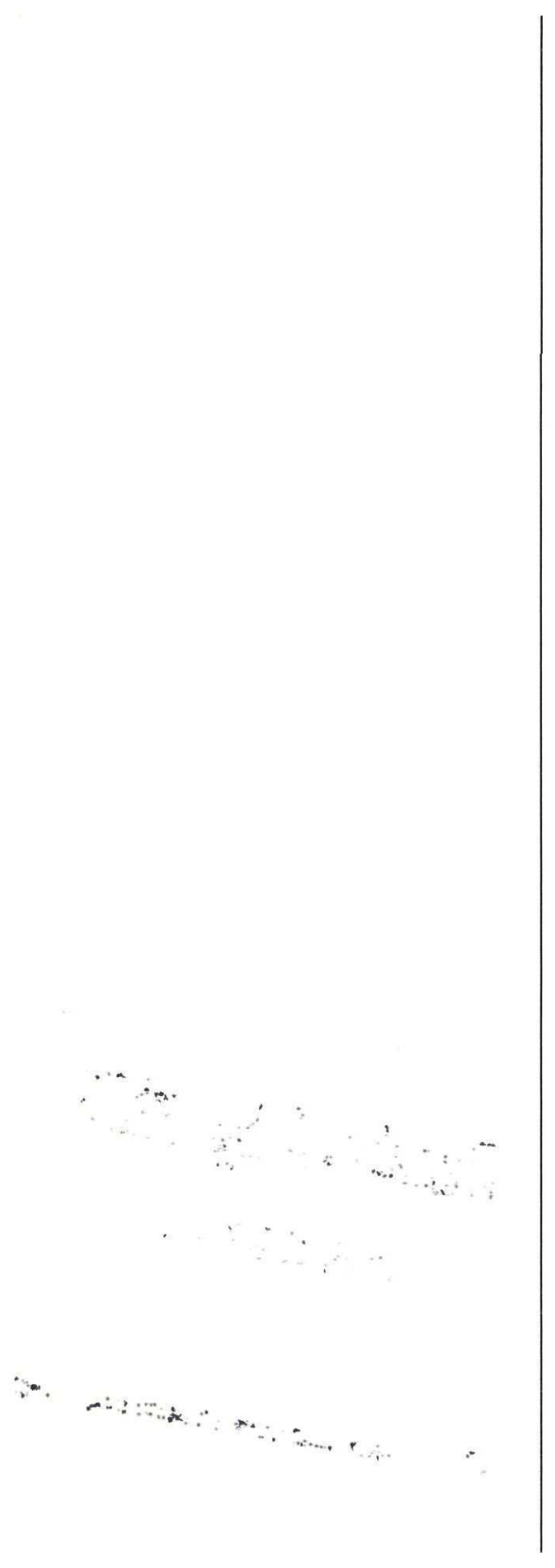

Edited by Paul W. Henriksen, Group IS-11

Prepared by Genara R. Jaramillo, N Division

An Affirmative Action/Equal Opportunity Employer

This report was prepared as an account of work sponsored by an agency of the

United States Government. Neither The Regents of the University of California, the

United States Government nor any agency thereof, nor any of their employees, makes any warranty, express or implied, or assumes any legal liability or responsibility for the accuracy, completeness, or usefulness of any information, apparatus, product, or process disclosed, or represents that its use would not infringe privately owned rights. Reference herein to any specific commercial product, process, or service by trade name, trademark, manufacturer, or otherwise, does not necessarily constitute or imply its endorsement, recommendation, or favoring by The Regents of the University of California, the United States Government, or any agency thereof. The views and opinions of authors expressed herein do not necessarily state or reflect those of The Regents of the University of California, the United States Government, or any agency thereof. 
Material Science Experience Gained from the Space Nuclear Rocket Program: Insulators

Paul Wagner

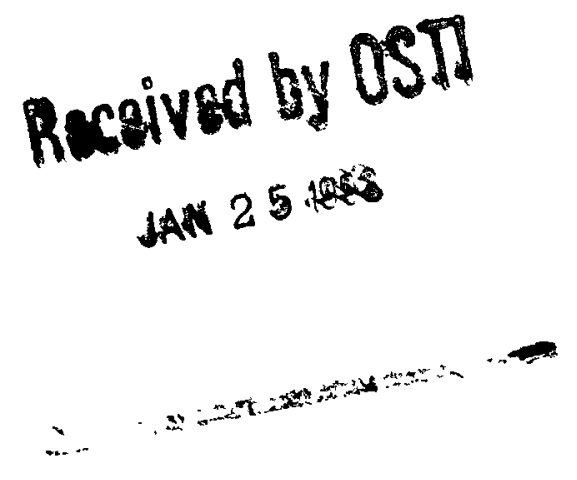


Blank Page 


\section{Preface}

In one of his last recorded educational television broadcasts, Nobel Laureate Richard Feynman observed that the generation of new knowledge is a slow, and often painful, process. This was certainly true in the Rover Program. Not only was our way beset with uncertainties in what materials to use and how to make them, but there were equally troublesome questions of how to evaluate the materials we had. The thermal conductivity of Rover materials is one illustration. The 1961 Thermophysical Properties Research Center Handbook, published by Purdue University, showed that the reported values for the thermal conductivity of graphite (the material we used most extensively in Rover) at room temperature varied by a factor of 10000 . It was clear that we did not know how to uniquely characterize the materials we were using, and moreover our measurement methods for thermal conductivity were not totally credible. The point to this is to emphasize that this report is a judgmental distillation of knowledge gained through approximately 75 manyears of research to define materials of engineering value, make those materials, and then verify their properties through thermophysical measurements. While detailed documentation of these activities would occupy several volumes, we feel that all the essential technological information can be transferred by this report.

The author received his Ph.D. in physical chemistry in 1952 from the University of Rochester. He performed research in materials science and high-temperature thermophysical measurements for the Rover Program from early 1956 until the program was abandoned in 1973. Largely as a result of these research efforts, he received the International Thermal Conductivity Award in 1989: only the sixteenth such award in the past 30 years. This recognition is a tribute to the vigorous effort exerted by the scientists and engineers involved in Rover as well as a recognition of the accomplishments of the individual. 


\title{
MATERIAL SCIENCE EXPERIENCE GAINED FROM THE SPACE NUCLEAR ROCKET PROGRAM : INSULATORS
}

\author{
by \\ Paul Wagner
}

\begin{abstract}
Although Rover reactors are viewed as the ultimate in high-temperature operating systems, many of the materials used in these reactors (for example, support rods, control drums, and the reflector) have to be held at relatively low temperatures while the reactor operates, in order to maintain their structural integrity. Thus the insulators needed to separate these temperature domains are crucial to the reactor's ultimate operating times and temperatures. All of the reactors that were tested used pyrolytic graphite as the primary insulator. However, it had been long planned to replace the graphite with zirconium carbide and a lengthy and intensive effort to develop the zirconium carbide insulators had been made at the time Rover was terminated. This report details research and development and the experience we gained with both these insulator materials.
\end{abstract}

\section{INTRODUCTION}

One of the primary goals of the 1955-1972 nuclear rocket propulsion (Rover) program was the development of reactors capable of heating hydrogen to an extremely high temperature to obtain a much higher engine specific impulse than the $400-500 \mathrm{~s}^{-1}$ obtainable from chemical rocket engines. The long-range goal for the temperature of the nuclear engine chamber was approximately $3000 \mathrm{~K}$, but short-range goals were more modest, progressively increasing from about $2000 \mathrm{~K}$ to $2500 \mathrm{~K}$. Near the end of the program, average fuel element exit-gas temperatures slightly above $2500 \mathrm{~K}$ were demonstrated during reactor tests. Coupled with the need for high temperature is the requirement for a sufficient engine lifetime to allow it to perform one or more missions. Thus, at least a portion of the reactor fuel and associated core components must be able to operate at temperatures at least slightly greater than the hydrogen chamber temperatures for 1 to 10 hours. On the other hand, the best materials for other reactor components can survive only at much lower temperatures. Therefore, there is a need for an insulating material in several reactor locations that can both withstand the high-temperature-hydrogen environment and sharply reduce the heat load to the low-temperature components. Furthermore, the thermal conductivity of the insulator should be as low as possible so that the insulator does not take up too much space. The progressive development of nuclear-rocket-reactor fuel elements able to operate at higher temperatures for longer times has been described in several recent publications. The purpose of this report is to describe the accompanying developments in insulators, which are also vital to improvements in nuclear engine performance.

These high-temperature insulator applications in Rover reactors are shown in Fig. 1. In Fig. 1a, the insulator reduces the heat flow to the metallic components of the core axial-support system; in Fig. 1b, the insulator protects the aft end of the support system; and in Fig. 1c, the insulator protects reactor components at the radial edge of the core.

The use of pyrographite (PyG or PyC for pyrolytic carbon) for the various insulator applications began with reactors built in 1961 and continued for the duration of the reactor test program.

While the choice of PyG as the insulating material was probably optimal from the standpoint of high-temperature thermophysical properties, neutronics, weight, cost, and ease of fabrication and machining, the PyG had major 


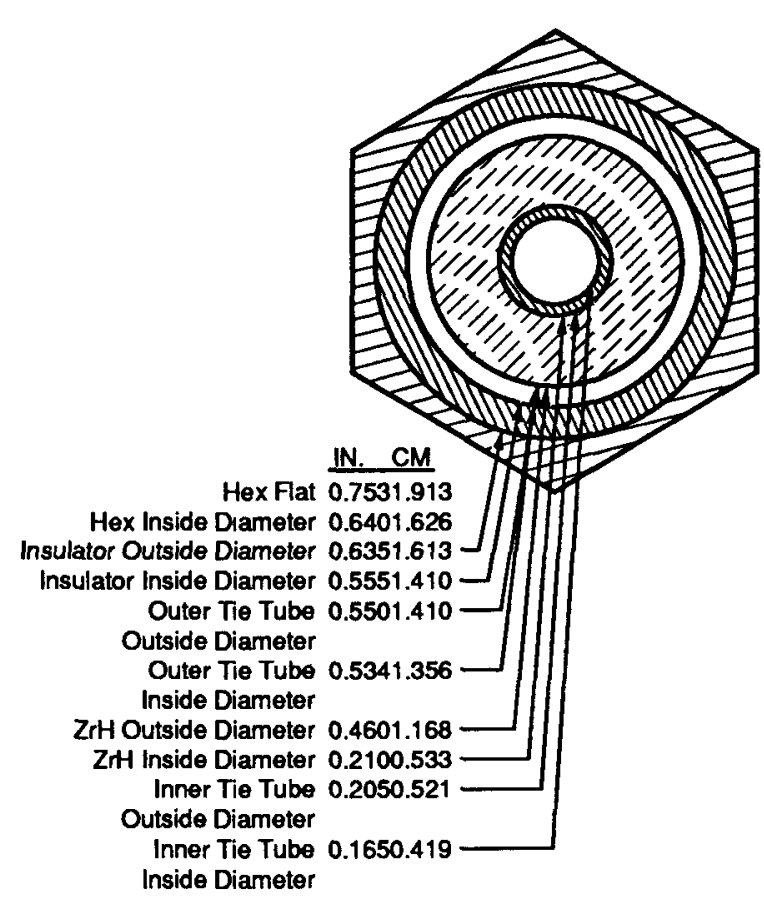

Fig. 1a. Nuclear engine reactor tie tube and support element geometry.

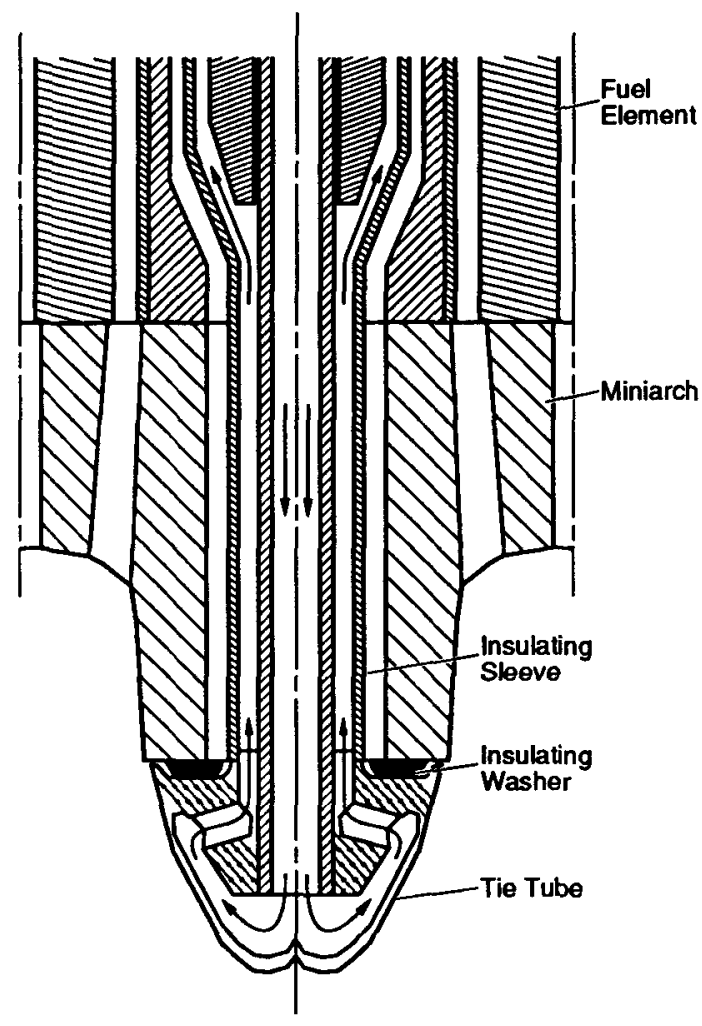

Fig. 1b. Hot-end-support axial section.

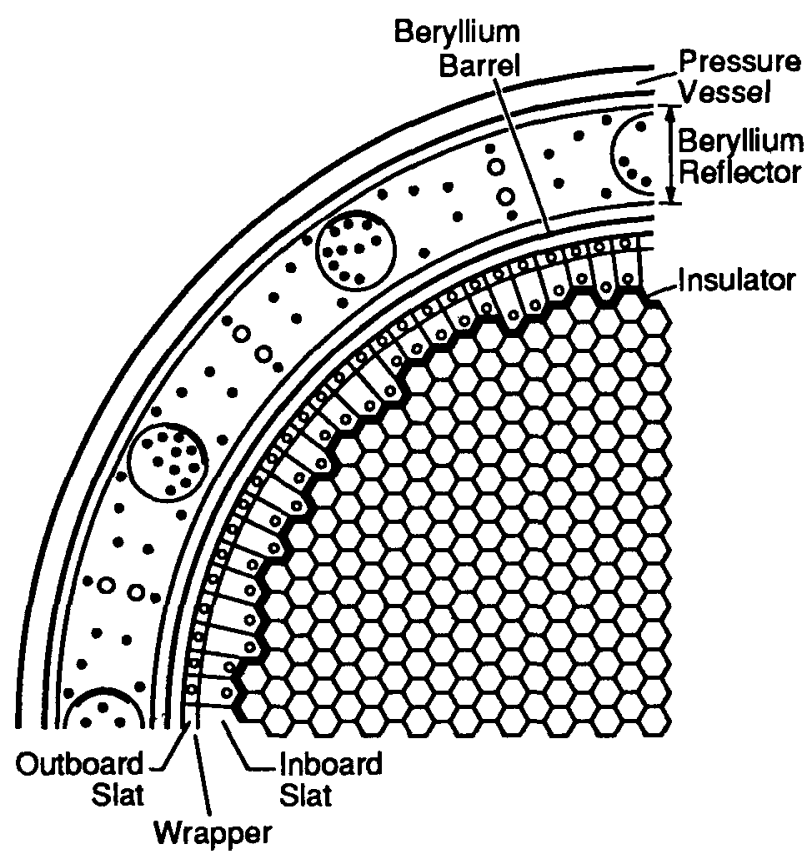

Fig. 1c. Reactor-core cross section. 
flaws for the space reactor application. The major problem is corrosion. The PyG reacts chemically with the hydrogen propellant at high temperatures as follows:

$$
\mathrm{xC}+\frac{\mathrm{y}}{2} \mathrm{H}_{2}=\mathrm{C}_{\mathrm{x}} \mathrm{H}_{\mathrm{y}} .
$$

Thus, as the reactor continues to operate, the carbon is removed from the insulating $\mathrm{PyG}$ and is either redeposited at another part of the reactor or exits with the propellant as a gas. In addition, at sufficiently high temperatures, the layered PyG structure undergoes a change in which the ultimate result is the structure of polycrystalline, isotropic graphite. This is energetically the most stable form of graphite and predictably is found in nature. Thus, the reactor operating lifetime was limited by the length of time that the PyG could maintain its integrity and fulfill its insulating function. When this no longer happened, the lower temperature materials that had been insulated from the high-temperature reactor parts could not withstand the high temperatures and would melt or creep, presaging ultimate destruction of the reactor (this never actually happened).

To mitigate the insulator corrosion problem, the Rover Program investigators sought an insulating material that would be structurally stable, neutronically acceptable, and chemically inert in the reactor environment. The material of choice was zirconium carbide, which fulfilled many of the material requirements but is not an insulator. The successful research program to alter this material to allow it to be used as an insulator is described in this summary.

\section{PYROLYTIC GRAPHITE}

\section{A. Structure and Properties}

Pyrolytic graphite (also called pyrographite, pyrocarbon, $\mathrm{PyG}$, or PyC) is graphite fabricated as a layered structure that gives it unique thermophysical properties. To understand this, it is important to understand the structure and how it influences the properties. Figures 2 and 3 show the structures of an idealized crystal of pyrolytic graphite. Figure 2 shows the structure viewed perpendicular to the layer planes. The planes are composed of carbon atoms in a two-dimensional set of hexagons with the carbon atoms at the apex of the hexagons, as shown in Fig. 2, by the solid line (a). The plane above (a) is displaced as shown in Fig. 2 by the dotted line (b). The next plane above is positioned directly above (a), the next above (b), and so on. This is called an (ab) stacking order. Figure 3 shows an angled view of the same structure with some key dimensions included. In Fig. 3 we can also more easily see the difference between the in-plane carbon-to-carbon distance $(1.42 \AA$ ) and the inter-planar (this is labelled the " $c$ " direction) distance ( $3.35 \AA$ ). These differences in dimensions give rise to the very anisotropic behavior of PyG. Because of the closeness of the carbon atoms in the "ab" direction, the interattractive forces and the lattice and electron field coupling are stronger than they are between the more distant planes in the " $c$ " direction. Because of the relatively large distance between the planes, heat flow (which is related to the lattice and electronic coupling) in the "c" direction is greatly reduced compared to the "ab" direction. Thermal conductivities in the " $\mathrm{c}$ " direction have been measured at $1 / 200$ th of the value in the "ab" direction. ${ }^{1}$ Similarly the decrease in interatomic force between the planes makes for a thermal expansion in the "c" direction about 10 times greater than that in the "ab" direction. Other properties are similarly affected. Taylor reported the thermal conductivity for PyG at room temperature to be $4-8 \mathrm{~W} / \mathrm{mK}$ making it one of the better thermal insulators known. ${ }^{1}$ The fact that the thermal conductivity doesn't change by a large factor at reactor operating temperatures (2273 K or greater) would make PyG an almost ideal choice for a Rover insulator if the structure and the hydrogen corrosion could be controlled. There are two caveats to this statement relating to the use of the PyG at temperatures above approximately $2273 \mathrm{~K}$. The idealized crystal structure that has formed the basis for this discussion will transform into an isotropic, polycrystalline system if unconstrained and kept at high temperature for a sufficiently long time. This polycrystalline graphite commonly forms rapidly at temperatures in the vicinity of $3000 \mathrm{~K}$; however, it has been observed to form at much lower temperatures $(2000 \mathrm{~K})$, but because the transformation rate is an exponential function of the temperature, the polycrystalline transformation can take a long time at the lower temperature. It is difficult to assign quantitative rates to this process because there are other influences on the crystallization process.

\section{B. Improving the Siructure of Pyrographile}

Under the correct circumstances, the nature of the PyG structure may be improved by high-temperature treatment as can be noted from the following excerpt from an August 1965 Rover Progress Report. (This work was done at about $2973 \mathrm{~K}$ ).

Simultaneous application of compression and torsion at high temperatures has converted a continuously-nucleated pyrolytic graphite, having a well-developed fine cone structure, into a highly-ordered graphite having essentially the interlayer spacing of an ideal single crystal and very high degree of order in the orientation of layer planes. Periodic rotational disorientations, however, at intervals of about 500 to $1000 \AA$, have not so far been eliminated, and means of producing large single crystals from this pyrographite have not yet been developed. ${ }^{2}$

Similar studies were done by Ubbelohde in the $1960 \mathrm{~s}$ in which the heat-treated PyG, compressed in the " $c$ " direction, yielded very nearly perfect crystals. Without these artificial constraints, however, the PyG will appreciably 
transform to the polycrystalline form at the temperatures at which the reactor was designed to operate $(2673 \mathrm{~K}$ and up) to the detriment of the desirable thermophysical properties.

The other caveat has to do with the hydrogen corrosion. The rate of the reaction of the hydrogen with the graphite is exponential with temperature. An extremely rough rule of thumb is a doubling of the reaction rate for every $10 \mathrm{~K}$ rise in temperature. Appreciable corrosion was observed on some Rover test materials at $2223 \mathrm{~K}$ (see Part II.D. of this summary). It is clear that a relatively small increase

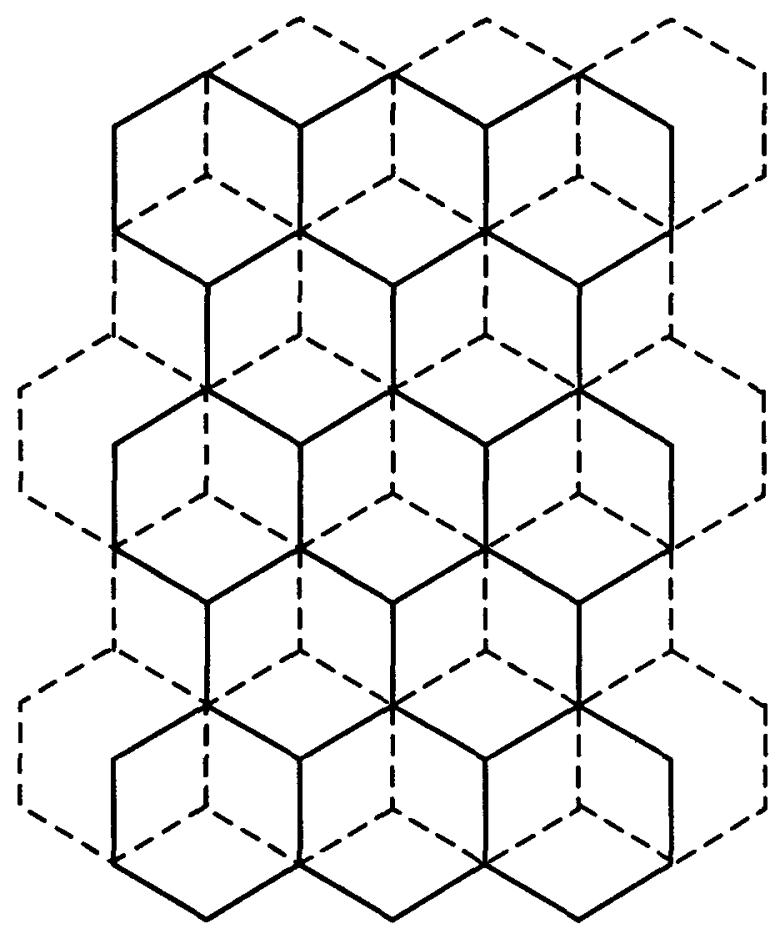

Fig. 2. Stacked planar structure of graphite viewed perpendicular to the ab planes. Solid lines (-) are the " $a$ " layer, while dashed lines (- .) are the " $b$ " layer.

in operating temperature could have an enormous effect on the corrosion rate of the insulators with a concommittant decrease in the reactor's operating lifetime. It was largely because of these problems and potential problems that the Rover program embarked, in the 1960 s, on an intensive study to identify insulator materials that would retain their structural integrity and resist any corrosive attacks under the reactor environment under optimized temperature and flow conditions.

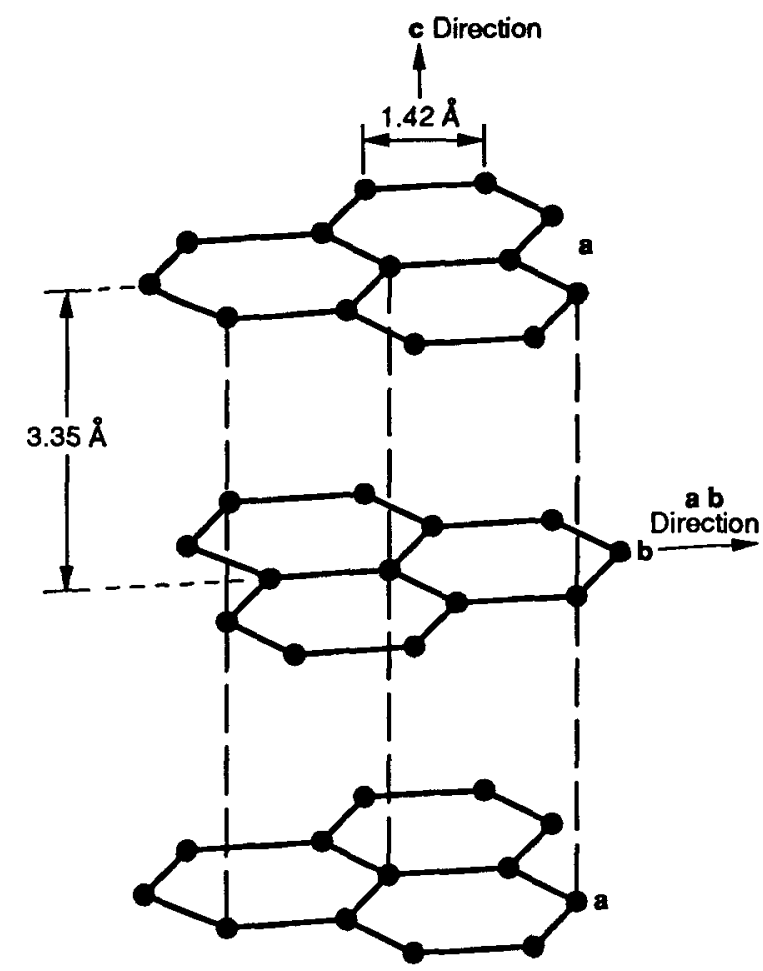

Fig. 3. Graphite crystal structure.

Pyrolytic graphite is fabricated by allowing a hydrocarbon gas (e.g. methane, ethane, or ethylene) to decompose at elevated temperatures (pyrolysis) and having the carbon deposit on a cooled pre-shaped substrate. By appropriate choice of gas, pressure, temperature, etc., the structure and the shape of the vapor-deposited artifact could be controlled. While ideal crystals, like that shown in Fig. 3, are not necessarily formed during the chemical vapor deposition (CVD) without further treatment, the properties of $\mathrm{PyG}$ made in this manner for commercial purposes are closer to the crystal properties than they are to those of the more common polycystalline-electrode graphites made by either extrusion or by hot pressing and as such were quite useable for the Rover reactor applications.

Attempts to clad the PyG to prevent hydrogen corrosion were largely unsuccessful. Corrosion- and ablation-resistant carbonaceous materials that were developed for the U.S. space program probably have better corrosion resistance than the PyG we have described; however, the corrosion resistance comes at the expense of some of the more desirable properties of the PyG, such as the low thermal conductivity. It is to be noted however, that other carbonaceous materials may become important in future high-temperature reactors if some of the severe dimensional restrictions in the Rover designs are relaxed. 


\section{Experience with PyG in the Rover Program}

Because of the large number of confusing units commonly used to report heat flow, Table I is included to show the relationship between various systems of units. The commercially procured PyG used in the Rover program had "c" direction thermal conductivities comparable to the values reported for the idealized materials already described. As an example, Table II (taken from a May 1969 Progress Report ${ }^{3}$ ) records thermal conductivities measured in the radial (i.e. "c") direction on PyG tubes made for Rover. The values are comparable to those reported by Taylor. ${ }^{3}$ The thermal conductivities are similar because of offsetting influences from the crystal structure and interplanar cracks that form when the tubes are cooled from the fabrication temperature (which is in excess of $1000 \mathrm{~K}$ ). While the crystal structure is not ideal, tending to increase the thermal conductivity in the " $\mathrm{c}$ " direction, the crack formation balances the increase. The cracks tend to decrease the thermal conductivity at temperatures below about $1500 \mathrm{~K}$. Other influences from impurities and mechanical flaws in the material cannot be evaluated at this time, but experience suggests strongly that these influences would be much less pronounced than those observed. In retrospect, more careful and direct control of the quality of the structural and physical character of the manufactured artifacts (something that would be far easier to do now with the tools available to us in the 1990s) could yield a product better fitted to the ultimate application.

A departure from ideality is also noted in the measurements of thermal expansion reported in August 1969.

\section{Properties of PyG}

Thermal Expansion of PyG Tubes. The thermal expansion of PG tubes, 0.633 -in. o.d. by 1.71 -in. long by 0.040 -in. thick, was measured. The longitudinal expansion was $1.86 \times 10^{6} /{ }^{\circ} \mathrm{C}$ and the transverse expansion was $2.40 \times 10^{-6} /{ }^{\circ} \mathrm{C}$ from 20 to $1750^{\circ} \mathrm{C}$ [ 293 to $2023 \mathrm{~K}$ ]. These tubes were similar to those used in Pewee 1 support elements and to those to be used in Pewee 2 support elements.

Here, instead of a "c" to "a" (i.e., "transverse" to "longitudinal") thermal expansion ratio of about 10 , as expected for the idealized material, the ratio is about 1.3. This is probably caused by a combination of crystal imperfections and partial exfoliation of the layer planes in the tubes used for the measurement. The cracking between the planes in the tubes (already described) decreases the measured thermal expansion in the "c" direction as well as the thermal conductivity. This was indeed observed in the tubes and the explanation was supported by the relatively low densities that were observed. Effects of impurities and mechanical flaws are minimal for this type of measurement of averaged thermal expansion. Again, if it is important that the properties of the artifact be closer to ideal, direct control of the crystal structure (and in the case of the tubes or other special shapes, the physical structure) will be crucial to that attempt.

The reactions between hydrogen and carbon have been known and reported in the open literature for many years. This was manifested in the Rover experience by corrosion of PyG by hydrogen coolant. Most of the studies reported

Table I. Conversion Factors for Thermal Conductivity

\begin{tabular}{|c|c|c|c|c|c|c|}
\hline To Go From & $\frac{\mathrm{W}}{\mathrm{mK}}$ & $\frac{\mathrm{W}}{\mathrm{cm} \mathrm{K}}$ & $\frac{\mathrm{cal}}{\mathrm{cms} \mathrm{K}}$ & $\frac{\mathrm{kcal}}{\mathrm{mh}^{\circ} \mathrm{F}}$ & $\frac{\mathrm{Btu}}{\mathrm{ft} \mathrm{h}^{\circ} \mathrm{F}}$ & $\frac{\text { Btu in. }}{\mathrm{ft}^{2} \mathrm{~h}{ }^{\circ} \mathrm{F}}$ \\
\hline $1 \frac{\mathrm{Jm}}{\mathrm{m}^{2} \mathrm{~s}^{\circ} \mathrm{C}}$ or $\frac{\mathrm{W}}{\mathrm{m} \mathrm{K}}$ & 1 & $1 \times 10^{-2}$ & $2.388 \times 10^{-3}$ & 0.8598 & 0.5778 & 6.933 \\
\hline $1 \frac{\mathrm{Jm}}{\mathrm{cm}^{2} \mathrm{~s}^{\circ} \mathrm{C}}$ or $\frac{\mathrm{W}}{\mathrm{cm} \mathrm{K}}$ & $1 \times 10^{2}$ & 1 & 0.2388 & 85.98 & 57.78 & 693.3 \\
\hline $1 \frac{\mathrm{cal} \mathrm{cm}}{\mathrm{cm}^{2} \mathrm{~s}^{\circ} \mathrm{C}}$ or $\frac{\mathrm{cal}}{\mathrm{cm} \mathrm{s} \mathrm{K}}$ & 418.68 & 4.1868 & 1 & 360 & 241.9 & 2903 \\
\hline $1 \frac{\mathrm{kcal} \mathrm{cm}}{\mathrm{m}^{2} \mathrm{~h}^{\circ} \mathrm{F}}$ or $\frac{\mathrm{kcal}}{\mathrm{m} \mathrm{h}{ }^{\circ} \mathrm{F}}$ & 1.163 & $1.163 \times 10^{-2}$ & $2.778 \times 10^{-3}$ & 1 & 0.6720 & 8.064 \\
\hline $1 \frac{\mathrm{Btuft}}{\mathrm{ft}^{2} \mathrm{~h}^{\circ} \mathrm{F}}$ or $\frac{\mathrm{Btu}}{\mathrm{ft} \mathrm{h}^{\circ} \mathrm{F}}$ & 1.731 & $1.731 \times 10^{-2}$ & $4.134 \times 10^{-3}$ & 1.488 & 1 & 12 \\
\hline 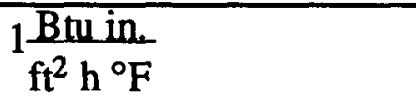 & 0.1442 & $1.442 \times 10^{-3}$ & $3.445 \times 10^{-4}$ & 0.124 & $8.333 \times 10^{-2}$ & 1 \\
\hline
\end{tabular}


an accelerated corrosion and attack at the edges of the PyG in the "ab" direction. The implication is that the carbon atoms at the edges of the carbon planes are more reactive than those in the plane. A reasonable approach to controlling the corrosion problem is to allow the layer planes to wrap around the edges of an artifact thus presenting only a "c" direction to the hydrogen corrosion. This was considered and reported in August of 1969 and is quoted below.

\begin{abstract}
Hydrogen Corrosion of Specially Oriented Pyrographite. Hot gas tests were performed to determine the corrosion resistance of pyrolytic graphite which had been formed into shapes intended to test the corrosion resistance of pyrographite in the "c" direction. One type resembled the button of a mushroom and the other a shear pin completely overcoated with pyrographite. Corrosion was not entirely uniform, but attack seemed [to] occur more rapidly on one area than on another. Exposure of $3 \mathrm{~min}$ to $\mathrm{H}_{2}$ at $4500^{\circ} \mathrm{R}$ [ $2500 \mathrm{~K}$ ] often removed carbon to a depth of $\sim 100$ mils or more. It is clear that pyrographite is vulnerable to $\mathrm{H}_{2}$ corrosion in the "c" direction at all temperatures above $4000^{\circ} \mathrm{R}$ [2222 K]. ${ }^{4}$
\end{abstract}

In an effort to blend the desirable high-temperature integrity and corrosion properties of $\mathrm{ZrC}$ with the excellent thermophysical properties of the PyG, ZrC-PyG composites were prepared and thermal diffusivities of the alloys measured. (Note: the thermal conductivity is the product of the thermal diffusivity, density, and heat capacity. To a first approximation, the trend in thermal diffusivity is the same as the trend in thermal conductivity.) The results of these measurements were reported in August of 1968 and are reproduced here.

Thermal Diffusivity of ZrC-PyC Composites. The thermal diffusivity of four $\mathrm{ZrC}$-pyrolytic graphite (PyC) composites, prepared by simultaneous deposition by [The] Raytheon [Co.], was measured from 800 to $2100^{\circ} \mathrm{C}$ [ 1073 to $2373 \mathrm{~K}$ ] by the laser flash technique. The composites contained $15,50,70$, and $80 \mathrm{wt} \% \mathrm{ZrC}$, respectively. The thermal diffusivity values vs composition at 1000,1500 , and $2000^{\circ} \mathrm{C}[1273,1773$, and $2273 \mathrm{~K}$ ] are plotted on a semilogarithmic scale [see Fig. 4].

There is an exponential relationship between the thermal diffusivity, $\alpha$, and the wt $\% \mathrm{ZrC}$ in the $\mathrm{ZrC}$-PyC composite, and $\mathrm{k}=0.0036 \mathrm{~cm}^{2} / \mathrm{sec}^{5}$

\section{E. Summary and Recommendations for Future Use}

Overall, we learned some lessons. The assumption that properties of PyG could be controlled by specifying processing conditions was certainly well founded, but hardly sufficient. As we commented earlier, with the vast variety of analytical techniques available today (1991), specifications that spell out the required structural, physical, and chemical parameters may be monitored directly on production runs of $\mathrm{PyG}$, thus allowing these materials to more closely match the engineering specifications (see Table III).

\section{ZrC BASED INSULATORS}

\section{A. Overview}

It was recognized early in the Rover program that any materials chosen for use in the high-temperature region of the reactor would have to resist hydrogen corrosion and radiation damage and maintain their integrity while not interfering with the reactivity and the control functions in the reactor. In the earliest days of the program, $R$. Schreiber (the Division leader) and I discussed the desirability of finding that most-important, all-purpose material with no negative characteristics, "impervium," that we both remembered from the Buck Rogers fantasies of the 1930s. If we could have legislated the materials for the program rather than been forced to use what nature willed to us, we would have done it. Having no other option, it became the job of the Rover management to pursue research and development on materials that offered the most tenable set of compromises for the job to be done. It was recognized in the 1950s that the most promising material would be a

Table II. Thermal Conductivity of PyG Sleeves

\begin{tabular}{|l|c|c|c|c|}
\hline $\begin{array}{c}\text { Gaseous } \\
\text { Environment }\end{array}$ & $\begin{array}{c}\text { Temperature } \\
(\mathrm{K})\end{array}$ & $\begin{array}{c}\text { Thermal Conductivity } \\
(\mathrm{w} / \mathrm{cm} \mathrm{K}) \times 10^{-3}\end{array}$ & $\begin{array}{c}\text { Temperature } \\
(\mathrm{K})\end{array}$ & $\begin{array}{c}\text { Thermal Conductivity } \\
(\mathrm{w} / \mathrm{cm} \mathrm{K}) \times 10^{-3}\end{array}$ \\
\hline Hydrogen & 1366 & 10.4 (upper limit) & 1921 & 11.4 (upper limit) \\
\hline Helium & 1366 & $8.5-10.1$ & 1921 & $10.1-11.1$ \\
\hline Nitrogen & 1366 & $6.6-7.2$ & 1921 & $8.1-8.6$ \\
\hline Vacuum & 1366 & $2.7-4.9$ & 1921 & $4.8-6.3$ \\
\hline
\end{tabular}


refractory zirconium compound, probably an oxide or a carbide. This was hardly startling in view of the country's power reactor experience, but even that experience had little to offer in terms of direct technology transfer. Rover's demands exceeded all engineering practice. For these reasons, an ever-accelerating, in-depth research program was initiated as the limit of usefulness of the PyG systems was approached in the 1960 s.

Figure 5 shows the areas of concentration and how they finally culminated in the vigorous and successful development of porous, sub-stoichiometric zirconium carbide insulators.

\section{B. $\mathrm{ZrO}_{2}-\mathrm{ZrC}$}

Development of the $\mathrm{ZrC}$ and the $\mathrm{ZrC}-\mathrm{ZrO}_{2}$ composite materials was spurred by the desire to replace the PyG in the Pewee reactors, especially inside the beryllium reflector at the core periphery (see Fig. 1c). Various composites were made by hot pressing the materials at $2073 \mathrm{~K}$ and $6400 \mathrm{psi}$. Measurements of thermal conductivity at room temperature are shown in Table IV (reported 11/69). ${ }^{6}$

Additional research yielded thermal conductivity measurements on materials exposed to various temperatures up to $2773 \mathrm{~K}$ (see Table V).

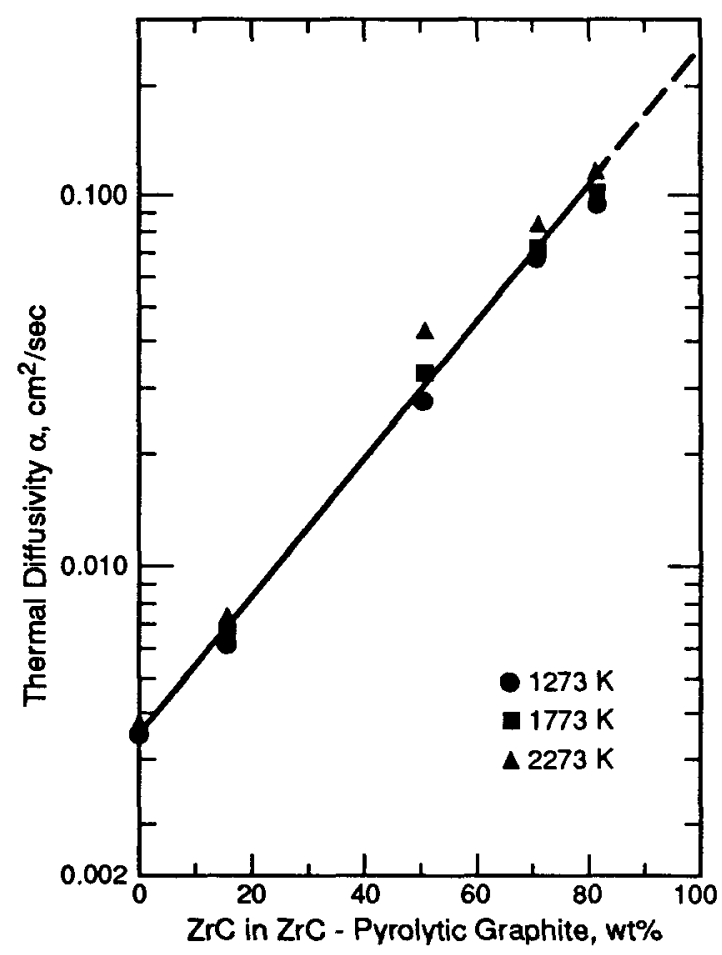

Fig. 4. Thermal diffusivity of ZrC-PyC composites.
Analysis of heat transfer in the Pewee 2 reactor using these composites showed that the composite, while effective, was far from the requirements specified in the engineering design. This is illustrated in Fig. 6.

Measurements were also made to demonstrate the viability of the concept of increasing the porosity of the insulator materials to decrease the thermal conductivity. Measurements of this genre on $\mathrm{ZrC}$ at room temperature are reproduced in Table VI.

The influence of added porosity on the insulators introduced another dimension to the use of these ceramic materials because changes in density affected strengths, creep properties, moduli, and potential operating characteristics of the reactor.

Once the decision was made to operate Pewee 3 with a core temperature of $2573 \mathrm{~K}$ or greater, the use of $\mathrm{ZrO}_{2}-$ $\mathrm{ZrC}$ composites was ruled out and in late 1970 the composites were dropped from consideration as peripheral insulators. It was decided that $\mathrm{ZrC}$ or a $\mathrm{ZrC}$ - $\mathrm{C}$ composite in some form would be more appropriate for future research.

\section{c. $\mathrm{ZrC}-\mathrm{C}$}

Experiments were also performed with $\mathrm{ZrC}-\mathrm{C}$ to examine its viability as an insulator. In August 1970, ZrC-C extrusions with about $5 \mathrm{wt} \%$ free carbon were reported. Initial measurements of these materials revealed that the thermal conductivity was substantially greater than that of hotpressed $\mathrm{ZrC}$. The samples were then heat treated in hot hydrogen and the thermal conductivities remeasured with the result that as the free carbon was removed by this treatment, the thermal conductivity was reduced. These data are reproduced in Table VII.

The conclusion was reached that $\mathrm{ZrC}$ would be a better insulating material if it contained no free carbon. Further experiments then concentrated on $\mathrm{ZrC}$.

\section{D. $\operatorname{ZrC}$}

The research on $\mathrm{ZrC}$ started in earnest in 1971. Initially there were investigations of the various thermal, physical, and mechanical properties of $\mathrm{ZrC}$ made at near theoretical density and with deliberately introduced porosity. While these efforts were not definitive, it was at about this time that discussions about the best way to measure the thermal conductivity (an area of uncertainty at the time) of the experimental insulator materials began to converge and the flash diffusivity method was adopted as the standard. ${ }^{1}$ We obtained a thesis written in one of the Max Planck Institutes (Stuttgart) which when translated led us toward looking carefully at substoichiometric $\mathrm{ZrC}$ made with vacancies in the carbon lattice because this alone was most effective in decreasing the thermal conductivity. This new information, combined with the fabrication of 


\begin{tabular}{|c|c|c|c|c|c|}
\hline \multirow[t]{2}{*}{ PyG } & \multirow[t]{2}{*}{$\begin{array}{l}\text { Density } \\
\left(\mathrm{g} / \mathrm{cm}^{3}\right)\end{array}$} & \multicolumn{2}{|c|}{$\begin{array}{l}\text { Thermal Conductivity } \\
(\mathrm{W} / \mathrm{mK})\end{array}$} & \multicolumn{2}{|c|}{$\begin{array}{c}\text { Thermal Expansion } \\
(\mathrm{cm} / \mathrm{cmK})\end{array}$} \\
\hline & & "c" & "ab" & "c" & "ab" \\
\hline Rover & $1.7-1.95$ & $1-5$ & not done & 26 & 20 \\
\hline Ideal & $1.9-2.05$ & $4-8$ & $800-1600$ & 100 & 10 \\
\hline
\end{tabular}

\begin{tabular}{|c|c|c|c|}
\hline \multicolumn{4}{|c|}{ Table IV. Thermal Conductivity Data } \\
\hline \multirow[b]{2}{*}{ Composition } & \multicolumn{2}{|c|}{ Density } & \multirow{2}{*}{$\begin{array}{l}\text { Thermal Conductivity } \\
(\mathrm{w} / \mathrm{cm} \mathrm{K})\end{array}$} \\
\hline & $\mathrm{g} / \mathrm{cm}^{3}$ & $\%$ Theor. & \\
\hline $\begin{array}{l}\mathrm{ZrO}_{2} \\
75 \text { vol } \% \mathrm{ZrO}_{2} 25 \text { vol } \% \mathrm{ZrC}^{*} \\
75 \text { vol \% } \mathrm{ZrO}_{2} 25 \text { vol \% } \mathrm{ZrC}^{* *} \\
50 \text { vol } \% \mathrm{ZrO}_{2} 50 \text { vol \% } \mathrm{ZrC}^{* *} \\
25 \text { vol } \% \mathrm{ZrO}_{2} 75 \text { vol } \% \mathrm{ZrC}^{* *} \\
\mathrm{ZrC}\end{array}$ & $\begin{array}{l}4.970 \\
5.394 \\
5.487 \\
5.362\end{array}$ & $\begin{array}{c}-- \\
93.91 \\
90.24 \\
92.60\end{array}$ & $\begin{array}{c}0.017 \\
0.018 \text { to } 0.023 \\
0.0155 \\
0.026 \\
0.035 \\
0.273\end{array}$ \\
\hline $\begin{array}{l}{ }^{*} \mathrm{CaO} \text {-stabilized } \mathrm{ZrO}_{2} \\
{ }^{* *} \text { Unstabilized } \mathrm{ZrO}_{2}\end{array}$ & & & \\
\hline
\end{tabular}

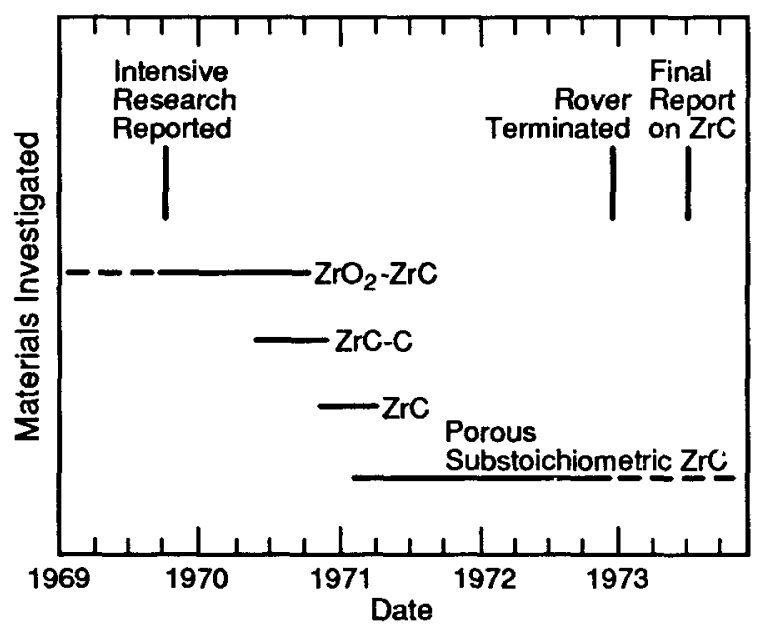

Fig. 5. Materials investigated during the Rover insulators program: 1969-1973. porous materials with the substoichiometric $\mathrm{ZrC}_{\mathrm{x}}$ (as it came to be known), led to a series of experiments and a redirected research and development program that had every indication of yielding a successful insulator material. Unfortunately, as this was coming to closure, the Rover program was terminated and all work in this area ceased.

\section{E. Porous Substoichlometric $\mathrm{ZrC}_{\mathrm{x}}$ Insulators}

Fortunately, a comprehensive and timely report on this effort was written and published at Los Alamos. This report, LA-5224, "Research, Development, and Production of Substoichiometric Zirconium Carbide for HighTemperature Insulation," (July 1973), written by Paul Wagner, is the final portion of this report on Rover insulators. 
Table V. Effect of Time and Temperature on Hot Pressed 75:25 Vol \% ZrQ-ZrC $\mathrm{Z}_{\mathrm{X}}$ Composites

\begin{tabular}{|c|c|c|c|c|}
\hline $\begin{array}{l}\text { Exposure } \\
\text { Temperature } \\
\text { (K) }\end{array}$ & $\begin{array}{l}\text { Time at } \\
\text { Temperature } \\
\text { (h) }\end{array}$ & $\begin{array}{l}\text { Room Temp. } \\
\text { Thermal } \\
\text { Conductivity } \\
(\mathrm{w} / \mathrm{cm} \mathrm{K})\end{array}$ & $\begin{array}{c}\text { Room } \\
\text { Temperature } \\
\text { Density } \\
\left(\mathrm{g} / \mathrm{cm}^{3}\right)\end{array}$ & Microstructure \\
\hline \multirow[t]{2}{*}{2073} & 0 & 0.022 & - & \multirow{2}{*}{$\begin{array}{l}\text { Specimens exposed for up to } 8 \mathrm{~h} \text { showed } \\
\text { little change. Exposure in flowing } \mathrm{H}_{2} \text { for } \\
8-16 \mathrm{~h} \text { showed formation of substoichio- } \\
\text { metric } \mathrm{ZrC} \text {. }\end{array}$} \\
\hline & 1 & 0.011 & - & \\
\hline \multirow[t]{6}{*}{2573} & 0 & 0.020 & 5.52 & \multirow{6}{*}{$\begin{array}{l}\text { Sample showed some formation of } \\
\text { substoichiometric } \mathrm{ZrC} \text { but there was no } \\
\text { evidence of melting or dimensional changes. }\end{array}$} \\
\hline & 1 & 0.015 & 5.29 & \\
\hline & 2 & 0.0145 & 5.20 & \\
\hline & 4 & 0.0198 & 5.09 & \\
\hline & 8 & 0.0124 & 5.24 & \\
\hline & 16 & 0.024 & 5.26 & \\
\hline \multirow[t]{4}{*}{2773} & 0 & 0.022 & - & \multirow{4}{*}{$\begin{array}{l}\text { Formed some substoichiometric } \mathrm{ZrC} \text {. } \\
\text { Pronounced evidence of melting with } \\
\text { increased time at temperature. }\end{array}$} \\
\hline & 1 & 0.0155 & - & \\
\hline & 2 & 0.011 & - & \\
\hline & 8 & 0.0072 & - & \\
\hline \multicolumn{5}{|c|}{$\begin{array}{l}\text { The samples treated at } 2073 \mathrm{~K} \text { showed a drop in conductivity from } 0.022 \text { to } 0.011 \mathrm{~W} / \mathrm{cm} \mathrm{K} \text { after } 1 \mathrm{~h} \text { suggesting the } \\
\text { possibility of a chemical reaction taking place. The sample treated at } 2073 \mathrm{~K} \text { for } 16 \mathrm{~h} \text { gave a value of } 0.019 \mathrm{~W} / \mathrm{cm} \mathrm{K} \\
\text { which was approaching that of the as-hot-pressed material. Metallographic examination showed what appeared to be } \\
\text { increased migration of } \mathrm{ZrC} \text { into the } \mathrm{ZrO} \mathrm{r}_{2} \text { with increasing time and temperature. There was no evidence of a skin or } \\
\text { surface reaction on these samples. }\end{array}$} \\
\hline
\end{tabular}

\begin{tabular}{|c|c|}
\hline \multicolumn{2}{|c|}{$\begin{array}{l}\text { Table VI. Effect of Density on Thermal } \\
\text { Conductivity of } \mathrm{ZrC}\end{array}$} \\
\hline Density & Thermal Conductivity \\
\hline$\left(\mathrm{g} / \mathrm{cm}^{3}\right)$ (\%theoretical) & $(\mathrm{W} / \mathrm{cmK})$ \\
\hline $\begin{array}{ll}6.43 & 97.3 \\
6.18 & 93.5 \\
4.48 & 67.8 \\
4.30 & 65.1 \\
4.08 & 61.7 \\
\end{array}$ & $\begin{array}{l}0.243 \\
0.119 \\
0.077 \\
0.0428 \\
0.0278 \\
\end{array}$ \\
\hline
\end{tabular}




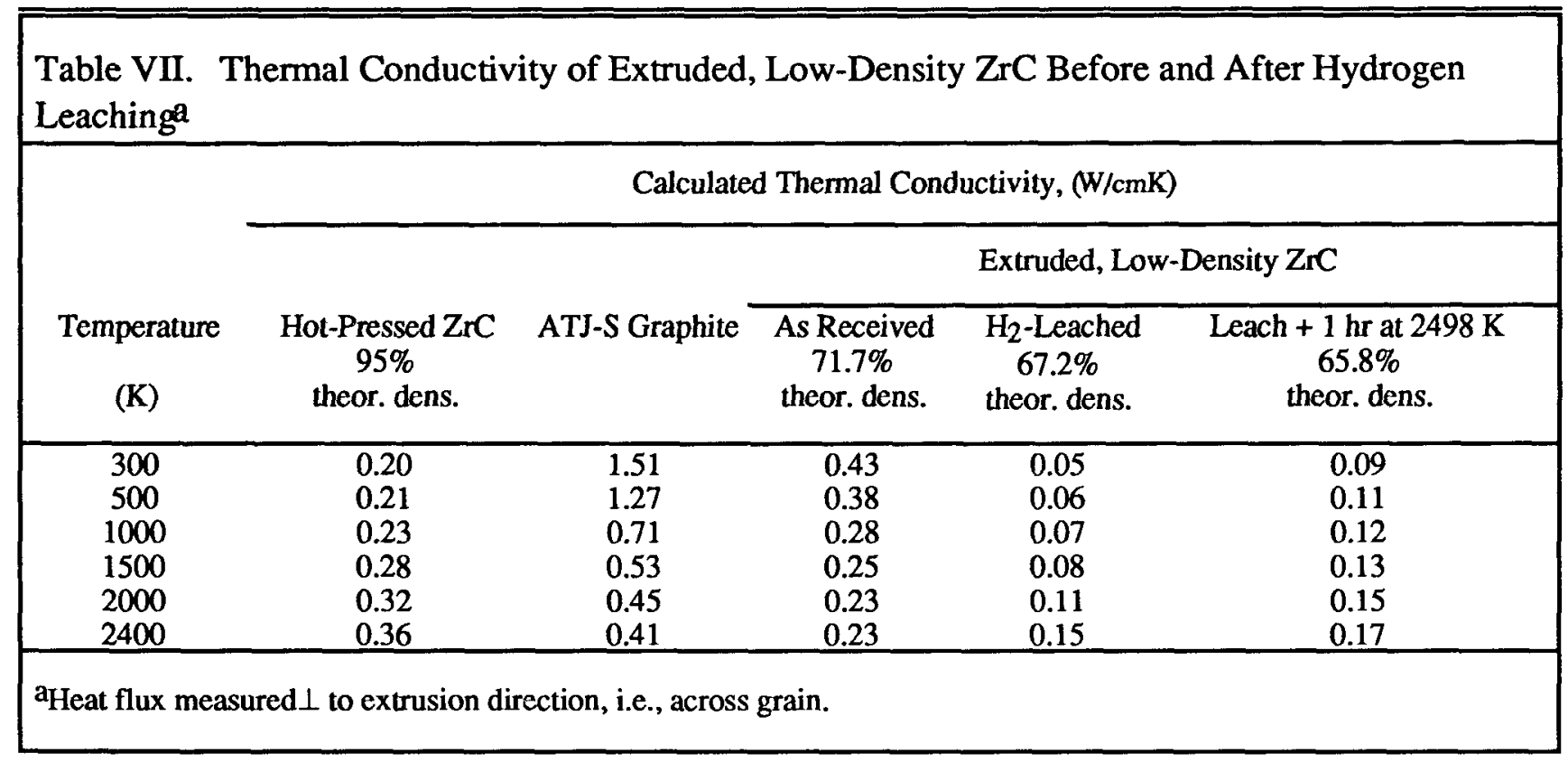

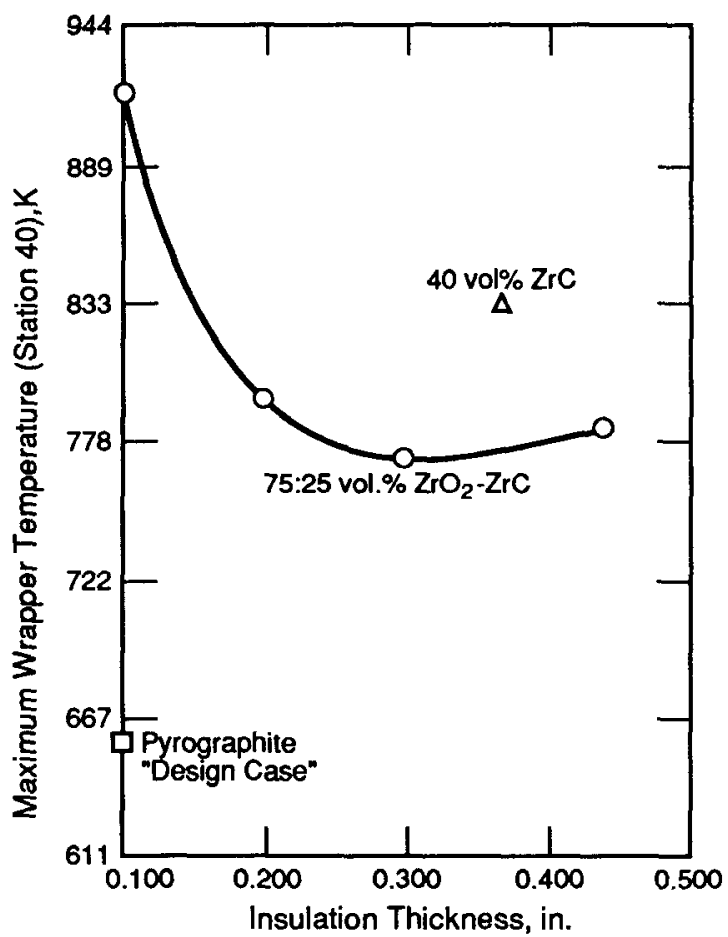

Fig. 6. Predicted performance of prospective insulation materials in Pewee 2 core periphery.

\section{References}

1. R. Taylor, "An Investigation of the Heat Pulse Method for Measuring Thermal Diffusivity," British Journal of Applied Physics 16, 509-515, 1965.

2. "Quarterly Status Report of LASL Rover Program for Period Ending August 31, 1965," Los Scientific Laboratory report LA-3398-MS (October 1965).

3. "Quarterly Status Report of LASL Rover Program for Period Ending May 31, 1969," Los Alamos Scientific Laboratory report LA-4203-MS (June 1969).

4. "Quarterly Status Report of the LASL Rover Program for Period Ending August 31, 1966," Los Alamos Scientific Laboratory report LA-3598-MS (September 1966).

5. "Quarterly Status Report of LASL Rover Program for Period Ending August 31, 1968," Los Alamos Scientific Laboratory report LA-4012-MS (October 1968).

6. "Quarterly Status Report of LASL Rover Program for Period Ending November 30, 1969," Los Alamos Scientific Laboratory report LA-4344-MS (December 1969). 


\title{
Research, Development, and Production of Substoichiometric Zirconium Carbide for High-Temperature Insulation
}

\author{
LA-5224 \\ originally published in July 1973
}

Editor's note:

The following is a reprint of a Los Alamos Scientific Laboratory report. It has been photographed from an original copy, with only the page numbers altered to fit with this report. The tables and figures retain their original numbering and sequence and hence are numbered separately from the first 10 pages of text. 


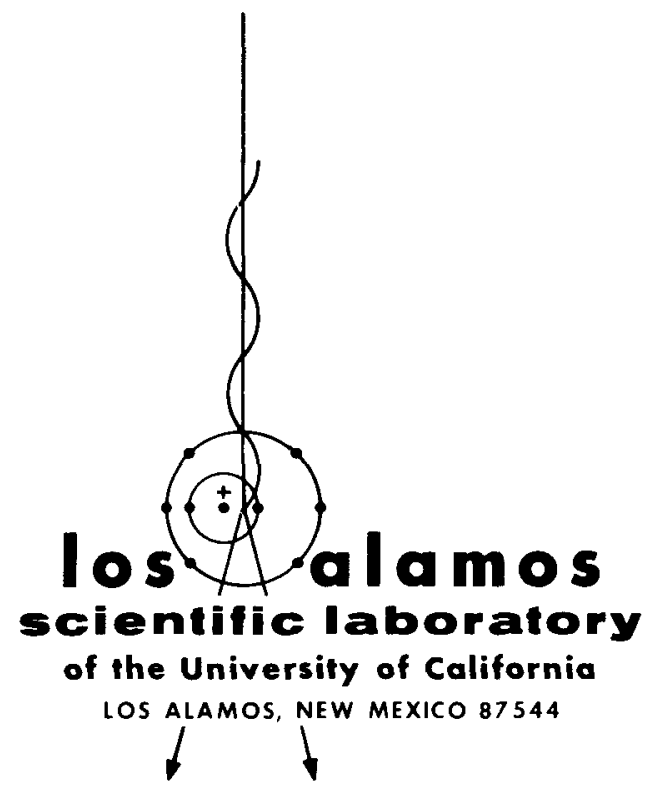

LA-5224

UC-25 and UC-80

ISSUED: July 1973

\section{Research, Development, and Production of Substoichiometric Zirconium Carbide for High-Temperature Insulation}

by

Paul Wagner

This work was done as a support effort in the Rover project. 


\section{CONTENTS}

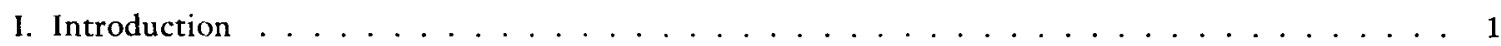

11. Properties of Substoichiometric $\mathrm{ZrC} \ldots \ldots \ldots \ldots \ldots \ldots$

III. Fabrication Methods for Porous $\mathrm{ZrC} \ldots \ldots \ldots \ldots$

IV. Extruded Porous $\mathrm{ZrC} \ldots \ldots \ldots \ldots \ldots$
A. Thermal-Conductivity Measurements at $300 \mathrm{~K} \ldots \ldots \ldots \ldots$
B. Thermal-Conductivity Measurements at Elevated Temperatures . . . . . . . . . 5
C. Modeling Porous $\mathrm{ZrC} \ldots \ldots \ldots \ldots$
D. Factors Which Influence the Thermal Conductivity . . . . . . . . . . . . 6
E. Properties of the Production Porous ZrC ....................8
F. Reactor Performance of the Porous Extruded $\mathrm{ZrC} \ldots \ldots \ldots$

V. Very Porous ZrC Made from Carbon Fibers . . . . . . . . . . . . . . . . 10

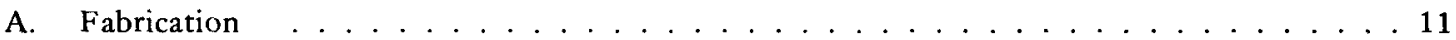
B. Thermal Conductivity of Very Porous $\mathrm{ZrC}$ at $300 \mathrm{~K} \ldots \ldots \ldots$. . . . . . . . . 12
C. Modeling the Very Porous $\mathrm{ZrC}$ Insulators . . . . . . . . . . . . . . . . . 12
D. High-Temperature Thermal Conductivity of NF-2 Insulators . . . . . . . . . . . . . 14
E. Effect of Temperature on the Compressive Strength of $\mathrm{ZrC} \ldots \ldots . . . . . .14$
F. Insulator Simulation Tests .........................15
G. Production Evaluation and Quality Assurance ...................15
H. Insulators and Reactor Design .......................... 15

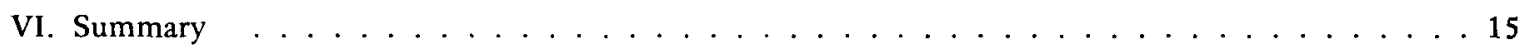

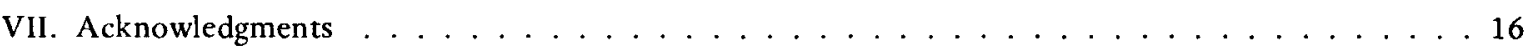

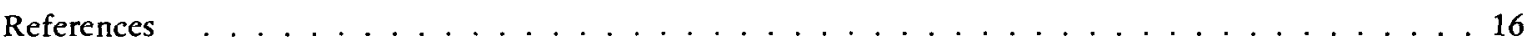

Appendix A: Characterization and Measurements on $\mathrm{ZrC}_{\mathbf{x}} \ldots \ldots \ldots$

Appendix B: Final Brief Summary of $\mathrm{ZrC}$ Insulators for the Rover Program . . . . . . . 23 J. M. Dickinson, D. H. Schell, and K. V. Davidson

Appendix C: Brief Summary of NF-2 Insulator Work . . . . . . . . . . . . . . . 26 A. R. Driesner

Appendix D: Contributions for Final Insulator Report . . . . . . . . . . . . . 31 T. J. Merson 


\title{
RESEARCH, DEVELOPMENT, AND PRODUCTION OF SUBSTOICHIOMETRIC ZIRCONIUM
}

\section{CARBIDE FOR HIGH-TEMPERATURE INSULATION}

\author{
by
}

\author{
Paul Wagner
}

\begin{abstract}
Zirconium carbide is a chemically stable, high-melting material uniquely suited to reactor applications. This report describes the research, development, fabrication, and evaluation of porous $\mathrm{ZrC}$ as an insulator intended for use in the high-temperature, gas-cooled Rover reactors. $\mathrm{ZrC}_{\mathbf{x}}$ is a stable, single-phase carbide in the $0.98 \geqslant x \geqslant 0.59$ region. The thermal conductivity of $\mathrm{ZrC}_{\mathrm{x}}$ is very sensitive to the vacancy concentration in the carbon sublattice $(1-x)$. To decrease sufficiently the thermal-conductivity value of $\mathrm{ZrC}_{x}$ to make the insulator, the carbon-zirconium ratio was decreased to an optimum value and the thermal conductivity was decreased further by introducing porosity in the $\mathrm{ZrC}_{x}$ matrix. By these techniques, the thermal conductivity of $\mathrm{ZrC}_{x}$ at $300 \mathrm{~K}$ was decreased from $50 \mathrm{~W} \mathrm{~m}^{-1} \mathrm{~K}^{-1}$ to less than $1 \mathrm{~W} \mathrm{~m}^{-1} \mathrm{~K}^{-1}$. Forty and seventy percent porosity $\mathrm{ZrC}_{\mathbf{x}}$ were investigated and their properties were measured. The production material was a $70 \%$ porous fiber-based $\mathrm{ZrC}_{\mathrm{x}}$ having satisfactory strength, thermal stress resistance, insulating power, and uniformity.
\end{abstract}

\section{INTRODUCTION}

As the Los Alamos Scientific Laboratory's (LASL) gas-cooled Rover reactor program progressed, reactor designs utilizing higher temperatures and longer use times evolved. Early designs employed pyrolytic graphite to insulate the thermally hot fuel elements from the cooler reactor components. Because pyrolytic graphite reacted with the hot hydrogen environment, reactor lifetimes were limited by the corrosion of the insulators. Interest was focused on the substoichiometric monocarbide of zirconium $\left(\mathrm{ZrC}_{\mathrm{x}}\right)$ as the more chemically stable insulator. Fabrication development on this material resulted in an end product that was a satisfactory insulator; also, an insulator system was generated where trade-offs could be made on the thermal conductivity, strength, and density of the $\mathrm{ZrC}_{\mathrm{x}}$. However, because of the structural nature of the $\mathrm{ZrC}$ fiber insulators, they were not wholly interdependent. It was possible to hold the density constant and yet to vary the strength and conductivity. With this kind of flexibility, the $\mathrm{ZrC}_{\mathrm{x}}$ system can be tailored to a set of specifications in conductivity, strength, density, or related properties unique in refractory materials.

of the various materials considered for the insulator, the carbides in the elements of groups $4 \mathrm{a}$ and $5 \mathrm{a}$ are the most attractive; all of which exhibit high melting points, chemical inertness in reducing atmospheres, and a spectrum of neutronic properties. Zirconium carbide was chosen because it has the lowest neutron capture cross section but it still retains the desired refractory qualities.

Using $\mathrm{ZrC}$ to insulate the hot fuel elements has one major drawback: in its theoretically dense state, $\mathrm{ZrC}$ is not an insulator. The thermal conductivity $(\lambda)$ of $\mathrm{ZrC}$ is about $50 \mathrm{~W} \mathrm{~m}^{-1} \mathrm{~K}^{-1}$ at $300 \mathrm{~K}$, whereas an effective insulator should have a $\lambda$ in the vicinity of $1 \mathrm{~W} \mathrm{~m}^{-1} \mathrm{~K}^{-1}$ or less. Thus, developing a $\mathrm{ZrC}$ insulator for the Rover reactors was reduced to a fabrication program wherein the prime figure of merit, the thermal conductivity, was to be minimized. This was done by combining several methods. First an understanding of the effects of stoichiometry on 
$\mathrm{ZrC}_{\mathbf{x}}$ properties was gained. Then, by using an optimized $\mathrm{C} / \mathrm{Zr}$ ratio, porous artifacts were manufactured with the intent of increasing the tortuosity of the heat-flow path and of increasing the thermal resistance. Of the several techniques employed in the fabrication investigations, the most successful was converting carbon fibers directly to $\mathrm{ZrC}$ by reaction with $\mathrm{ZrCl}_{4}$. When the Rover project was terminated, insulator units of pure $\mathrm{ZrC}_{\mathbf{x}}$ with thermal conductivities less than $1 \mathrm{~W} \mathrm{~m}^{-1} \mathrm{~K}^{-1}$ were being fabricated on a routine schedule.

Our investigations were complicated by the uncertainty of whether or not $\lambda$ measurements could be made accurately on the very porous materials. For this reason, various aspects of thermal-conductivity measurements and analyses are an essential part of the insulator development.

\section{PROPERTIES OF SUBSTOICHIOMETRIC ZrC}

The first step in the $\mathrm{ZrC}$ insulator development was to define the effects of structure of the substoichiometric $\mathrm{ZrC}_{\mathrm{x}}$ on the thermal-conductivity and associated properties. Some work had been done in this area; ${ }^{1}$ however, large gaps existed in the available information. We made an effort to generate self-consistent information that would demonstrate unambiguously the dependence of the thermal conductivity on the $\mathrm{ZrC}_{\mathbf{x}}$ structure in the monophase region $(0.98>x>0.59)$. Similar work was done with $\mathrm{NbC}_{x}$ partly because $\mathrm{NbC}_{x}$ has many of the properties that make $\mathrm{ZrC}_{x}$ so attractive and partly to aid in interpreting the $\mathrm{ZrC}_{\mathbf{x}}$ results.

These researches consisted of a group of measurements done on carefully made and characterized samples of single-phase $\mathrm{ZrC}_{\mathrm{x}}$. Details of the methods used for sample preparation, sample characterization, thermal-diffusivity measurements, density determinations, porosity corrections (for nearly theoretically dense samples), heat capacity estimation, electrical resistivity measurements, and impurity influences are given in Appendix A.

The data on the effect of $\mathrm{C} / \mathrm{Zr}$ atom ratio on $\lambda$ at $300 \mathrm{~K}$ are summarized in Fig. 1. The crystal structure of both $\mathrm{ZrC}$ and $\mathrm{NbC}$ are of the rock-salt type (type B 1, face-centered cubic). The metal and the carbon atoms form interlocking face-centered cubic sublattices. The zirconium sublattice is stable only when all the lattice sites are occupied, but the $\mathrm{ZrC}_{\mathrm{x}}$ is stable when there are vacancies in the carbon sublattice and when the substoichiometric carbide is formed. The change in $\lambda$ shown in Fig. 1 was caused by an increase in the vacancy concentration in the carbon sublattice; the effect of impurities such as oxygen, nitrogen, and sulfur is minimal (for details see Appendix A). A similar dependence of $\lambda$ on the carbon-to-metal ratio was observed in $\mathrm{NbC}$.

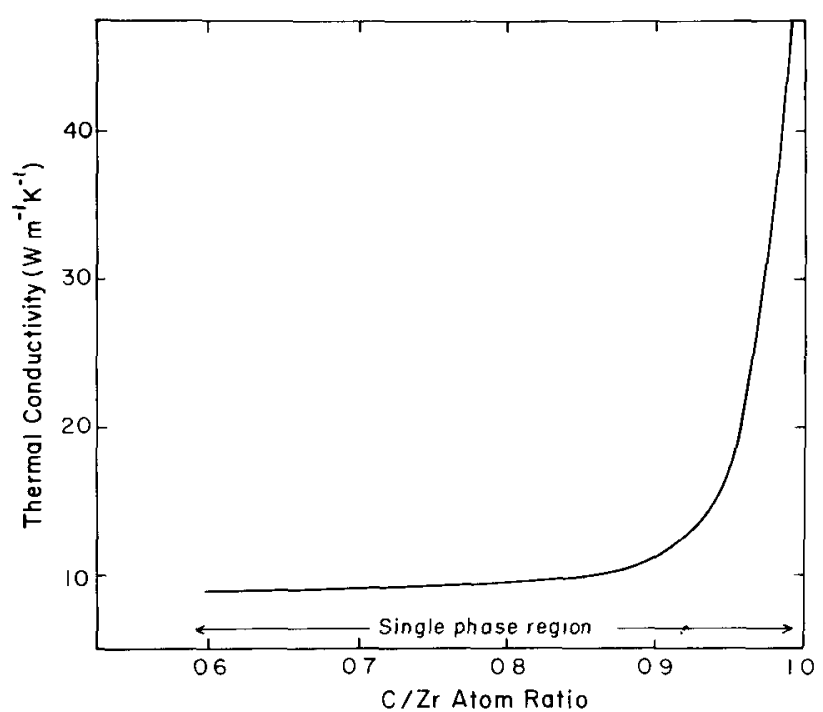

Fig. 1.

Effect of stoicbiometry on thermal conductivity in $\operatorname{ZrC}_{x}$.

The data in Fig. 1 and the electrical resistivity measurements made at $300 \mathrm{~K}$ on these samples show that about $37 \%$ of the thermal energy is carried by electrons and the other $63 \%$ is carried by lattice waves (phonons). If one estimates that, based on the pure material, a $1 \%$ increase in the vacancy concentration doubles the electrical resistivity (observed for a variety of metals such as copper, zinc, and aluminum) and if the phonon scattering is proportional to the square root of the defect concentration, $^{2}$ then the very sharp dependence of $\lambda$ on $\mathrm{C} / \mathrm{Zr}$ is understandable. The electronic component of the thermal conductivity is related to the electrical resistivity by

$$
\lambda_{\text {electronic }}=\frac{\mathrm{LT}}{\rho_{\mathrm{R}}} \text {, }
$$

where $\mathrm{T}=$ temperature; $\rho_{\mathrm{R}}=$ resistivity, ohm $\mathrm{m}$; and $\mathrm{L}=$ Lorenz function, $2.45 \times 10^{-8} \mathrm{~V}^{2} \mathrm{~K}^{-2}$. For $\mathrm{C} / \mathrm{Zr}=0.9$, that is, for a vacancy concentration of $10 \%$ in the carbon sublattice, the above-type calculation predicts a $\lambda=12 \mathrm{~W} \mathrm{~m}^{-1} \mathrm{~K}^{-1}$, which is very close to the value shown in Fig. 1. The behavior of the thermal conductivity with temperature is also consistent with this mechanism. The high-temperature measurements reported in Refs. 3 and 4 show a monotonic increase in $\lambda$ with temperature. Because these measurements are made at temperatures that exceed the Debye temperature, the phonon contribution will decrease as the reciprocal of the absolute temperature, but the behavior of the electrical resistivity indicates that a simultaneous filling of the conduction 
band occurs with sufficient magnitude to cause a net increase in $\lambda$ This increase was confirmed by observations made at $\mathrm{LASL}^{5}$ where the electronic component of the total thermal conductivity increased to about $75 \%$ at temperatures above $1500 \mathrm{~K}$.

$\mathrm{NbC}$ acts similarly to $\mathrm{ZrC}$ despite the difference in the band structure of the two materials This is a powerful indication that the mechanistic description of the behavior of the conductivity is realistic

Russian data $^{6}$ indicate that the linear coefficient thermal expansion (CTE) is nearly constant with stoich1ometry The following CTEs were reported

\begin{tabular}{l} 
Composition \\
\hline $\mathrm{ZrC}_{10}$ \\
$\mathrm{ZrC}_{090}$ \\
$\mathrm{ZrC}_{080}$ \\
$\mathrm{ZrC}_{075}$ \\
$\mathrm{ZrC}_{065}$
\end{tabular}

$$
\begin{aligned}
& \text { CTE }\left(K^{-1}\right) \\
& \hline 657 \times 10^{-6} \\
& 662 \times 10^{-6} \\
& 666 \times 10^{-6} \\
& 670 \times 10^{-6} \\
& 675 \times 10^{-6}
\end{aligned}
$$

Note CTE averaged from $300 \mathrm{~K}$ to $1273 \mathrm{~K}$

\section{FABRICATION METHODS FOR POROUS ZrC}

Several methods were used to manufacture porous $\mathrm{ZrC}$ during the development program These methods are indicated in Table I In addition to the methods listed in Table I, fabric, papers, carbonized bodies, and extruded carbons and graphites can also be converted into porous ZrC A combination of these methods can also be used The table gives those methods that proved most promising for the Rover applications
Hot-pressing technıques may be applied by using pure $\mathrm{ZrC}$ at sufficiently elevated temperatures and pressures To achieve desired porosities, most of the hot-pressing work was done with mixtures of $\mathrm{ZrC}, \mathrm{ZrO}_{2}$, carbon in some form, and a variety of pore-formers, such as Teflon Excess carbon was removed by reaction with hot hydrogen (leaching) There is an endless variety of raw materials from which porous $\mathrm{ZrC}$ can be made by using this technique The final product is strong and the porosity may be controlled by a combination of the material formulation and the pressing pressures One Westinghouse Astronuclear Laboratory $\mathrm{ZrC}$ made by this method had $\mathrm{P}=55 \%, \lambda=2 \mathrm{~W} \mathrm{~m}^{-1} \mathrm{~K}^{-1}, \quad \sigma=138 \mathrm{MPa}$, and $\mathrm{E}=$ $138 \mathrm{GPa}$ This hot-pressing method was used to fabricate parts used in L.ASL's Nuclear Furnace No 2 (NF-2), however, specifications other than the thermal conduc tivity had to be met for this application

The fiber impregnation method was used by the McDonnell Douglas Astronautics Company under contract to the National Space Aeronautics and Space Administration (Contract No SNPC-67) ${ }^{7}$ In this method, woven flber made of carbon or of carbon precursor matenals was soaked in a $\mathrm{Zr}\left(\mathrm{NO}_{3}\right)_{4}$ solution, which formed $\mathrm{ZrC}$ when heated This process could be repeated as often as desired to build the density up to the desired value Measurements of $\lambda$ on these materials are reported to be as low as $05 \mathrm{~W} \mathrm{~m}^{-1} \mathrm{~K}^{-1}$ however, LASL tests proved uncertain because relatively large amounts of residual carbon fibers were found to exist in the purported $\mathrm{ZrC}$ matrix The technique is attractive because of the potential control of the geometric structure of the $\mathrm{ZrC}$ fibrous

\begin{tabular}{|c|c|c|c|}
\hline Method & $\begin{array}{c}\text { Porosity } \\
\text { Range } \\
(\%)\end{array}$ & $\begin{array}{l}\text { Minimum Thermal } \\
\text { 300K Conductivity } \\
\left(\mathrm{W} \mathrm{m}^{-1} \mathrm{~K}^{-1}\right)\end{array}$ & Comments \\
\hline Hot-pressing & 0.70 & 30 & Strong \\
\hline Extrusion & $20-50$ & 30 & Strong \\
\hline Fiber impregnation & $15-60$ & 05 & Flexıble technique \\
\hline $\begin{array}{l}\text { Carbospheres }+\mathrm{ZrCl}_{4} \\
\text { gas }\end{array}$ & 80 & 08 & Slow process \\
\hline $\begin{array}{l}\text { Carbon foam }+\mathrm{ZrCl}_{4} \\
\text { gas }\end{array}$ & 80 & 50 & Slow process \\
\hline $\begin{array}{l}\text { Carbon fibers }+\mathrm{ZrCl}_{4} \\
\text { gas }\end{array}$ & $65-90$ & 04 & Fast, flexible method \\
\hline
\end{tabular}
phase

Direct reaction of carbon or graphite bodies with $\mathrm{ZrCl}_{4}$ gas to yield $\mathrm{ZrC}$ was tried by using hollow carbon

TABLE I

FABRICATION METHODS FOR POROUS ZrC 
spheres (carbospheres) that were bonded together with a polyfurfural alcohol binder, using carbon foam and carbon fibers The carbospheres and foams are relatively impermeable to the reacting gas and, as a consequence, the reaction times required for conversion are extremely long in comparison with those for the fiber systems The interlocked spheres in the $\mathrm{ZrC}$ carbospheres created a strong material, and the point contacts between the spheres provided an effective thermal resistance for a $\lambda$ $(300 \mathrm{~K})=08 \mathrm{~W} \mathrm{~m}^{-1} \mathrm{~K}^{-1}$ The carbon-foam system suffers from the same deficiencies as the carbospheres except that a high value of $\lambda$ may be expected for a foam matrix In particular, a trial test ${ }^{8}$ of the $72 \%$ porous $\mathrm{ZrC}$ made from foam yielded $\lambda(300 \mathrm{~K})=5 \mathrm{~W} \mathrm{~m}^{-1} \mathrm{~K}^{-1}$ or higher, the modulus of rupture was $105 \mathrm{MPa}$, the elastic modulus was $149 \mathrm{GPa}$, and the average strain to fallure was about $007 \%$ It took ten times longer to fabricate this material than it did to fabricate the carbon-fiber systems of the same mass

The extrusion methods used for porous $\mathrm{ZrC}$ and the carbon fiber-gas conversion to $\mathrm{ZrC}$ were the most success ful technıques employed Both systems were important to the Rover insulator program and are discussed separately in this report

\section{EXTRUDED POROUS ZrC}

An extensive study was made on the fabrication and properties of extruded $\mathrm{ZrC}$ of approximately $40 \%$ porosity during the insulator development program In general, this material was made by extruding a mixture of $\mathrm{ZrC}, \mathrm{ZrO}_{2}$ a polyfurfural alcohol (binder), carbon or graphite powder, and Teflon or nylon This mixture was then sintered in helium or argon at $2773 \mathrm{~K}$ for $72 \mathrm{ks}$ $(2 \mathrm{~h})$, excess carbon was removed by exposure to hydrogen at $2573 \mathrm{~K}$ for $288 \mathrm{ks}$ This gave a very high-strength material of about $60 \%$ theoretical density that was grey in appearance, was machineable, and was quite tractable The results and detals of the fabrication development effort on these materials is included in greater detail in Appendix B, and will not be discussed further here

\section{A. Thermal-Conductivity Measurements at $300 \mathrm{~K}$}

Although the thermal conductivity $(\lambda)$ of the porous $\mathrm{ZrC}$ insulators was the prime figure of merit, disparities in early $\lambda$ results and the uncertainty about whether or not transient methods could be successfully applied to systems of $40 \%$ vord stimulated a vigorous effort to define the accuracy, the reproducibility (using a variety of methods), and the precision of the measurements The first step was to assure the inherent accuracy of the equipment used-two flash-diffusivity systems, a contact probe system and a cut-bar steady-state apparatus Standardization was done using Armco iron (which had been calibrated vs a sample of Round Robin Armco), pyroceram (Code 9606), and fired Lava $\mathrm{A}^{9}$ The second step was to have different investigators make $\lambda$ measurements on the porous $\mathrm{ZrC}$ to assure that the introduction of the porosity did not influence adversely the reproducibility of the thermal-conductivity measurements The thırd step was to make a relative measurement of $\lambda$ for $\mathrm{ZrC}$ aganst well-known standards to assure that the results obtained by the flash method still retained the necessary degree of accuracy

Three investigators measured the room temperature thermal conductivity, and thermal diffusivity of four $\mathrm{ZrC}$ extrusions ${ }^{10}$ Where possible, identical samples were used to obtain characteristic data for production materials (Lots $4558,4575,4706,4742$ ) and some statistics on the reproducibility of the measurements made by the different investigators These data, compiled in Table II, show no disparity in measured results and show a data spread of less than $10 \%$ where identical samples were used For one of the extrusions, the sample thickness was varied from $00202 \mathrm{~m}$ to $00383 \mathrm{~m}$ (a factor of $36 \mathrm{in}$ influence in the diffusivity measurements because the thickness term is squared) Measurements were made in vacuum, argon (at $01 \mathrm{MPa}$ and at $10 \mathrm{kPa}$ ), helium, and air and were corrected for the convective heat losses All these data are shown in Table II in general, there were no contradictions in the measurements If samples of identical materials (but not identical samples) were used, variations in the investigators results could exceed the $10 \%$ precision demonstrated for the measurements It is inferred from this that the variability in these materials from one point to another was greater than the uncertainty in the measurements

The third step in verifying the methods used was to make a direct comparison of the results obtained by steady-state technıques with those obtained by transient methods on identical samples of the porous $\mathrm{ZrC}$ in question The thermal conductivity of a $40 \%$ porous $\mathrm{ZrC}$ sample was measured near room temperature using an axial-flow, steady-state comparison A detaled description of this apparatus is given in Ref 9 These measurements were compared with those made by the flashdiffusivity method on samples used for the steady-state measurements ${ }^{11}$ The results of these investigations are summarized very briefly as follows 
TABLE II

\section{COMPILATION OF THERMAL CONDUCTIVITIES OBTAINED AT LASL ON CONTROLLED SAMPLES OF $40 \%$ POROUS, EXTRUDED ZrC ALL DATA IN Wm $\mathrm{K}^{-1} \mathrm{~K}^{-1}$ UNITS}

\begin{tabular}{|c|c|c|c|c|c|c|c|c|}
\hline \multirow[b]{2}{*}{ Sample } & \multirow[b]{2}{*}{ Condition } & \multirow{2}{*}{$\begin{array}{c}\text { Sibbitt's } \\
\text { Results } \\
\end{array}$} & \multirow{2}{*}{$\begin{array}{c}\text { Wagner's } \\
\text { Results }\end{array}$} & \multicolumn{5}{|c|}{ Morrison's Results } \\
\hline & & & & Vacuum & Air & Helium & Argon & Argon $^{a}$ \\
\hline \multirow[t]{6}{*}{4706} & NF-1 production & $4.6(2 \mathrm{det})$ & 4.7 & 4.8 & - & 4.9 & 4.9 & -- \\
\hline & material. & 4.4 (2 det) & $\overline{4.9}$ & $\overline{4.7}$ & 4.7 & $\overline{4.8}$ & $=$ & - \\
\hline & Leached & $4.5(2 \mathrm{det})$ & $\overline{4.3}$ & $\overline{-}$ & $\overline{4.1}$ & $\overline{4.1}$ & 4.1 & 4.0 \\
\hline & & & & 4.3 & $\overline{4.6}$ & $\overline{4.4}$ & - & $\overline{4.4}$ \\
\hline & & & & 4.0 & 4.4 & 4.3 & - & 4.1 \\
\hline & & & & 4.3 & 4.3 & 4.3 & - & 4.4 \\
\hline \multirow[t]{3}{*}{4706} & Leached & $4.4(2 \mathrm{det})$ & - & - & - & -- & -- & -- \\
\hline & & $4.7(2 \mathrm{det})$ & - & - & - & - & -- & -- \\
\hline & & 4.5 (2 det) & - & - & - & -- & - & -- \\
\hline \multirow[t]{4}{*}{$4558 \mathrm{Zr}-1$} & Leached & 3.7 mean & 4.7 & 4.7 & - & - & -- & - \\
\hline & & $4.9 \max$ & $\overline{4.8}$ & $\overline{4.8}$ & - & -- & -- & -- \\
\hline & & (9 det) & $\overline{4.6}$ & $\overline{4.4}$ & - & - & - & -- \\
\hline & & & $\overline{4.4}$ & $\overline{-}$ & -- & -- & - & -- \\
\hline \multirow[t]{4}{*}{$4574 \mathrm{Zr}-2$} & Leached & 3.4 mean & 3.7 & 3.7 & - & -- & -- & -- \\
\hline & & $3.7 \max$ & $\overline{3.5}$ & $\overline{3.5}$ & - & -- & - & -- \\
\hline & & (5 det) & $\overline{3.4}$ & $\overline{3.7}$ & - & -- & - & -- \\
\hline & & & 3.8 & $\overline{-}$ & - & - & - & -- \\
\hline \multirow[t]{4}{*}{$4742 \mathrm{Zr}-1$} & Leached & 4.2 mean & 4.4 & 4.4 & - & - & - & -- \\
\hline & & $4.5 \max$ & 4.6 & 4.6 & - & - & -- & - \\
\hline & & (8 det) & 4.7 & 4.8 & - & - & -- & - \\
\hline & & & $\overline{4.8}$ & - & - & - & -- & -- \\
\hline
\end{tabular}

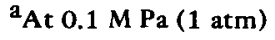

NOTE: Underlined data indicate identical samples (horizontally).

\begin{tabular}{|c|c|c|c|}
\hline Method & $\begin{array}{c}\text { Sample } \\
\text { Orientation }\end{array}$ & $\begin{array}{c}\text { Temp } \\
\text { (K) }\end{array}$ & $\begin{array}{c}\text { Thermal } \\
\text { Conductivity } \\
\mathrm{Wm}^{-1} \mathrm{~K}^{-1}\end{array}$ \\
\hline Steady state & $\begin{array}{l}\text { Parallel to } \\
\text { extrusion } \\
\text { axis }\end{array}$ & 380 & 6.3 \\
\hline $\begin{array}{l}\text { Transient } \\
\text { (flash dif- } \\
\text { fusivity) }\end{array}$ & $\begin{array}{l}\text { Parallel to } \\
\text { extrusion } \\
\text { axis }\end{array}$ & 295 & 6.2 \\
\hline
\end{tabular}

The indeterminate error is estimated to be $\sim 10 \%$ for the steady-state results and $\sim 5 \%$ for the flash-diffusivity results.
It is clear from the preceding that the $\lambda$ measurements reported here occupy a very high confidence level. Of the various techniques employed during this project, all but one gave accurate and self-consistent answers. The exception was the Colora method which gave self-consistent results, but the answers were invariably lower than all others. ${ }^{12}$ The necessity for proving the validity of the measurements upon which an entire development program is based cannot be over-emphasized.

B. Thermal-Conductivity Measurements at Elevated Temperatures

The questions concerning the validity of the $\lambda$ measurements at $300 \mathrm{~K}$ also existed for measurements of $40 \%$ 
porous $\mathrm{ZrC}$ materials at elevated temperatures. One of the first groups of experiments was performed to demonstrate the reproducibility of the change of the thermal conductivity with increasing temperature. ${ }^{13}$ Samples from different extrusion lots, but with nominally similar properties, increased in $\lambda$ as the temperature was increased from 300 to $2600 \mathrm{~K}$. In vacuum, $\lambda(2600 \mathrm{~K}) / \lambda(300 \mathrm{~K})$ was approximately 2.75 for all the extruded materials studied. The reliability of the transient laser flash-diffusivity technique for elevated temperature measurements using porous $\mathrm{ZrC}$ was demonstrated by sending samples, measured at LASL by this method, to the Thermo-Physical Properties Measurement Facility, Sandia Laboratories (Albuquerque, NM), for the same type measurements. The LASL and Sandia results were in excellent agreement. ${ }^{14}$ The final step in the experimental $\lambda(\mathrm{T})$ program was to make measurements of $\lambda(T)$ using a radial heat flow, steadystate measurement on the $40 \%$ porous $\mathrm{ZrC}$. All these $\lambda(\mathrm{T})$ results $\mathrm{s}^{5,14,15}$ are shown in Fig. 2. Figure 2 shows that although details from the steady-state measurements are not available below $1300 \mathrm{~K}$, excluding $\lambda(300 \mathrm{~K})$, in regions of overlapping temperature there is little to choose between the results obtained from the flashdiffusivity measurements and those obtained from the steady-state experiments. The error-estimate bands shown in Fig. 2 imply that high-temperature results of $\lambda$ measurements are very difficult to make with the same level of confidence as those reported for $300 \mathrm{~K}$.

\section{Modeling Porous ZrC}

Originally, the insulator was to be used in an environment of high-pressure hydrogen, but because no facility existed for making $\lambda(\mathrm{T})$ measurements in this environment, it was necessary to model the porous $\mathrm{ZrC}$ to calculate $\lambda(T)$ for the reactor applications. If we postulate that

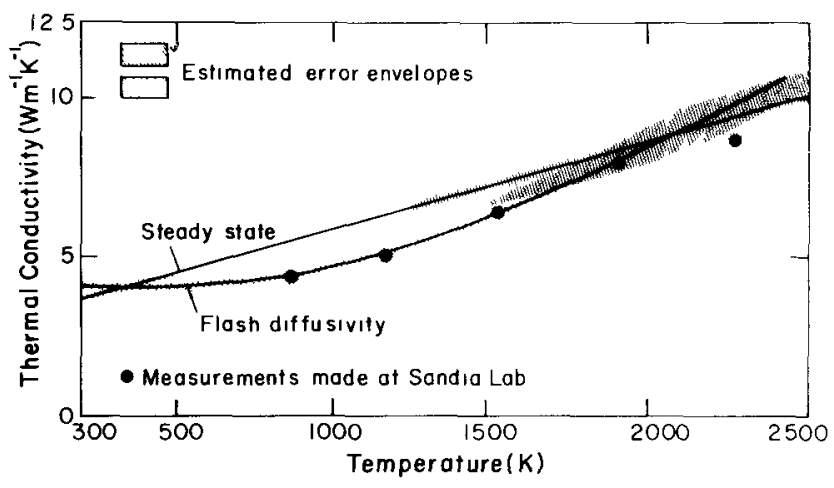

Fig. 2.

Thermal conductivities of $40 \%$ porous $\mathrm{ZrC}$ shown as a function of temperature. the porous $\mathrm{ZrC}$ consists of three phases, one a continuous matrix of the $\mathrm{ZrC}$, one a discontinuous phase (of fixedbed), and one a void structure, it is possible to calculate some of the system properties. This was done for extrusion lot No. 4706 by utilizing published data for $\lambda(T)$ of continuous $\mathrm{ZrC}^{3,4}$ and predicting, from engineering principles, the conductivity of the fixed-bed phase. The void structure was postulated to be isometric and calculations were made for two pore sizes. ${ }^{16}$ The results of these studies are summarized in Fig. 3. Here the calculated $\lambda(T)$ is compared directly with the measured $\lambda(T)$ for the same material as that used for the modeling. The agreement is quite good. Note the sharp upturn of the measured values compared with the calculated values for the thermal conductivity at higher temperatures. This is probably associated with the difficulty in characterizing the void geometry. A photomicrograph of the $40 \%$ void extruded $\mathrm{ZrC}$ is included (Fig. 4) to illustrate this point. It is likely that the postulated void structure gives a smaller radiation heat transfer component than actually noted in the experiments.

\section{Factors Which Influence the Thermal Conductivity}

Section II reports the effect of vacancies in lowering the thermal-conductivity. The introduction of the porosity, as in the $40 \%$ porous $\mathrm{ZrC}$, was also a large step forward in decreasing the heat-conducting power of the

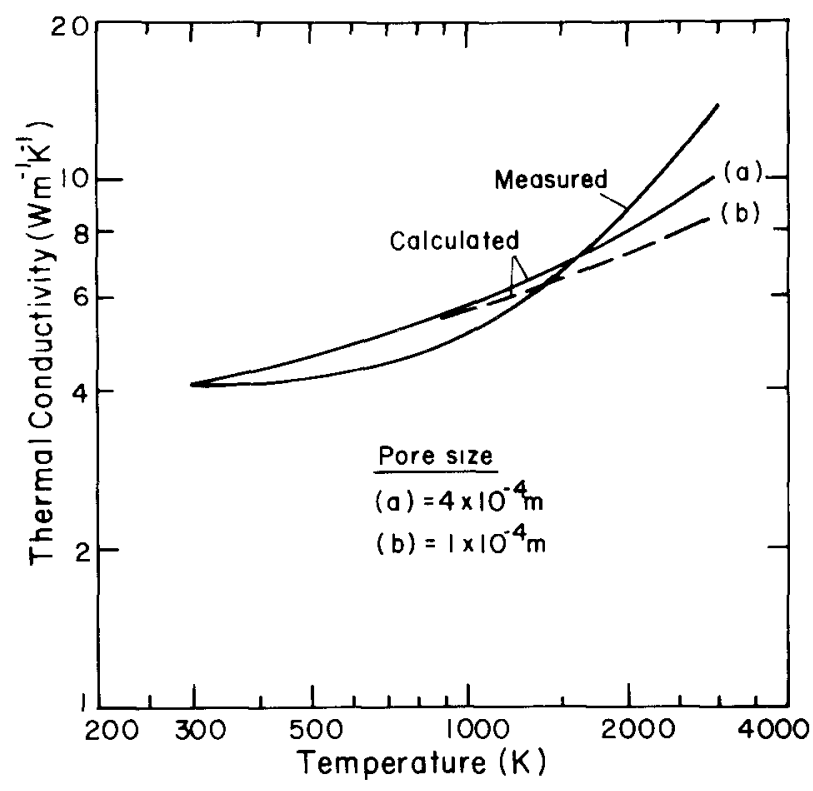

Fig. 3.

Thermal conductivities vs temperature for $40 \%$ porous $\mathrm{ZrC}$. Comparison of experiment with values calculated for two porosities. 

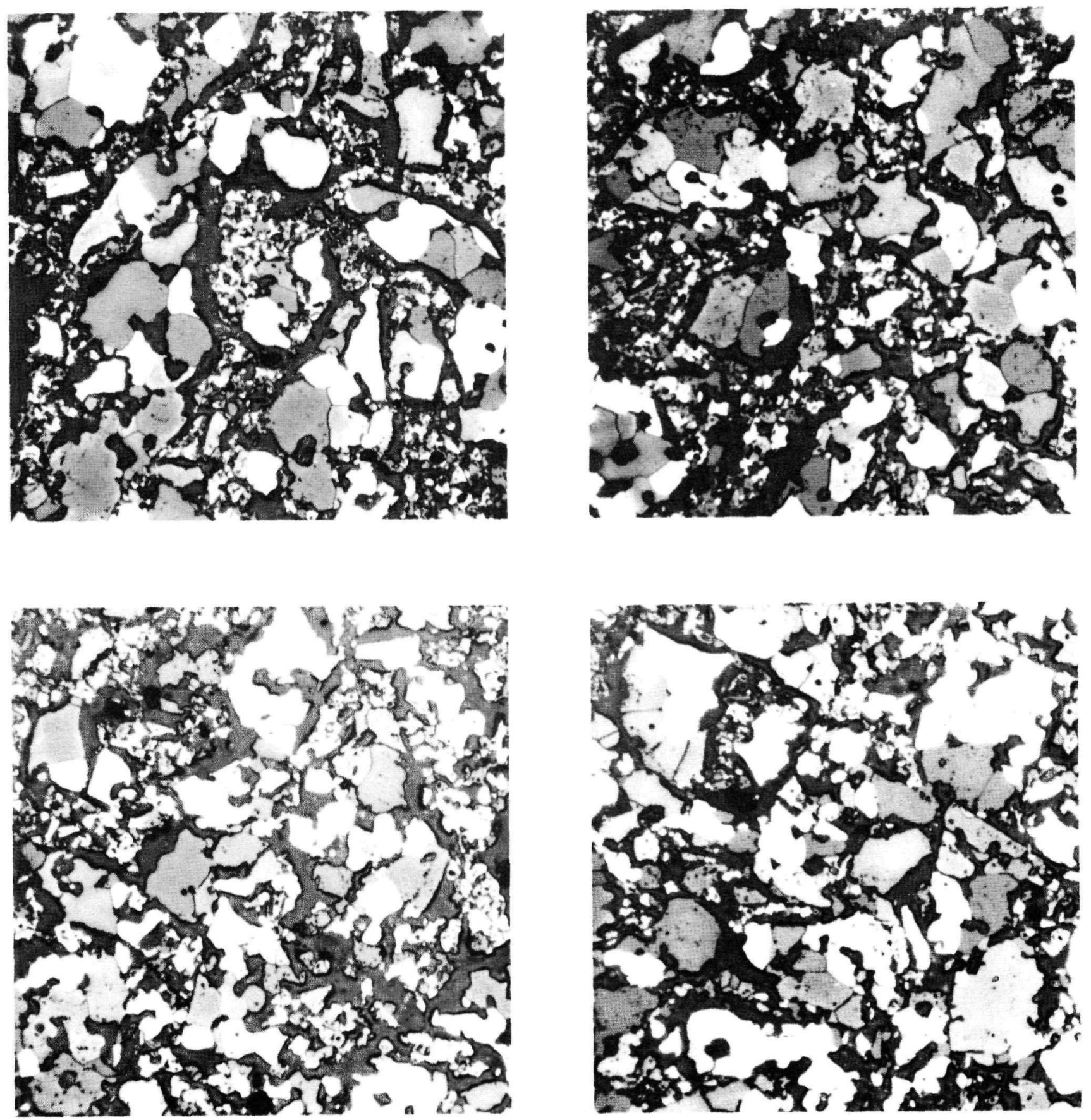

Fig. 4.

Pbotomicrograph of $60 \%$ dense extruded $\mathrm{ZrC}(150 \mathrm{X})$.

insulator. These two factors operate in parallel; therefore, the insulator system may be generalized by the following formula (Matthiesen's Rule).

$R_{\text {Total }}=R_{\text {Matrix }}+R_{\text {Pores }}+R_{\text {Interfaces }}$
Here, $\mathbf{R}$ is the thermal resistance and is equal to $\lambda^{-1}$. Factors that influence $\lambda$ fall into one of the categories on the RHS of the equation, and will be discussed separately.

$R_{M \text { atrix }}$ : The effect of vacancies has already been discussed. It has been demonstrated that optimizing the $\mathrm{C} / \mathrm{Zr}$ ratio can decrease $\lambda$ by 3 to 4 times $^{17}$ even in the 
$40 \%$ void $\mathrm{ZrC}$. Chafik ${ }^{18}$ reported that when the $\mathrm{C} / \mathrm{Zr}$ ratio is greater than one, that is, when the phase limit is exceeded and the $\mathrm{ZrC}$ contains excess carbon, $\lambda$ may increase sharply. This conclusion is neither confirmed nor denied in the work done at LASL. It has been confirmed that the introduction of nitrogen or oxygen at elevated temperatures will elevate the thermal conductivity. ${ }^{19}$ In this case, the oxygen or nitrogen atoms occupy vacancy sites in the carbon sublattice; the effect in elevating $\lambda$ is not as large as if the sites were occupied by carbon atoms, but it is considerable. For example, $\mathrm{ZrC}_{0.96}$ ( $40 \%$ porous) when exposed to nitrogen at $1773 \mathrm{~K}$ for $23.4 \mathrm{ks}(6-1 / 2 \mathrm{~h})$ underwent an unambiguous increase in $\lambda$ of a factor of 2 or greater. ${ }^{19}$

$\mathbf{R}_{\text {Pores: }}$ Introducing porosity will increase the thermal resistance of a system unless the $\lambda$ contribution from radiation or from contained gases is intrinsically greater than that of the matrix. To some degree this is attributable to the increase in the tortuosity of the heat-flow path. The shape of the pores, as well as their concentration, influences the increase in tortuosity. For example, pores shaped like platelets with their largest dimensions normal to the direction of the flow of heat would cause a greater impedance than would pores oriented so that the long dimension was parallel to the heat-flow path. For this reason, it is not possible to correlate properties such as the thermal conductivity with the densities of the manufactured $\mathrm{ZrC}$ without completely characterizing the concentration, structure, and distribution of the included voids. Figure 4 emphasizes the difficulty in doing this. Similar complications arise when analyzing the influences of gaseous conduction in the pores and when considering radiation heat transport.

$R_{\text {Interfaces: }}$ The degree of intimacy of contact will define the ability of the interface to carry the heat. It has been demonstrated that the thermal transport mechanism is by phonons and electrons and any disruption of the periodicity of the lattice (grain boundaries, crystallite interfaces, etc.) will increase the thermal impedance. Large particles would have relatively large masses of matrix and few intercrystalline junctions and would be expected to demonstrate relatively high thermal impedances. Mixing particles with a wide range of sizes would increase the number of interconnections between particles with a relatively small increase in total mass, thus decreasing the net thermal resistance. These effects have been observed in the $40 \%$ porous $\mathrm{ZrC}$. This point is made in Sec. IV.C: by varying the relationship between the continuous matrix and the fixed bed, the thermal conductivity may be varied.

\section{E. Properties of the Production Porous $\mathrm{ZrC}$}

Room-temperature thermal conductivities were measured on samples taken from a large production run. The sample materials were nominally $38 \%$ porous, extruded, leached $\mathrm{ZrC}$ microslates collectively labeled Lot 4887. The material was single phase, with no free carbon, and with a $\mathrm{C} / \mathrm{Zr}=0.96$ (i.e., $\mathrm{ZrC}_{0.96}$ ). Measurements of $\lambda(300 \mathrm{~K})$ were done on 88 samples. ${ }^{20}$ The results are displayed in Fig. 5 where the measured thermal conductivities are plotted against the frequency of the appearance of $\lambda$, tabulated in $0.1 \mathrm{~W} \mathrm{~m}^{-1} \mathrm{~K}^{-1}$ units. The average $\lambda$ for all 88 samples is $6.8 \mathrm{~W} \mathrm{~m}^{-1} \mathrm{~K}^{-1}$ with a standard deviation $(\sigma)$ of $1 \mathrm{~W} \mathrm{~m}^{-1} \mathrm{~K}^{-1}$. Eighty-four of the 88 determinations fall within the $95 \%$ limit $( \pm 2 \sigma)$. Densities averaged $4.10 \mathrm{Mg} \mathrm{m}^{-3}\left(4.10 \mathrm{~g} \mathrm{~cm}^{-3}\right)$ with a standard deviation of $0.13 \mathrm{Mg} \mathrm{m}^{-3}$. Three of the above specimens were subjected to hydrogen at $2575 \mathrm{~K}$, at a pressure of $3.1 \mathrm{MPa}$ (450 psi) for $3.6 \mathrm{ks}$ in an effort to leach out some of the carbon. ${ }^{17}$ At the conclusion of the experiment the $\mathrm{C} / \mathrm{Zr}$ had decreased from 0.96 to 0.86 and the average of the $\lambda(300 \mathrm{~K})$ was $3.4 \mathrm{~W} \mathrm{~m}^{-1} \mathrm{~K}^{-1}$.

Measurements made on the linear thermal expansion of the $40 \%$ porous extruded $\mathrm{ZrC}$ yielded results identical to those listed in Sec. II of this report. As expected, the porosity had no significant effect on the CTE. Little additional work was done in this area because engineering information could be taken from the measurements made on the dense material.

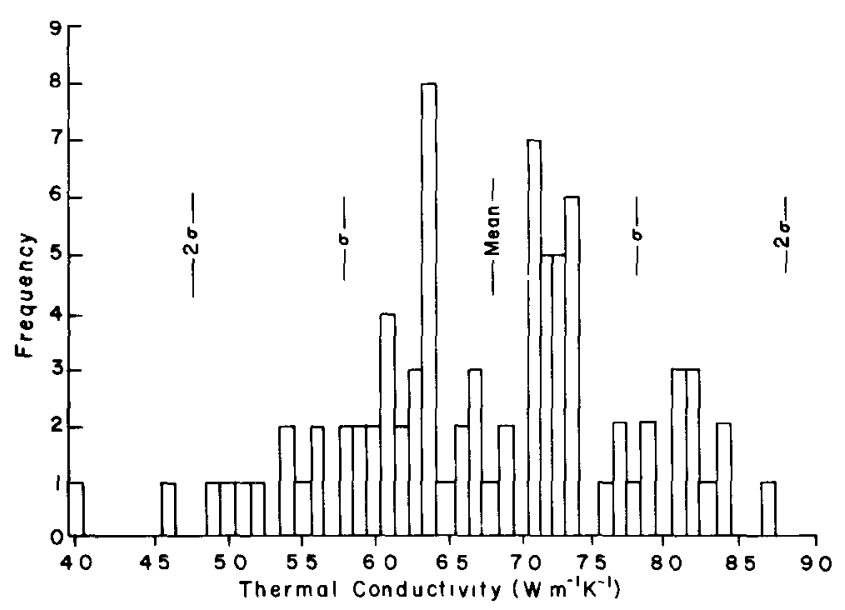

Fig. 5.

Frequency distribution for thermal-conductivity measurements of porous $\mathrm{ZrC}$ insulators from NF-2 production run (Lot $4887 \mathrm{Zr}$ ). 
Because of the minimal strength requirements placed upon the insulators used in the reactors associated with the Rover program, little effort was expended in this area. Some exploratory work was done ${ }^{21}$ on the compressive strength properties of the extruded $\mathrm{ZrC}$ and the results are shown in Table III.

During the course of the high-temperature, steadystate, thermal-conductivity measurements, ${ }^{5}$ surprisingly high-temperature gradients were attained, and survived, by the test specimen. For a long hollow cylinder, resistance heated and cooled by radiation on its outer surface, the maximum tensile strains occur on the outer surface and are given by

$$
\epsilon_{\theta}=\epsilon_{\mathrm{z}}=\alpha\left[\overline{\mathrm{T}}-\mathrm{T}_{\mathrm{min}}\right],
$$

where $\epsilon_{\theta}$ and $\epsilon_{\mathrm{z}}$ are the maximum tensile strains in the azimuthal and axial directions, $\alpha$ is the instantaneous coefficient of thermal expansion at temperature $\bar{T}, \bar{T}$ is the mean temperature of the cylinder, and $T_{\min }$ is the minimum temperature which occurs at the outer wall.

If the thermal conductivity and the power density are constant across the wall of the specimen, then the quantity $\left(\overline{\mathrm{T}}-\mathrm{T}_{\min }\right)$ can be related to the measured quantity $\mathrm{T}_{\max }-\mathrm{T}_{\min }$ by the following equation.

$$
\frac{\overline{\mathrm{T}}-\mathrm{T}_{\min }}{\mathrm{T}_{\max }-\mathrm{T}_{\min }}=\frac{\frac{1}{2}-\frac{3}{2} \mathrm{a}-\frac{\mathrm{a} \ln \mathrm{a}}{\frac{1}{\mathrm{a}}-1}}{1-\mathrm{a}+\mathrm{a} \ln \mathrm{a}}
$$

where $\mathrm{a}$ is the square of the ratio of outer radius to inner radius.

The $\mathrm{ZrC}$ extrusion used survived temperature gradients as high as $150 \mathrm{~K}$ at the higher temperatures, which

\section{TABLE III}

\section{SOME COMPRESSIVE DEFORMATION AND STRENGTH

\begin{tabular}{|c|c|c|c|}
\hline $\begin{array}{c}\text { Sample porosity } \\
(\%)\end{array}$ & $\begin{array}{c}\text { Temperature } \\
(\mathbf{K})\end{array}$ & $\begin{array}{l}\text { Stress } \\
(\mathrm{MPa}) \\
\end{array}$ & $\begin{array}{c}\text { Deformation Rate } \\
(\mathrm{ks})^{-1}\end{array}$ \\
\hline $40^{\mathrm{a}}$ & 1673 & 7.0 & 0 \\
\hline $40^{a}$ & 2775 & 0.7 & 0.003 \\
\hline $40^{\mathrm{a}}$ & 2775 & 2.1 & 0.0167 \\
\hline $40^{a}$ & 2775 & 7.0 & 0.0556 \\
\hline $34^{b}$ & 1673 & 7.0 & 0 \\
\hline $34^{b}$ & 2775 & 0.7 & 0 \\
\hline $34_{b}^{b}$ & 2775 & 2.1 & 0.0028 \\
\hline $34^{b}$ & 2775 & 7.0 & 0.0194 \\
\hline $\begin{array}{l}\text { Oriented paralle } \\
300 \mathrm{~K}, 123 \mathrm{MPa}\end{array}$ & e extrusion & s. Ultim & e strength at \\
\hline
\end{tabular} PROPERTIES OF POROUS, EXTRUDED ZrC}

corresponds to a strain of $0.1 \%$ that was survived by the specimen. This is surprisingly high for a brittle material such as $\mathrm{ZrC}$ and suggests that creep and/or plastic flow can relieve thermal stresses in this material at high temperatures.

\section{F. Reactor Performance of the Porous Extruded ZrC}

Two of the 49 cells in LASL's Nuclear Furnace No. 1 used $\mathrm{ZrC}$ in the interstices between the fuel element and the water-cooled cell wall (the other cells used pyrolytic graphite). The function of the $\mathrm{ZrC}$ was that of a barrier and a spacer for keeping the fuel element centered. The hydrogen that flowed in the channel provided the necessary insulation. The configuration of the $\mathrm{NF}-1 \mathrm{ZrC}$ is shown in Fig. 6. These tests are the only in-reactor tests made using $\mathrm{ZrC}$, and they provide some qualitative information on the ability of the $\mathrm{ZrC}$ to withstand the environmental combination of hydrogen at $2700 \mathrm{~K}$ temperatures and the radiation field. The postmortem work on NF-1 was not completed when the Rover program was cancelled. The $\mathrm{ZrC}$ spacers showed longitudinal cracks; however, because of the tight dimensions, it was not clear whether the cracks were formed by mechanical loading during the reactor heat-up or by thermal stress. The general appearance of the $\mathrm{ZrC}$ weighted the

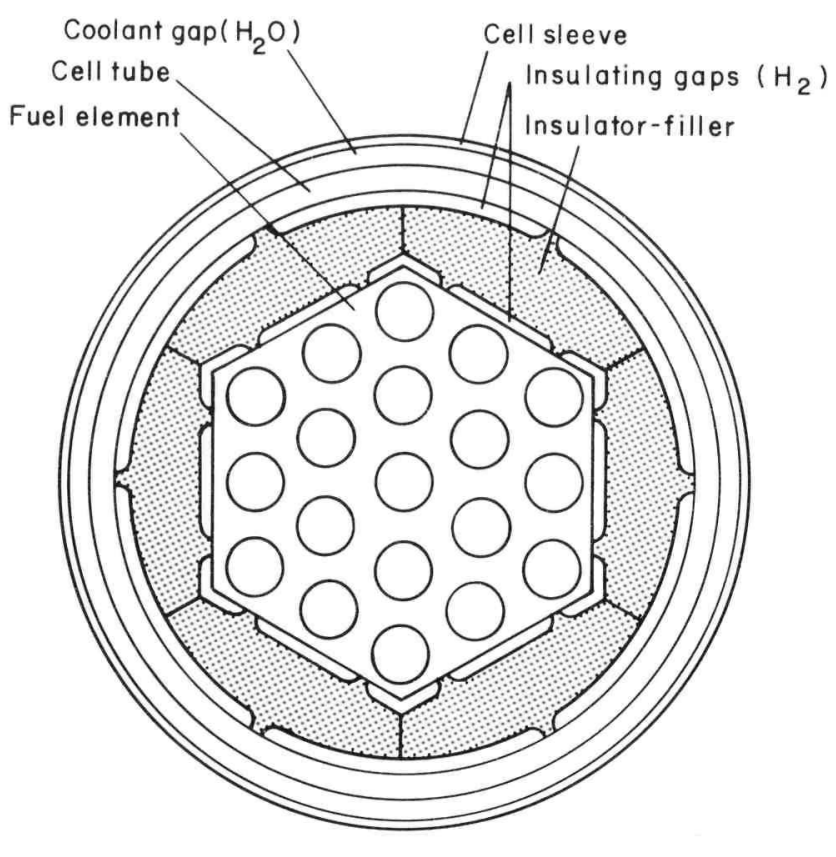

Fig. 6.

Cross section of NF-1 cell showing location and shape of the experimental porous $\mathrm{ZrC}$ insulators. 
mechanical loading rationale. There were no indications of reaction with hydrogen nor any indication of any form of degradation in the appearance of the material. The one thermal-conductivity measurement was made on a sample taken from a section halfway between the cold inlet and the hot-gas exit which should have seen the maximum temperature and radiation field intensity. The thermal conductivity of this irradiated $\mathrm{ZrC}$ was $3.2 \mathrm{~W} \mathrm{~m}^{-1} \mathrm{~K}^{-1}$ at $300 \mathrm{~K}$, which may be compared with the NF-1 production $\lambda(300 \mathrm{~K})$ of about $4.5-5.0 \mathrm{~W} \mathrm{~m}^{-1} \mathrm{~K}^{-1}$ (Lot 4706) listed in Table II. The expected change in $\lambda$ from the introduction of a high concentration of point defect scattering centers is not an unreasonable value.

\section{VERY POROUS ZrC MADE FROM CARBON FIBERS}

The insulator system chosen for NF-2 and the system that would have been used for high-performance flight reactors was made by the solid-gas reaction of carbon fibers with $\mathrm{ZrCl}_{4}$. Because of the compressed time scale (the decision to use $\mathrm{ZrC}$ made in this manner was made about seven months before the "parts on hand" date) the development, evaluation, and production proceeded along parallel paths. As a result, descriptions of production and properties of the very low-density $\mathrm{ZrC}$ are inevitably tied to the NF-2 design needs. A discussion of the porous, fiber-based $\mathrm{ZrC}$ would include an interlacing of various aspects of these factors. Appendix $\mathrm{C}$ is a LASL internal document describing some aspects of the fabrication of the NF-2 insulator units.

Figure 7 is a sketch of the NF-2 insulator configuration. The reactor consisted of 49 such cells. We expected that the fuel element would run as hot as $2900 \mathrm{~K}$; the aluminum tube was water cooled and the inner surface of the aluminum tube was not expected to exceed $500 \mathrm{~K}$. Thus, the $2400 \mathrm{~K}$ temperature drop would have to be taken by the $\mathrm{ZrC}$ insulator; and since the mean thickness was about $4.0 \mathrm{~mm}(5 / 33 \mathrm{in}$.), the extent of the insulating power required is amply demonstrated (Fig. 8 ). Figure 8 shows the radial heat-flow leak vs the value of $\lambda$ for the insulator configuration shown in Fig. 7 and for the fullpower operation for an NF-2 cell. Figure 8 shows that to transfer $95 \%$ of the thermal energy to the coolant gas, a $300 \mathrm{~K} \lambda$ of about $0.5 \mathrm{~W} \mathrm{~m}^{-1} \mathrm{~K}^{-1}$ would be required. This then set the goal for the NF-2 insulator design and for the target thermal conductivity of less than $1 \mathrm{~W} \mathrm{~m}^{-1} \mathrm{~K}^{-1}$ at $300 \mathrm{~K}$.
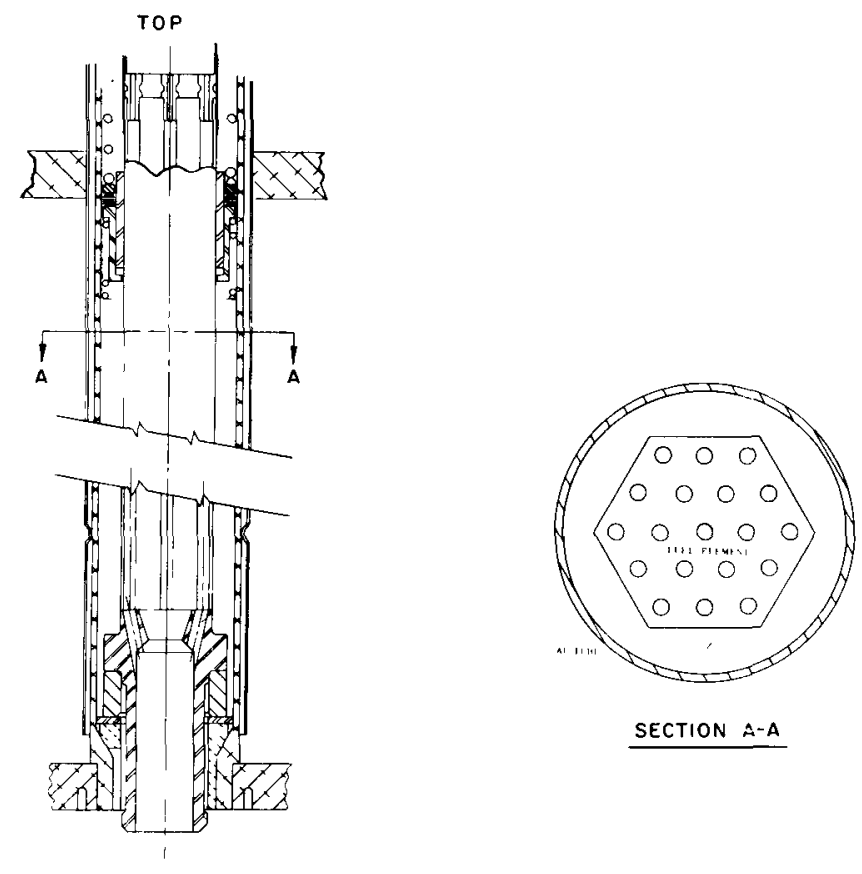

воттом NF-2 INSULATOR

Fig. 7.

$N F-2 \mathrm{ZrC}$ insulator configuration.

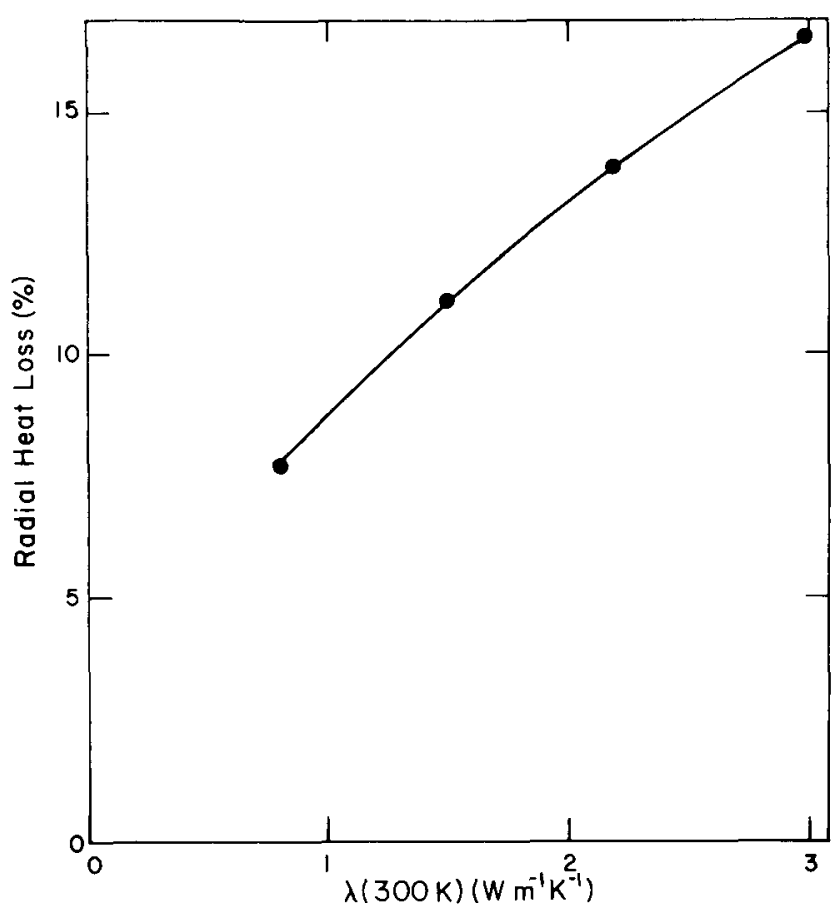

Fig. 8 .

Relation between radial beat leak and $\lambda(300 \mathrm{~K})$ for NF-2 insulators. 


\section{A. Fabrication}

The NF-2 insulator units were produced in a multiplestep, single-pass operation. The tubular carbon-fiber raw material was premachined to approximate cross-section dimensions and was converted directly to the final product. The starting material and the finished product are shown in Fig. 9. The carbon-fiber tube was converted to

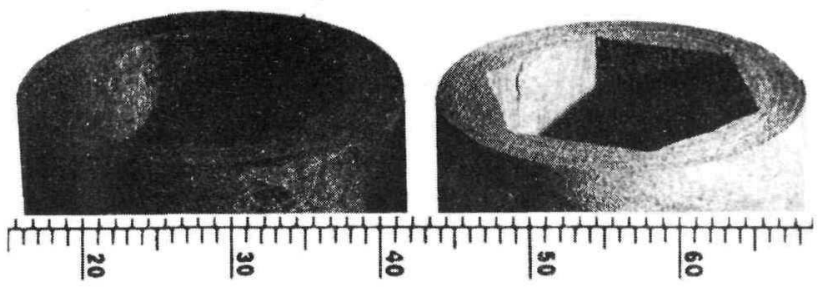

Fig. 9.

The carbon-fiber tube before conversion and the finisbed $\mathrm{ZrC}$ product (right).
$\mathrm{ZrC}$ by exposure to a mixture of $\mathrm{ZrCl}_{4}, \mathrm{H}_{2}$, argon, and $\mathrm{HCl}$ at $1600 \mathrm{~K}$ for $40 \mathrm{~h}$, which resulted in a product composition of $\mathrm{ZrC}_{0.95}$ and a $76 \%$ porosity (24\% theoretical density). The temperature was then dropped to $1500 \mathrm{~K}$ and $\mathrm{CH}_{4}$ was added to the gas mixture; under these conditions, a coating of $\mathrm{ZrC}$ was deposited on each fiber. After $10 \mathrm{~h}$ of this latter treatment, the porosity was decreased to about $72 \%$. Finally, the temperature was raised to $2800 \mathrm{~K}$ and the insulators were held at this temperature in an argon environment for $2 \mathrm{~h}$. The insulators were ready for final machining after they were removed from the conversion furnaces. Figures 10, 11, and 12 are scanning electron micrographs of the carbon fibers, the converted $\mathrm{ZrC}$, and the fiber-coated converted $\mathrm{ZrC}$, respectively. Note that the fiber coating increases the degree of filleting and fiber interconnection. Intuitively it would be expected that fiber coating would increase both the strength and the thermal conductivity, which proved to be the case. The $2800 \mathrm{~K}$ heat treatment seemed to counteract the coating effects by decreasing the thermal conductivity, although the reason for this phenomenon is obscure.

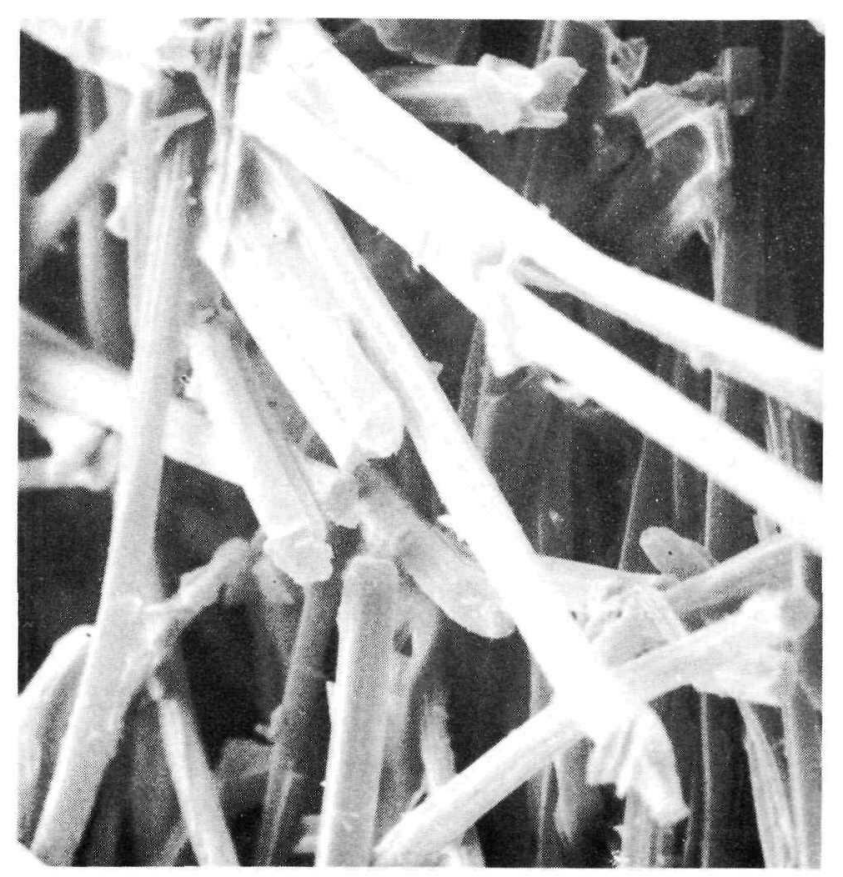

Fig. 10.

Scanning electron micrograph of carbon-fiber starting material (1000X).

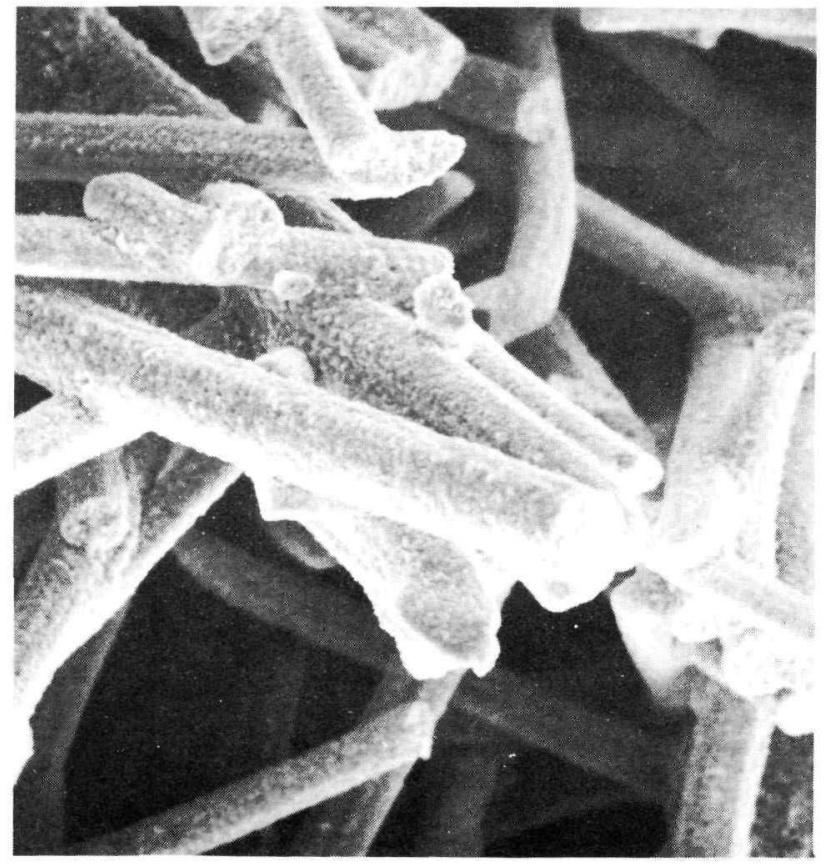

Fig. 11.

Scanning electron micrograph of fiber $\mathrm{ZrC}$ after conversion (1000X). 


\section{ROOM TEMPERATURE THERMAL CONDUCTIVITY OF PRODUCTION POROUS FIBER-ZrC}

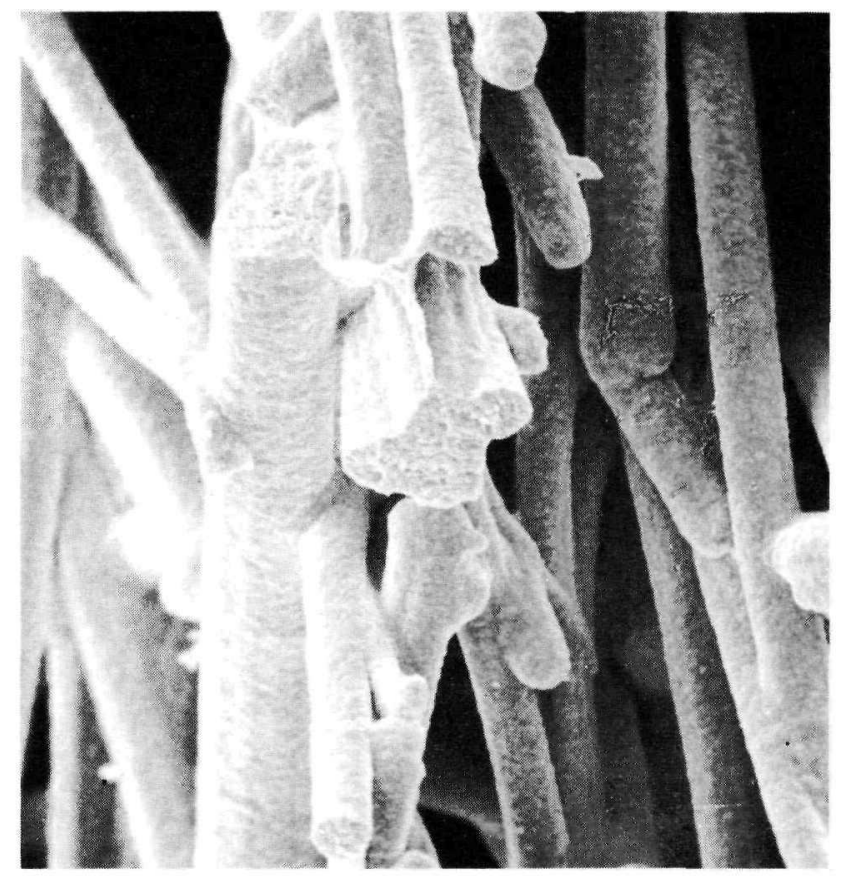

Fig. 12.

Scanning electron micrograph of $\mathrm{ZrC}$ after conversion and vapor-deposited $\mathrm{ZrC}$ fiber coat (1000X).

\section{B. Thermal Conductivity of Very Porous $\mathrm{ZrC}$ at $300 \mathrm{~K}$}

All the thermal-conductivity measurements made at $300 \mathrm{~K}$ on the very porous $\mathrm{ZrC}$ were made with the flashdiffusivity method. Despite all the precautions taken to assure the accuracy of such measurements (see Sec. IV.A), unpublished work done in LASL Group N-7, just before the group was dissolved, indicated that the flash-diffusivity measurements yielded answers that were too high. The insulating power of the $\mathrm{ZrC}$ insulators, as reported in this document, is probably pessimistic and the fibrous $\mathrm{ZrC}$ insulators are, in fact, more effective than the numbers indicate. Results of $\lambda$ measurements made at $300 \mathrm{~K}$ using the flash-diffusivity method ${ }^{22-23}$ are compiled in Table IV. This work was done independently by two investigators with essentially identical results and shows the variation of thermal conductivity with degree of completeness of the fabrication. The increase in $\lambda$ due to the fiber coating is explained by the increase in the intimacy of contact of the fibers and by a slight increase

\begin{tabular}{|c|c|c|c|}
\hline Sample Condition & $\begin{array}{c}\text { Porosity } \\
(\%) \\
\end{array}$ & $\begin{array}{l}\lambda(300 k)^{a} \\
\left(W m^{-1} k^{-1}\right) \\
\end{array}$ & 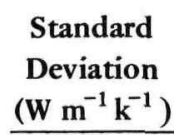 \\
\hline \multirow[t]{6}{*}{ Converted to $\mathrm{ZrC}$} & 74 & 0.65 & \\
\hline & 71 & 0.65 & \\
\hline & 75 & 0.62 & \\
\hline & 73 & 0.85 & \\
\hline & 79 & 0.42 & 0.04 \\
\hline & 75 & 0.45 & 0.04 \\
\hline \multirow{2}{*}{$\begin{array}{l}\text { Fiber coated } \\
\text { with } \mathrm{ZrC}\end{array}$} & 66 & 1.00 & 0.10 \\
\hline & 65 & 1.32 & 0.25 \\
\hline \multirow{4}{*}{$\begin{array}{l}\text { After } 2800 \mathrm{k} \\
\text { heat treatment }\end{array}$} & 92 & 0.35 & \\
\hline & 72 & 0.35 & \\
\hline & 72 & 0.43 & 0.04 \\
\hline & 72 & 0.36 & 0.02 \\
\hline
\end{tabular}

in the density. Table IV shows that the heat treatment is very effective in reducing $\lambda$, but before we could make further studies, the project was terminated.

Figure 9 shows a void orientation in the converted $\mathrm{ZrC}$ in the form of circumferential cracks. This was a particularly fortunate development because such cracks serve as thermal-stress fracture relief modes and, because of the configuration of the insulator (Fig. 7), would not be expected to have deleterious effects on the reactor operation. Another consequence of this void structure was the introduction of an anisotropy in the thermal conductivity. Measurements made parallel and perpendicular to the insulator tube axis showed that this anisotropy could be as large as a factor of five. ${ }^{25}$ The effect of the cracks as thermal barriers was great enough that having a $\mathrm{C} / \mathrm{Zr}=\mathbf{0 . 9 5}$ proved to be no disadvantage; as a matter of fact, this slightly high value resulted in a product with more desirable handling and machining characteristics than the systems with lower carbon contents.

\section{Modeling the Very Porous ZrC Insulators}

Before discussing the high-temperature measurements of the very porous $\mathrm{ZrC}$, it is necessary to consider the mechanism by which heat is transferred in a heterogeneous medium of this type. In principle, the modeling 
rationale is the same as that discussed in Sec IV C for the $40 \%$ void $\mathrm{ZrC}$ In practice, the situation is far more complex ${ }^{26}$ In the very porous systems, with porosities in the 70 to $75 \%$ region, the nature of the voids will be important in determinıng the thermal conductivity, not only at temperatures where the radiation is effective but also at lower temperatures where the nature of the gas in the voids is significant The critical factor is the description of the pores, however, Figs 10,11, and 12 show that characterization of such a void structure presents a formidable problem Added to this are the anisotropic effects described in the previous section Thus, altering the ratio of the continuous-fiber $\mathrm{ZrC}$ to the fixed-bed $\mathrm{ZrC}$ and changing the void structure afford an endless group of combinations This is the heart of the $\mathrm{ZrC}$ system For a given density, the variations described permit the fabricator to tailor the value of the thermal conductivity and related properties ( $F_{1}$ 13) In Fig 13 we assumed that the fiber diameter was fixed, that a pore diameter could be assigned to the system, and the overall porosity of the $\mathrm{ZrC}$ was taken to be $\mathbf{8 0 \%}$ The three curves were gener ated by varying the ratio of the fixed bed to the continuous $\mathrm{ZrC}$, by including the effect of the hydrogen at

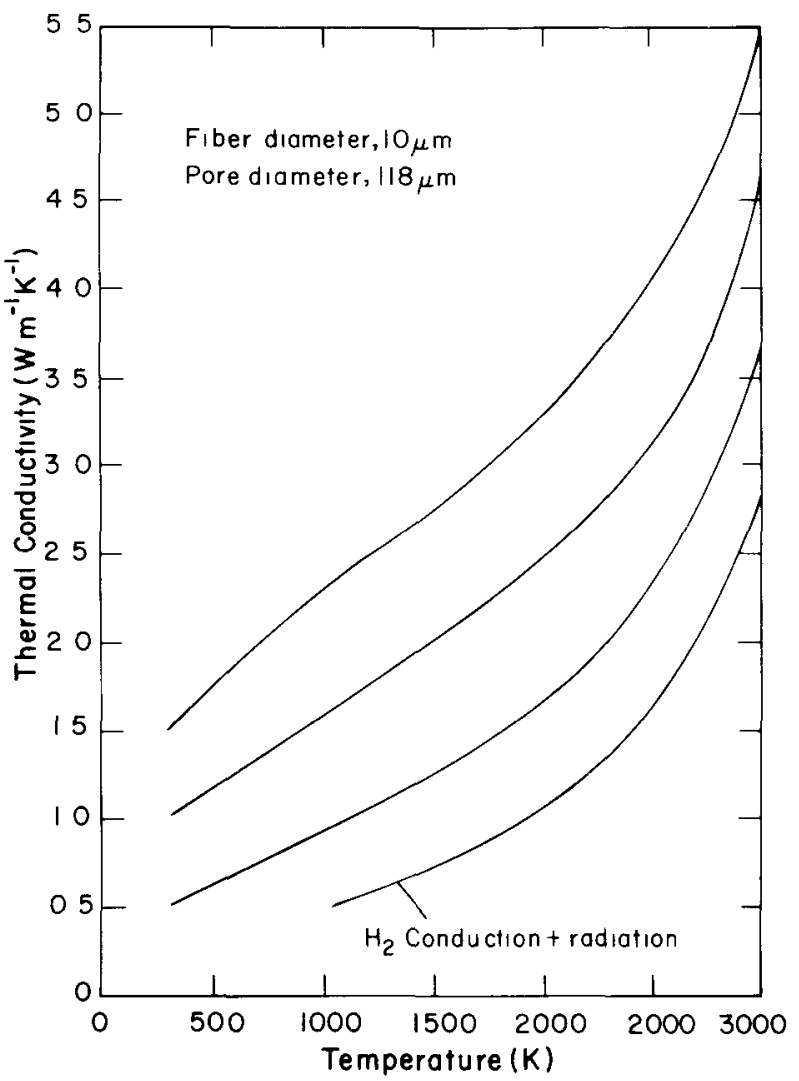

Fig 13

Calculated thermal conductivities for $80 \%$ porous $\mathrm{ZrC}$
$34 \mathrm{MPa}$ ( $500 \mathrm{ps} 1$ ), and by thermal radiation effects The hydrogen effects were included originally because there are no facilities avalable for measuring $\lambda$ in high-pressure hydrogen at elevated temperatures Hydrogen effects were included here to illustrate the drastic effects that the environment may have on the intrinsic properties of such a porous material (compare Figs 13 and 2)

Practical lower limits of the thermal conductivities to be expected from highly porous $\mathrm{ZrC}$ were calculated and the results are displayed in Fig 14 Here the pore structure was taken to be similar, except for the magnitude of the void fraction, the matrix structure was fixed ( $1 \mathrm{e}$, ratio of the continuous $\mathrm{ZrC}$ to the fixed bed = constant) Thermal-conductivity measurements were calculated for the insulators with radiation, and hydrogen gas inclusion at $34 \mathrm{MPa}$ was considered Porosity effects are of a magnitude similar to that effected by changing the matrix structure (Fig 13) This was important in fabrication considerations because it demonstrated clearly that the $\mathrm{ZrC}$ could be fabricated with densities high enough to retain any required structural integrity without sacrificing the desirable insulating properties

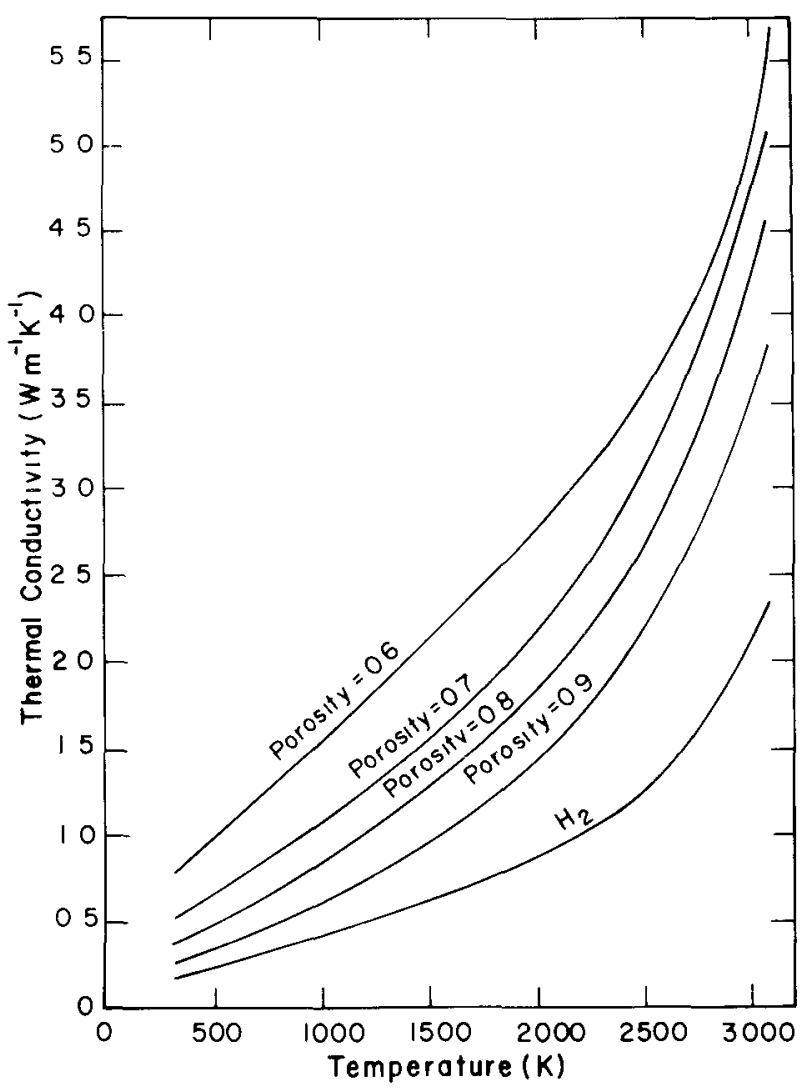

Fig 14

Calculated limiting values for thermal conductivities of $\mathrm{ZrC}$ of different porosities 
These ideas were tested by making thermal-conductivity measurements of very porous $\mathrm{ZrC}$ at elevated temperatures. A $\mathrm{ZrC}$ tube (with $84 \%$ porosity, $\mathrm{C} / \mathrm{Zr}=0.93$, and fabricated expressly for this purpose) was used for steady-state radial heat-flow measurements of $\lambda(T)$ in vacuum from 1300 to $2450 \mathrm{~K}^{27}$ These data are shown in Fig. 15 where the experimental points, fitted curve, and predicted $^{16,26}$ curve are compared. As shown in Fig. 2, the upturn of the experimental data at the high temperatures is somewhat greater than would have been predicted; however, the difficulty in characterizing the void structure is probably at the root of this problem and was not solved when efforts in this area ceased.

\section{High-Temperature Thermal Conductivity of NF-2 Insulators}

Samples cut from production NF-2 insulators were used for thermal-conductivity measurements using the

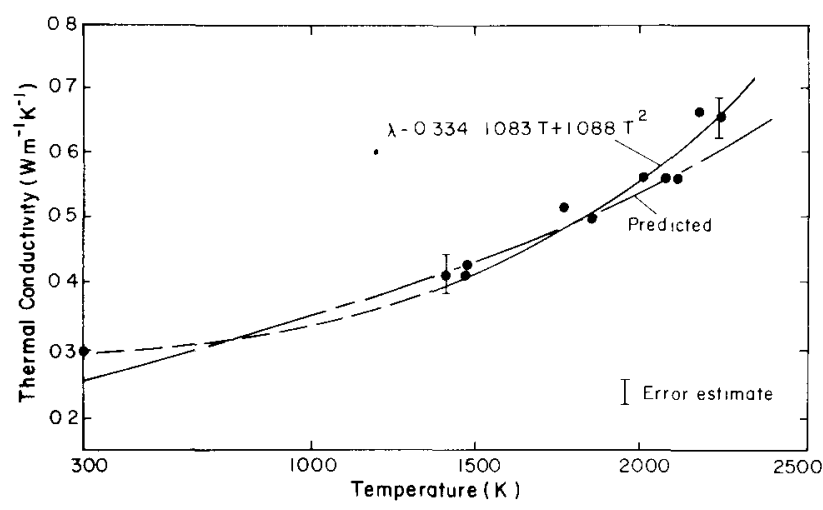

Fig. 15.

Comparison of predicted thermal conductivity with experiment for $84 \%$ porous fiber $\mathrm{ZrC}$.

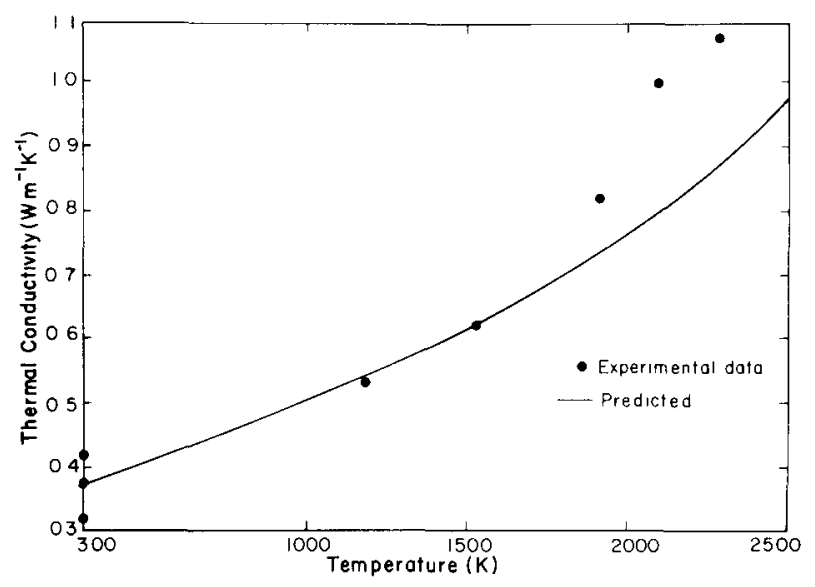

Fig. 16

Thermal conductivities of NF-2 production insulators compared with predicted temperature trend. laser-flash technique $\lambda[\alpha(\mathrm{T})]$ from 300 to $2200 \mathrm{~K}^{24}$ These measurements were made in vacuum. Because of the inherent uncertainties associated with the $\lambda[\alpha(T)]$ method for these very porous materials, the data are shown along with normalized predicted values of the thermal conductivity ${ }^{16,26}$ in Fig. 16. The material used had a porosity of $72 \%$, was heat treated, and had a $\lambda(300 \mathrm{~K})$ in air of $0.38 \mathrm{~W} \mathrm{~m}^{-1} \mathrm{~K}^{-1}$. As in other comparisons of this type, the agreement is quite good until temperatures in excess of $2000 \mathrm{~K}$ are reached, then the experimental data rise faster with temperature than would be expected.

E. Effect of Temperature on the Compressive Strength of $\mathrm{ZrC}$

It was necessary to define the temperature limits of the usefulness of the insulators in terms of their resistance to compressive stress. ${ }^{28}$ Standard NF-2 production materials $\left(72.5 \%\right.$ porosity, $\mathrm{ZrC}_{0.94}$, heat treated at $2800 \mathrm{~K}$ ) were subjected to compressive stress from 300 to $3073 \mathrm{~K}$. The stress was applied parallel to the cylinder axis of the insulator units with a fixed strain rate of $42.3 \mu \mathrm{msec}^{-1}$. These tests were done at 300, 1273, 1873, 3073, 2273, 2473,2773 , and $3073 \mathrm{~K}$, in a helium environment. The strength of the $\mathrm{ZrC}$ was (somewhat arbitrarily) defined as that stress level where yield first occurred. From the data generated during these experiments, it appeared that the yield time was short enough to make the creep phenomena unimportant. The curve showing the effect of temperature on the yield stress for these materials is given in Fig. 17. The shape of the curve is reasonably characteristic of that for a brittle material which undergoes plastic deformation at temperatures greater than half the melting temperature. The data suggest that $3100 \mathrm{~K}$ is an upper limit for $\mathrm{ZrC}$ use to avoid excessive deformations.

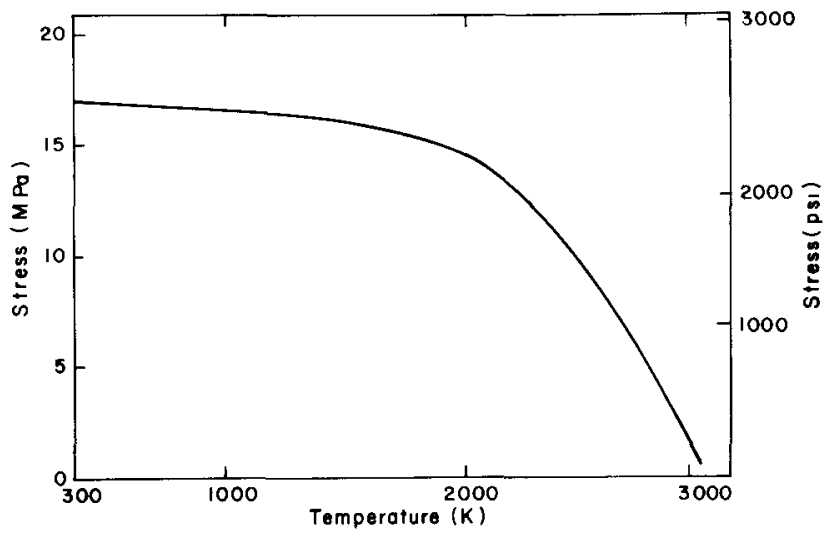

Fig. 17.

Effect of temperature on yield stress for $72.5 \%$ porous fiber $\mathrm{ZrC}$. 
TABLE V

The porous fiber-based $\mathrm{ZrC}$ was never reactor tested; NF-2 was scheduled for testing when the Rover program was cancelled. As part of the performance evaluation of the insulator units, a test was made to investigate the behavior of $\mathrm{ZrC}$ in a simulated NF-2 fuel cell. ${ }^{29}$ An 8-cm-long piece of full cross-section NF-2 insulator was slipped over a standard thermal-stress fuel element specimen (Fig. 7). The insulator was centrally located on the fuel element so that the heat flux was normal to the insulator axis. The outer surface was free to radiate to the water-cooled furnace wall. This insulator came from an early NF-2 production run. It was converted but was not fiber-coated and had not been heat treated. The insulator was $77 \%$ porous ( $23 \%$ theoretical density). The test procedure was the same as that followed for a fuel element thermal-stress fracture experiment where the coolant flow is established and the power is increased until the specimen fractures. In this case, the test was terminated by the fracture of the fuel element at a power density of about $4050 \mathrm{MW} \mathrm{m}^{-3}$. At the conclusion of the test, the insulator was cracked but did not break up. The minimum temperature drop across the insulator unit was estimated to be $1000 \mathrm{~K}$. Based on these very rudimentary experiments, (the only simulation experiments performed) the outlook for a satisfactory reactor performance from the porous $\mathrm{ZrC}$ insulators was optimistic.

Similar evaluation tests ${ }^{30}$ were made on converted and fiber-coated $\mathrm{ZrC}$ tubes (63\% porous). These insulators were made expressly for evaluation purposes. These tubes were subjected to temperature gradients as great as $900 \mathrm{~K}$ across the tube walls. Examination of the insulators after two cycles revealed no significant changes in the structure. These tests suggest that the fiber-coating process improved the structural integrity of the fiber $\mathrm{ZrC}$ under high-temperature test conditions.

\section{G. Production Evaluation and Quality Assurance}

The only figure of merit available for the entire production run of about 500 insulator units was the gross density. Some nondestructive measurements of density variations along the length of the insulator units were also made. From these two sets of information, two facts appear: the density was not uniform within the insulators, and the gross density of the insulator units was dependent on the position it had occupied in the conversion furnace. If the densities are broken down according to furnace positions, there are four groups of about 125 insulators each and, with this size sample, a meaningful standard deviation was calculated (Table V). So far as could be

\section{GROSS DENSITIES OF ZrC INSULATOR PRODUCTION}

\begin{tabular}{|c|c|c|}
\hline Furnace Position & $\begin{array}{l}\text { Gross Density } \\
\% \text { theoretical }\end{array}$ & $\begin{array}{c}\text { Standard Deviation } \\
(\%)\end{array}$ \\
\hline Top & 30.09 & 4.0 \\
\hline Middle upper & 28.48 & 4.0 \\
\hline Middle lower & 28.01 & 3.5 \\
\hline Bottom & 28.04 & 2.0 \\
\hline
\end{tabular}

determined during the insulator evaluation work, these variations in densities, in the individual insulator units and for the insulator production as a whole, were insignificant. The variation seen in measured properties had an undetectable effect on the anticipated (in the reactor) and measured performances.

Techniques for making measurements $[\lambda(\alpha)]$ of the overall average thermal conductivity for an entire insulator unit at room temperature had been developed. The plans called for a $100 \%$ survey of the production insulators to pass on to the reactor operation personnel the best values for $\lambda$. Unfortunately, the $\lambda(\alpha)$ techniques developed had just proved effective for this task when the efforts ceased. The only number reported for an insulator unit was $0.8 \mathrm{~W} \mathrm{~m}^{-1} \mathrm{~K}^{1}$ at $300 \mathrm{~K}$. Little more than this was reported. It did appear, however, that the goal for fabricating a pure $\mathrm{ZrC}$ insulator with a thermal conductivity of less than $1 \mathrm{~W} \mathrm{~m}^{-1} \mathrm{~K}^{-1}$ had been reached.

\section{H. Insulators and Reactor Design}

A very brief outline of the design concepts for which the insulator applications were intended is given in Appendix D. The likelihood that the porous $\mathrm{ZrC}$ insulators could be tailored to fit the designs then on the drawing boards, or being evolved, was very good.

\section{SUMMARY}

The development of a satisfactory substitute for the pyrographite insulators, which had been used in all but the very last of the Rover reactors, was very successful. The overall loss of insulating power due to the change to the substoichiometric porous $\mathrm{ZrC}$ occurred largely at elevated temperatures and was of a manageable magnitude. After considering other properties, including density, strength, thermal-stress resistance, chemical 
inertness, ease of procurement, controllability in fabrication, uniformity of production, and machinability, we favored the $\mathrm{ZrC}$ as the more desirable insulator system. The details in this report demonstrate the flexibility of the $\mathrm{ZrC}$ and related carbides and indicate, in a very positive manner, the desirability for using the carbides, in particular $\mathrm{ZrC}$, where such flexibility in physical properties might be required.

\section{ACKNOWLEDGMENTS}

The coordination of the $\mathrm{ZrC}$ development program was accomplished by an interdivisional group known as the "Insulator Committee." When the Rover program terminated, the Committee consisted of the following personnel.

Paul Wagner, N-7 (Engineering Analysis Group), Chairman

Allen R. Driesner, N-1 (Materials Group)

Edmund K. Storms, CMB-3 (High-Temperature Chemistry Group)

James M. Dickinson, CMB-6 (Fabrication Group)

Thomas J. Merson, N-3 (Engineering Design Group)

Herbert J. Newman, N-3 (Engineering Design Group)

The work reported here could not have been accomplished without the unstinting efforts of each Committee member. Without the support of J. C. Rowley, R. W. Spence, M. G. Bowman, T. C. Wallace, and others from CMB, M, N Divisions, and SD-1 this work would not have been possible.

Special acknowledgment is given to Filmore F. Criss whose imaginative efforts in the development of the fiber $\mathrm{ZrC}$ insulator were invaluable.

\section{REFERENCES}

1. V. S. Neshpor, S. S. Ordan'yan, A. I. Avgustinik, and M. B. Khusidman, "The Effect of the Chemical Composition of Zirconium and Niobium Carbides in the Homogeneity Region on Their Electric and Thermal Properties," National Aeronautics and Space Administration report NASA-TT-F 9350 (April 1965).

2. P. G. Klemens, "Thermal Resistance Due to Point Defects at High Temperatures," Phys. Rev. 119, 507-509 (1960).

3. R. E. Taylor, "Thermal Conductivity of Zirconium Carbide at High Temperatures," J. Amer. Ceram. Soc. 45, 353-354 (1962).

4. L. N. Grossman, "High Temperature Thermophysical Properties of Zirconium Carbide," J. Amer. Ceram. Soc. 48, 236-242 (1965).
5. P. Wagner and H. D. Murphy, "Steady-State Thermal Conductivities for Extruded Porous $\mathrm{ZrC}$ at High Temperatures," Los Alamos Scientific Laboratory (Group $\mathrm{N}-7$ ) internal document (February 18, 1972).

6a. G. V. Samsonov and V. Ya. Naumenko, "Thermal Expansion of the Carbides of the Transition Metals of Group IV-V in Their Homogeneity Range," Teplofizika Vysokikh Temperatur 8, 1093-1095 (1970).

6b. V. G. Bukatov, G. A. Rymashevskii, and V. B. Fedorov, "Thermal Expansion of Nonstoichiometric Zirconium Carbides," Izv. Akad. Navk. SSSR, Neorg. Mater. 7, 519-520 (1971)

7. J. O. Gibson, "Low Thermal Conductivity ZrC-Graphite Fiber Reinforced Composite Studies," McDonnell Douglas Astronautics Laboratory report MDC G 3125 (July 1971).

8. P. Wagner, "ZrC Made from Converted Kreha Foam (Box 100)," Los Alamos Scientific Laboratory (Group N-7) internal document (October 11, 1972).

9a. P. Wagner and L. B. Dauelsberg, "Thermal Conductivity of ZTA Graphite," Carbon 5, 271-279 (1967).

9b. W. L. Sibbitt, "Discussion of Conductivity Values as Obtained from the Comparison Probe Technique and Those Computed from Diffusivity Values," Los Alamos Scientific Laboratory (Group N-7) internal document (April 16, 1971).

9c. W. L. Sibbitt, "Thermal Conductivity of a Test Sample of Iron," ibid. (April 9, 1971).

9d. H. D. Murphy, "Room Temperature Flash Diffusivity of a Fired, Grade A Lava Tube," ibid. (August 10, 1971).

9e. P. Wagner, "Thermal Diffusivity Measurements on Grade A Lava and on Code 9606 Pyroceram," ibid. (August 11, 1971).

10a. P. Wagner, "Thermal Diffusivity and Conductivity of Porous $\mathrm{ZrC}$, Extrusion Lot No. 4706-2," ibid. (August 23, 1971).

10b. W. L. Sibbitt, "Thermal Conductivity of Extruded ZrC Ribbon Insulators (4706 Series)," ibid. (September 7, 1971).

10c. B. H. Morrison, "Room Temperature Thermal Diffusivity and Conductivity of Porous ZrC Extrusion Lot No. 4706-2," ibid. (September 9, 1971).

10d. P. Wagner, W. L. Sibbitt, and B. H. Morrison, "Thermal Conductivity of Porous $\mathrm{ZrC}$ at Room Temperature: Review and Summary," ibid. (January 28, 1972).

11. P. Wagner, "Thermal Conductivity of Porous $\mathrm{ZrC}$ Using an Axial Flow, Steady-State Comparison Apparatus," ibid. (January 25, 1972)

12. P. Wagner, "Colora Measurements on $\mathrm{ZrC}$ Lot 4706," ibid. (November 19, 1971).

13. B. H. Morrison, "Thermal Diffusivity-Conductivity of Porous, Extruded $\mathrm{ZrC}$ (Lots Nos. 4558 and 4575) from $300 \mathrm{~K}$ to $2600 \mathrm{~K}$," ibid. (February 11, 1972).

14. P. Wagner, "Comparison of High Temperature Thermal Diffusivities of Porous ZrC. Results on Lot 4706 Measured at LASL and Sandia Laboratories," ibid. (December 22, 1971). 
15 W L Sibbitt, "Thermal Conductivity of Extruded ZrC Ribbon Insulators (4705 Serıes)," Ibıd (October 10, 1971)

16 W L Sibbitt, "A Model of the Porous Insulators," ibıd (January 24, 1972)

17 P Wagner, "Effect of High Pressure Leaching on Porous $\mathrm{ZrC}$ Lot No 4887," ibid (July 26, 1972)

18 E M Chafik, "Ein Verfahren Zur Messung der Temperaturleitzahl fester Stoffe be1 hohen Temperaturen unter Anwendung eines modulierten Lichtstrahls," PhD thesis, University of Stuttgart (W Germany), (April 1970)

19a P Wagner, "Thermal Conductivity of Porous ZrC Effect of Exposure to $\mathrm{N}_{2}$ at High Temperatures" (in two parts), Los Alamos Scientific Laboratory (Group N-7) internal document (January 11 and 25,1972 )

19b P Wagner and H D Murphy, "Stabilization of Porous, Extruded ZrC for High Temperature Experiments," ibid (April 4, 1972)

20 P Wagner, "Thermal Conductivities of Lot 4887, Porous $\mathrm{ZrC}$ Insulators for NF 2," ibıd (May 4, 1972)

21 A R Driesner and R G Merryman, "Mechanıcal Properties of $60 \%$ Dense $\mathrm{ZrC}$," Los Alamos Scientific Laboratory (Group N 1) internal document (November 10, 1972)

22 B H Morrison, "Room Temperature Thermal Diffusivity-Conductivity of Low Density ZrC for NF-2," Los Alamos Scientific Laboratory (Group N-7) internal document (November 15, 1972)
23 B H Morrison, "Thermal Conductivity of Low Density, Fiber-Coated ZrC for NF-2 Insulators," ibid (December 18 , 1972)

24 B H Morrison and P Wagner, "Thermal Conductivity of Heat Treated NF-2 Insulators," ibıd (December 26, 1972)

25 P Wagner, "Thermal Conductivity (300 K) of Very Porous ZrC," ibıd (September 1, 1972)

26 W L Sibbitt, "Predicted Values of Thermal Conductivity of Porous Fibrous $\mathrm{ZrC}$ (A Note Concerning Analytical Methods)," ibid (July 24, 1972)

27 P Wagner, "Steady-State Thermal Conductivity of Porous ZrC Tubes at Elevated Temperatures," lbıd (February 21, 1973)

28 P Wagner, "Effect of Temperature on the Strength of Porous $\mathrm{ZrC}$," lbid (January 18, 1973)

29 W R Prince, "Photograph Showing Performance of NF 2 Porous ZrC Insulator Surrounding a Heated Fuel Element," lbıd (January 5, 1973)

$30 \mathrm{~W} R$ Prince, "Structural and Thermal Performance of Fiber Coated, Porous, Fibrous ZrC Cylindrical Insulators," lbid (February 20, 1973) 


\section{APPENDIX A \\ CHARACTERIZATION AND MEASUREMENTS ON $\mathrm{ZrC}_{x}$}

\section{EXPERIMENTAL}

\section{A. Sample Preparation}

The samples were prepared as 12.7 -mm-diam by 2.5 -mm-thick disks by hot pressing the powdered carbides at $3000 \mathrm{~K}$ under a pressure of $100 \mathrm{MN} / \mathrm{cm}^{2}$ using a graphite die. The billet was ground to the desired diameter and sliced into disks with a wire saw. These disks were then ground to thickness and repurified by heating in vacuum. Measurements were made on three disks from each billet.

\section{B. Sample Characterization}

All samples were analyzed for total carbon by combustion in oxygen and for oxygen by platinum fusion. Except when the impurity content was high, the remainder of the material was assumed to be the major metal. All samples were single phase and, except for the sample containing sulfur, had sharp powder patterns. Photomicrographs showed a collection of crystals of various sizes and relatively large isolated voids.

\section{Thermal-Conductivity Measurements}

All measurements of thermal conductivity $(\lambda)$ were made at $300 \mathrm{~K}$ using the flash-diffusivity technique. The description of the apparatus used and its characteristics have appeared in the literature. ${ }^{1}$ This equipment is capable of generating data with a standard deviation of about $3 \%$ accuracy when used with well-known, well-characterized materials. However, because of the uncertainty in the specific heat and the necessity for correcting all measurements to theoretical density, it is estimated that the accuracy of the reported values of the thermal conductivity will lie within a $5 \%$ standard deviation band.

Thermal conductivities were calculated from

$$
\lambda=\alpha \rho \mathrm{C}_{\mathbf{P}}
$$

where $\alpha$ is the thermal diffusivity, $\rho$ is the density, and $C_{P}$ is the specific heat. The data were reduced to that for a theoretically dense material by

$$
\lambda=\lambda^{\prime} \frac{2+P}{2(1-P)}
$$

Here $\mathrm{P}$ is the fractional porosity $\left(=1-\rho^{\prime} / \rho\right)$ and the primed quantities are the measured values, whereas $\lambda$ and $\rho$ refer to values for the theoretically dense $\mathrm{ZrC}$. In deriving Eq. (A-2), Maxwell ${ }^{2}$ assumed that the pores were isolated and isotropic. For the densities of the specimens used in this work, the assumption of pore isolation is reasonable; however, the assumption of pore isotropicity is more difficult to demonstrate and, as such, adds to the uncertainty in the derived results.

\section{Density Measurements}

The densities used for the calculation of $\lambda$ from $\alpha$ [Eq. (A-1)] were obtained by measuring and weighing the samples used for the $\alpha$ measurements. Because a knowledge of the theoretical density $(\rho)$ is required for calculating the porosity and because the theoretical density depends on the carbon-to-metal ratio, this also had to be measured. The theoretical densities were calculated from measured lattice parameters for different values of $C / M$ and the dependence of the densities on the $C / M$ ratio was established (Fig. A-1).

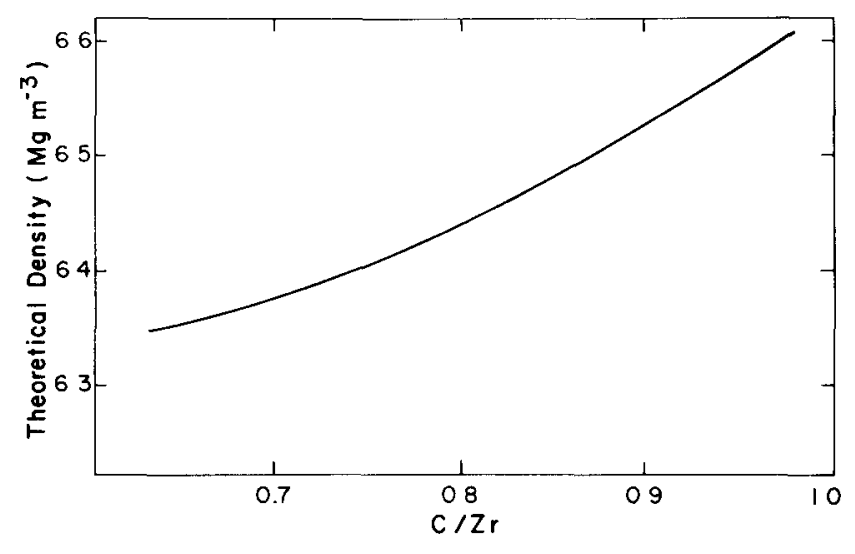

Fig. A-1. Densities of substoichiometric $\mathrm{ZrC} \boldsymbol{x}_{\boldsymbol{x}}$. 


\section{E. Specific Heat for $\mathrm{ZrC}_{x}$}

The specific heat for $\mathrm{NbC}_{\mathrm{x}}$ is known over the $\mathrm{C} / \mathrm{Nb}$ range considered here The specific heat for $\mathrm{ZrC}_{x}$ is known only for $\mathrm{ZrC}_{098}$ (Ref 3) The Cp's used in Eq (A-1) for $\mathrm{ZrC}$ were obtained by estımating these values by analogy with the $\mathrm{NbC}_{x}$ system This is shown in $\mathrm{F}_{1} \mathrm{~A}$ A-2 where the $\mathrm{NbC}$ and $\mathrm{ZrC}$ Cp's are displayed as $\mathrm{f}(\mathrm{C} / \mathrm{M})$

\section{F. Electrical Resistivity Measurements}

Measurements of electrical resistivity $\left(\rho_{R}\right)$ were made at $300 \mathrm{~K}$ using a Kelvin double bridge The $\rho_{\mathrm{R}}^{\prime}$ measure ments were made on specimens cut from the disk shaped $\lambda$ samples, thus the $\lambda^{\prime}$ and $\rho_{R}^{\prime}$ values were obtained in orthogonal directions In principle, the direction of measurement should not influence the results because the samples used were polycrystallıne and $\mathrm{ZrC}$ has a rock-salt structure The electrical conductivities $\left(=1 / \rho_{\mathrm{R}}\right)$ were reduced to the value for the theoretically dense material by Eq (A-2)

\section{RESULTS}

\section{A. $\mathrm{ZrC}$}

The data obtaned during the experımental investiga tions on $\mathrm{ZrC}$ and $\mathrm{NbC}$ are compled in Tables $\mathrm{A} \mathrm{I}$ and A-II As shown in the tables, not all the data were gath ered on all the samples because the samples were prepared for very specific purposes For example, as seen in Table A-I, some of the samples were purposely prepared with large amounts of impurities so that the relative effects of vacancies and impurities could be compared The rela tively large concentrations of oxygen and sulfur did not affect the electrical and thermal properties nearly so much as did a change in the vacancy concentration ( $1 \mathrm{e}$, change in $\mathrm{C} / \mathrm{Zr}$ ) The dependence of the thermal conductivity upon the $\mathrm{C} / \mathrm{M}$ ratio in the single-phase $\mathrm{ZrC}$ and $\mathrm{NbC}$ is shown in Fig A-3 A more detalled curve of $\lambda$ vs $\mathrm{C} / \mathrm{Zr}$ is presented in Figs $A-4$ and A-5 where the data from this investigation are collected and compared with data taken from the literature ${ }^{4-6}$ Figure A-6 displays the behavior of the electrical resistivity with $\mathrm{C} / \mathrm{Zr}$ plotted along with $\rho_{\mathrm{R}}$ data and an interpretation of the electrical data in terms of the thermal conductivity The electronic component of the thermal conductivity was obtained from the Weidemann-Franz relationship

$$
\lambda_{\mathrm{e} \ell}=\frac{\mathrm{LT}}{\rho_{\mathrm{R}}},
$$

where the value of $\mathrm{L}$ used was that for fully degenerate electronic energy states, $\mathrm{L}=245 \times 10^{-8}(\nu / \mathrm{K})^{2}$ It appears that on this basis, the electronic component of the thermal conductivity is about $37 \%$ from $\mathrm{ZrC}_{0}$ 65 to $\mathrm{ZrC}_{085}$ From $\mathrm{ZrC}_{08}$ to $\mathrm{ZrC}, \lambda_{\mathrm{el}}$ may be smaller, however, because of the steepness of the $\lambda$ and $\rho_{R}$ curves with $C / Z r$, measurements of greater accuracy in the dependent and independent variables would have to be made to establish this firmly With this in mind, it is proposed that for the monophase $\mathrm{ZrC}$ system at $300 \mathrm{~K}$,

$$
\lambda_{\mathrm{el}} / \lambda=037 \text { and } \lambda_{\mathrm{ph}} / \lambda=063
$$

where $\lambda_{p h}$ is the phonon contribution to the thermal conductivity

\section{B. $\mathrm{NbC}$}

Four substoichiometric samples of $\mathrm{NbC}_{\mathrm{x}}$ were used for $\lambda^{\prime}$ measurements The data obtained on these specimens are shown in Table A-II The behavior of the thermal conductivity for $\mathrm{NbC}_{x}$ is demonstrated in $\mathrm{F}$ ig $\mathrm{A}-3$ where a striking similarity between the behavior of the $\lambda$ 's for $\mathrm{NbC}$ and $\mathrm{ZrC}$ can be seen Further, the electronic component of the thermal conductivity for $\mathrm{NbC}$ is of the same magnitude $(\sim 34 \%)$ as that calculated for $\mathrm{ZrC}$

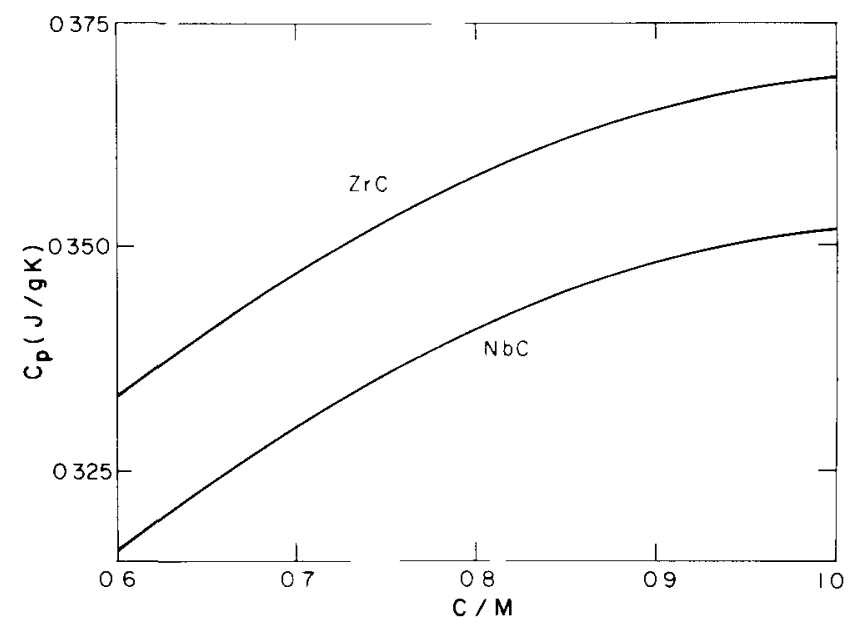

Fig $A 2$

Heat capacties of substoichiometric $N b C_{x}$ and $\mathrm{ZrC}_{\boldsymbol{x}}$ 
TABLE A-I

$\operatorname{ZrC}_{\mathbf{x}}$ DATA

\begin{tabular}{|c|c|c|c|c|c|c|c|c|c|c|}
\hline Analized & $\begin{array}{c}\text { Oxygen } \\
\text { (ppm) }\end{array}$ & $\begin{array}{c}\text { Lattice } \\
\text { Parameter } \\
(\mathbf{n m}) \\
\end{array}$ & $\begin{array}{c}\text { Measured } \\
\text { Density } \\
\mathbf{M g ~ m}^{-3} \text { ) }\end{array}$ & $\begin{array}{l}\text { Theoretical } \\
\text { Density } \\
\left(\mathrm{Mg} \mathrm{m}^{-3}\right)\end{array}$ & Porosity & $\begin{array}{c}\text { Heat } \\
\text { Capacity } \\
\left(\mathrm{J} \mathrm{kg}^{-1} \mathrm{~K}^{-1}\right)\end{array}$ & $\begin{array}{c}\text { Thermal } \\
\text { Conduc- } \\
\text { tivity } \\
\left(\mathbf{W} \mathbf{m}^{-1} \mathbf{K}^{-1}\right)\end{array}$ & $\begin{array}{l}\text { Conductivity, } \\
\text { Corrected for } \\
\text { Porosity } \\
\left(\mathrm{W} \mathrm{m}^{-1} \mathrm{~K}^{-1}\right)\end{array}$ & $\begin{array}{c}\text { Measured } \\
\text { Electrical } \\
\text { Resistivity } \\
(\Omega \mathrm{m}) \\
\end{array}$ & $\begin{array}{l}\text { Resistivity, } \\
\text { Corrected for } \\
\text { Porosity } \\
(\Omega \mathrm{m}) \\
\end{array}$ \\
\hline $1.000^{\mathrm{a}}$ & 525 & 0.46988 & 4.93 & 6.60 & 0.25 & 368 & 24.5 & 36.8 & & \\
\hline 0.982 & 400 & 0.46983 & 6.27 & 6.60 & 0.05 & 368 & 44.5 & 48.0 & & \\
\hline 0.980 & & & 5.96 & 6.60 & 0.08 & 368 & 41.5 & 44.7 & & \\
\hline 0.975 & 260 & 0.46992 & 5.38 & 6.59 & 0.18 & 368 & 28.6 & 37.3 & 205 & 167 \\
\hline 0.965 & 300 & 0.46992 & 6.00 & 6.60 & 0.09 & 368 & 32.2 & 36.9 & & \\
\hline 0.946 & 800 & 0.46997 & 5.38 & 6.56 & 0.18 & 367 & 13.1 & 17.4 & & \\
\hline 0.915 & 870 & 0.46988 & 5.60 & 6.54 & 0.14 & 366 & 12.9 & 16.1 & & \\
\hline 0.897 & 148 & 0.47014 & 5.75 & 6.32 & 0.12 & 363 & 8.9 & 11.1 & & \\
\hline 0.870 & 640 & 0.47015 & 5.33 & 6.50 & 0.18 & 362 & 7.5 & 9.9 & & \\
\hline 0.839 & 380 & 0.47016 & 5.54 & 6.47 & 0.14 & 360 & 7.8 & 9.7 & & \\
\hline 0.790 & 940 & 0.47013 & 5.55 & 6.44 & 0.14 & 355 & 6.2 & 7.7 & 296 & 238 \\
\hline 0.750 & $\begin{array}{c}8100 \\
(1.4675)\end{array}$ & 0.47149 & 5.90 & 6.41 & 0.08 & 351 & 7.3 & 8.3 & & \\
\hline 0.743 & 300 & 0.47001 & 6.00 & 6.41 & 0.06 & 351 & 7.8 & 8.6 & 259 & 237 \\
\hline 0.736 & 200 & 0.46990 & 5.12 & 6.39 & 0.19 & 349 & 5.9 & 8.0 & & \\
\hline 0.682 & 1250 & 0.46972 & 6.22 & 6.37 & 0.02 & 343 & 7.5 & 7.7 & 232 & 222 \\
\hline 0.648 & 420 & 0.46970 & 6.17 & 6.35 & 0.03 & 339 & 8.3 & 8.7 & 233 & 222 \\
\hline 0.64 & 1300 & 0.46939 & 6.20 & 6.35 & 0.02 & 339 & 6.3 & 6.5 & & \\
\hline 0.64 & 1250 & 0.46955 & 6.17 & 6.35 & 0.03 & 339 & 6.5 & 6.8 & & \\
\hline
\end{tabular}

${ }^{a}$ Sample contained $0.5 \%$ free carbon.

TABLE A-II

$\mathrm{NbC}_{x}$ DATA

\begin{tabular}{|c|c|c|c|c|c|c|c|c|c|c|}
\hline $\begin{array}{c}\mathbf{c} / \mathbf{Z r} \\
\text { Analized } \\
\end{array}$ & $\begin{array}{c}\begin{array}{c}\text { Oxygen } \\
\text { (ppm) }\end{array} \\
\end{array}$ & $\begin{array}{c}\text { Lattice } \\
\text { Parameter } \\
(\mathbf{n m}) \\
\end{array}$ & $\begin{array}{c}\text { Measured } \\
\text { Density } \\
\left(\mathbf{M g ~ m}^{-3}\right)\end{array}$ & $\begin{array}{c}\text { Theoretical } \\
\text { Density } \\
\left(\mathrm{Mg} \mathrm{m}^{-3}\right) \\
\end{array}$ & Porosity & 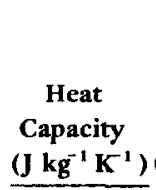 & $\begin{array}{c}\text { Measured } \\
\text { Thermal } \\
\text { Conduc- } \\
\text { tivity } \\
\left(\mathbf{W ~ m}^{-1} \mathbf{K}^{-1}\right) \\
\end{array}$ & $\begin{array}{c}\text { Thermal } \\
\text { Conductivity, } \\
\text { Corrected for } \\
\text { Porosity } \\
\left(\mathbf{W} \mathbf{~ m}^{-1} \mathrm{~K}^{-1}\right) \\
\end{array}$ & $\begin{array}{c}\text { Measured } \\
\text { Electrical } \\
\text { Resistivity } \\
(\Omega \mathrm{m}) \\
\end{array}$ & $\begin{array}{l}\text { Electrical } \\
\text { Resistivity, } \\
\text { Corrected for } \\
\text { Porosity } \\
(\Omega \mathrm{m}) \\
\end{array}$ \\
\hline 0.975 & & 0.44700 & 6.50 & 7.78 & 0.16 & 352 & 18.8 & 24.2 & 114 & 87 \\
\hline 0.925 & 1600 & 0.44671 & 6.49 & 7.75 & 0.16 & 351 & 11.0 & 14.1 & & \\
\hline 0.815 & 520 & 0.44519 & 6.64 & 7.72 & 0.14 & 341 & 7.7 & 9.6 & & \\
\hline 0.702 & 840 & 0.44335 & 6.74 & 7.72 & 0.13 & 329 & 5.8 & 7.0 & & \\
\hline
\end{tabular}




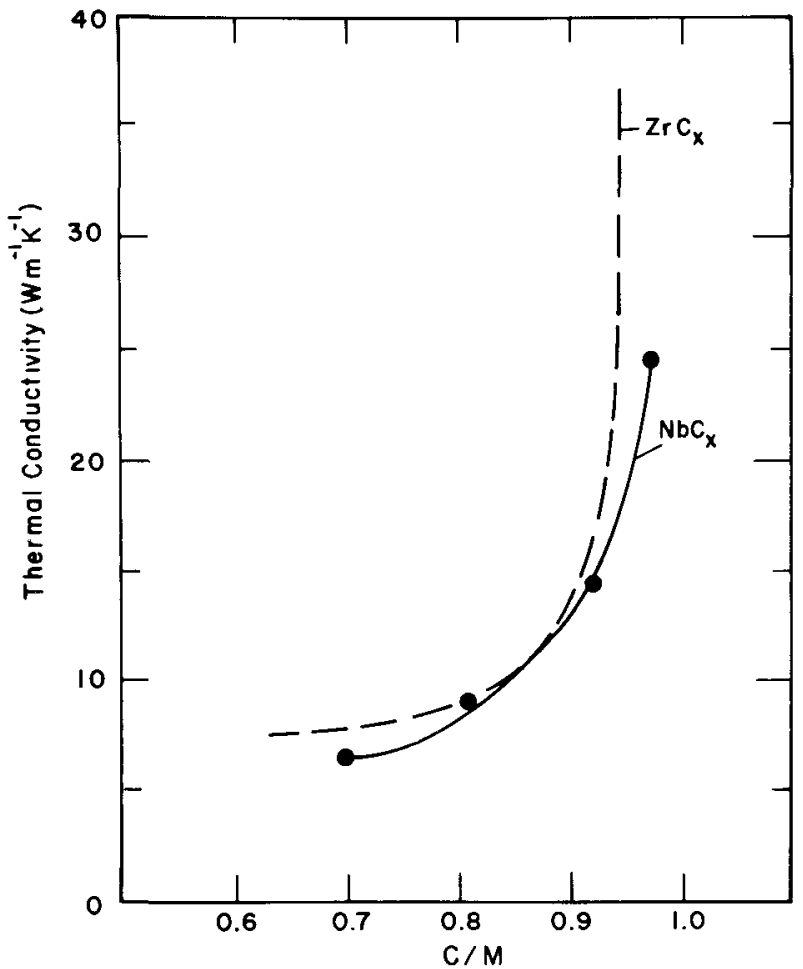

Fig. A-3.

Thermal conductivities of $\mathrm{NbC}_{x}(300 \mathrm{~K})$ and $\mathrm{ZrC}{ }_{x}$ (300 K).

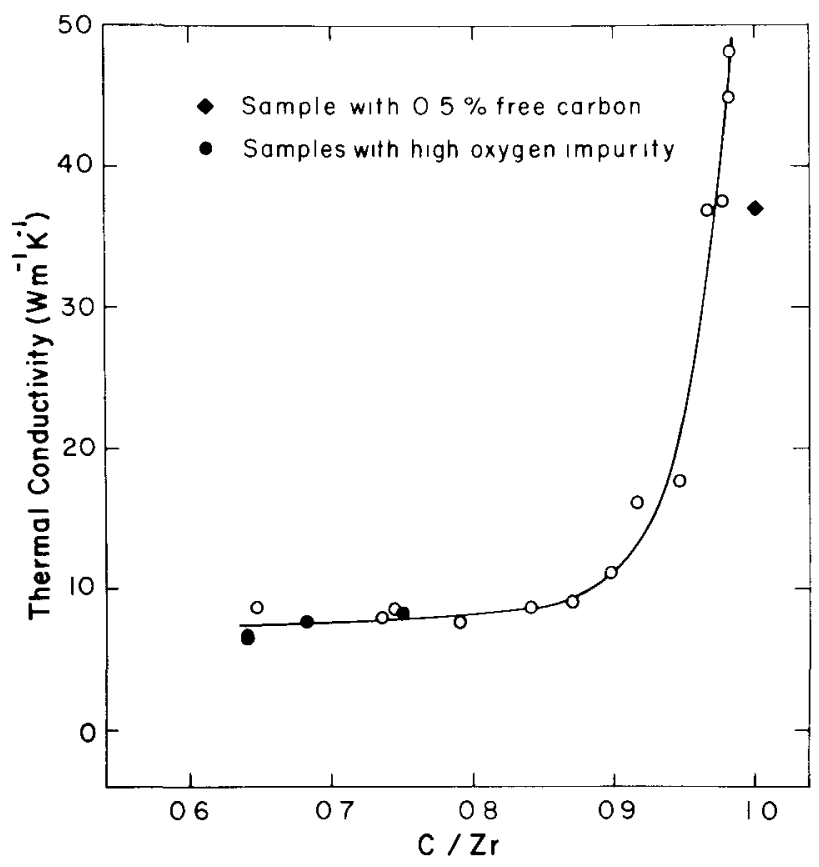

Fig. A-4.

LASL thermal-conductivity data at $300 \mathrm{~K}$ for $\mathrm{ZrC} C_{x}$.

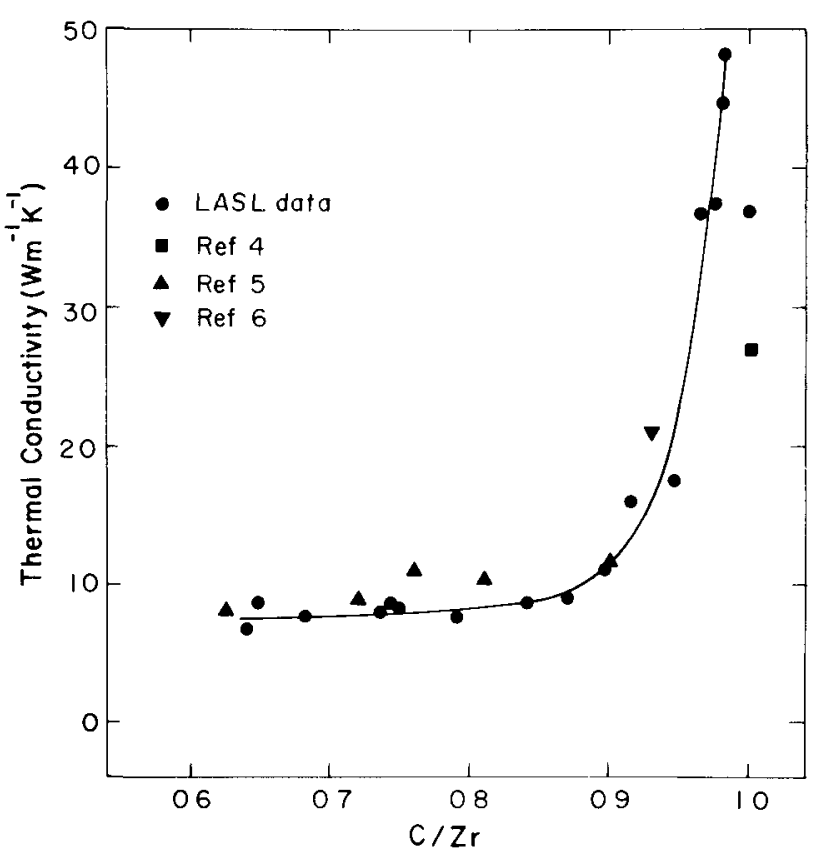

Fig. A-5.

Comparison of LASL thermal-conductivity measurements for $\mathrm{ZrC}_{x}$ at $300 \mathrm{~K}$ with literature data.

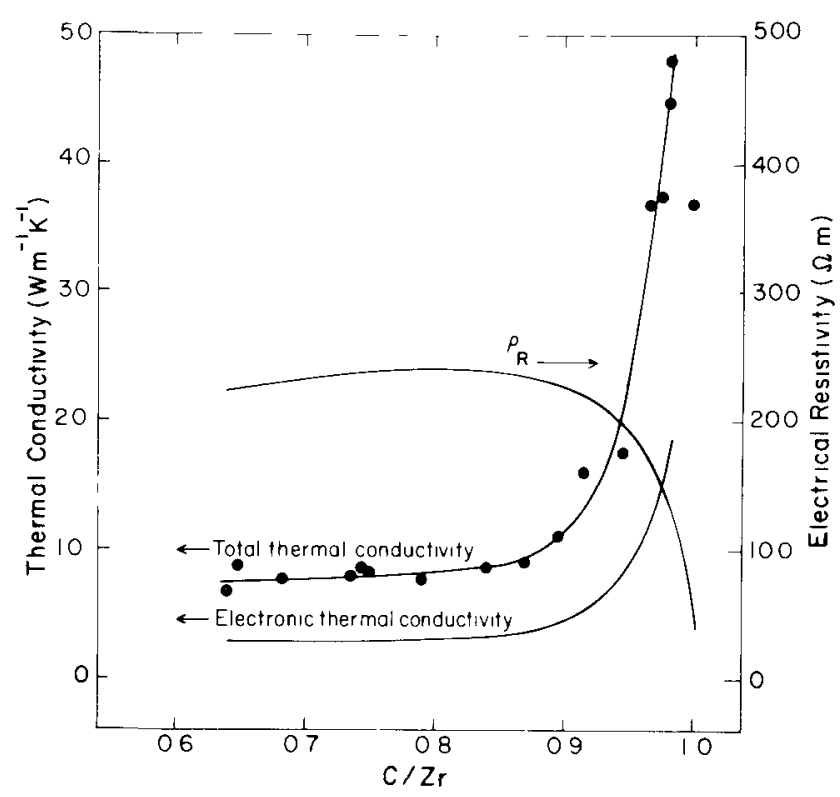

Fig. $A-6$.

Comparison of total thermal conductivity at $300 \mathrm{~K}$ for $\mathrm{ZrC}_{x}$ with electronic component. 


\section{REFERENCES}

1 P Wagner and L B Dauelsberg, "Thermal Conductivity of ZTA Graphite," Carbon 5, 271 (1967)

2 J C Maxwell, Treatise on Electricity and Magnetism, (Oxford University Press, London, 1904), Vol I, 3rd Ed

3 E F Westrum, Jr, and G Feıck, "Zirconıum Carbıde Heat Capacity and Thermodynamic Properties from 5 to $350^{\circ} \mathrm{K}$," J Chem Eng Data 8, 176 (1963)
4 R E Taylor, "Thermal Conductivity of Zirconium Carbide at High Temperatures," J Amer Cer Soc 45, 353 (1962)

5 V S Neshpor, S S Ordan'yan, A I Avgustınık, and M B Khusidman, "The Effect of the Chemical Composition of Zirconium and Niobium Carbides in the Homogeneity Region on Their Electric and Thermal Properties," Zhurnal Prikladnoy Khımı 37, 2375 (1964) (NASA TT F-9350)

6 B H Morrison and L L Sturgess, "The Thermal Diffusivity and Conductivity of Zirconium Carbide from 100 to $2500 \mathrm{~K}$," Rev Int Hautes Temper et Refract 7, 351 (1970) 


\title{
APPENDIX B
}

\section{FINAL BRIEF SUMMARY OF ZrC INSULATORS FOR THE ROVER PROGRAM}

\author{
by
}

J. M. Dickinson, D. H. Schell, and K. V. Davidson

This brief summary of the work on ZrC-related insula tor materials in LASL Group CMB-6 is in two sections The first section discusses material made by hot pressing and the second section discusses extruded insulators

\section{A. Hot-Pressed ZrC Insulators}

The hot pressing approach was started in 1969 and was continued intermittently. until the recent demise of the Rover program The insulators produced for the program fall generally into two classes-the carbide-oxide mixtures and the porous carbides

Mixtures of $\mathrm{ZrC}-\mathrm{ZrO}_{2}$ and of $\mathrm{HfC}-\mathrm{HfO}_{2}$ were made at $85 \%$ of theoretical density, and thermal conductivities below $2 \mathrm{~W} / \mathrm{m}-\mathrm{K}$ were achieved The $\mathrm{ZrC}-\mathrm{ZrO}_{2}$ mixture was stable for $8 \mathrm{~h}$ at $2575 \mathrm{~K}$ and the $\mathrm{HfC}-\mathrm{HfO}_{2}$ was stable for several hours at $2825 \mathrm{~K}$ and for $1 \mathrm{~h}$ at $3075 \mathrm{~K}$ Detals of the procedures and results are reported by Riley and Taub ${ }^{1}$

Porous hot-pressed $\mathrm{ZrC}$ insulators were also investigated during this period with interesting results By limiting the density to about $40 \%$ theoretical, hot pressings having thermal conductivities of less than $2 \mathrm{~W} / \mathrm{m}-\mathrm{K}$ can be made, some have reached less than $1 \mathrm{~W} / \mathrm{m}-\mathrm{K}$ Control of particle size is particularly important in the porous carbides to obtain low conductivities and some reasonable strength level These materials appear to be stable for at least $10 \mathrm{~h}$ at $2575 \mathrm{~K}$

Very recently, some studies of $\mathrm{ZrC}+\mathrm{ZrO}_{2}+\mathrm{C}$ to give porous $\mathrm{ZrC}$ have shown that thermal conductivities of less than $1 \mathrm{~W} / \mathrm{m}-\mathrm{K}$ can be obtained and that thermal conduc tivities below $2 \mathrm{~W} / \mathrm{m}-\mathrm{K}$ are not uncommon at densities of $50 \%$ These are moderately strong materials and were being considered for hot-end washer applications The procedures and results of the hot-pressed porous carbides will be described in a later report

\section{B. Extruded ZrC Insulators}

Porous $\mathrm{ZrC}$ insulators were made for the Rover program by the extrusion process in an attempt to provide a method for mass producing insulators that would be easier and more reproducible than the hot-pressing method

We feel that a good insulator should have a microstructure consisting of large, dense $\mathrm{ZrC}$ particles with large, clean voids between the particles Such a structure has been shown to have low conductivity, reasonable strength, and to be thermally stable The insulators should have thermal conductivities less than $2 \mathrm{~W} / \mathrm{mK}$

Insulators were extruded either as tubes, up to $13-\mathrm{cm}$ od or with a rectangular cross section, usually $1 \mathrm{~cm}$ by $2 \mathrm{~cm}$

The following three types of extrusions were made in attempts to obtain the desired microstructure

$1 \mathrm{ZrC}$ at about $60 \%$ of theoretical density contained little or no free carbon when heat treated These extrusion mixes contained $\mathrm{ZrC}, \mathrm{ZrO}_{2}$, carbon, pore former, and binder

2 Composite extrusions containing 40 to $50 \% \mathrm{ZrC}$ and from 9 to $24 \%$ free carbon when heat treated The extrusion mixes contained $\mathrm{ZrC}$, carbon, pore former, and binder

3 Extrusions containing $\mathrm{ZrC}$ at 25 to $45 \%$ of theoretical density and very little free carbon These mixes contained $\mathrm{ZrC}, \mathrm{ZrO}_{2}$ carbon, pore former, and binder, or $\mathrm{Zrr}_{2}$ carbon, pore former, and binder

A large variety of materials and particle sizes of materials were used to make the insulators Practically all mixes contained coarse, dense $\mathrm{ZrC}$ particles These 
partıcles were usually in the -65 to +150 mesh range, but in some instances were in the -150 to +270 mesh range Particles having such a small range of sizes tend to pack poorly thus leaving large voids between the particles

The $\mathrm{ZrO}_{2}$ powder avalable for most of the develop ment period consisted of fine particles, 1 - to $2-\mu \mathrm{m}$, or coarser particles that consisted of porous agglomerates of the fine particles When these particles converted to the carbide they tended to retain their size, shape, and posi tion in the extrusion The fine $\mathrm{ZrO}_{2}$ powder ended in voids between the large $\mathrm{ZrC}$ particles The net result was a porous $\mathrm{ZrC}$ network in these voids that increased the conductivity of the insulator This was not always the case because some good insulators were made that contained fine $\mathrm{ZrO}_{2}$ in the extrusion mix

Coarse, dense $\mathrm{ZrO}_{2}$ particles became avallable late in the development program These particles, when converting to the carbide, migrated into the surrounding carbon forming a shell of $\mathrm{ZrC}$ with a void where the $\mathrm{ZrO}_{2}$ particle had originally been This was fortunate in that it provided a method of making stoichiometric extrusions containing large, clean voids

Free carbon was added to the extrusion mix to and in the extrusion operation and, in the case of the composite extrusions, to produce discrete voids after the carbon was leached The carbon added as an extrusion and was always -200 mesh and for many extrusions was a graphite flour having an average particle size of $06 \mu \mathrm{m}$ Carbon added to the composite extrusions to create voids was usually smaller than 200 mesh and was either equiaxed graphite flour or spherical particles

All extrusions contained some pore-forming material that would decompose or vaporize during the insulator heat treatment Powdered Teflon was the preferred pore former and could be added to the extrusion mix in almost any desired quantity Pores were desirable in the heattreated insulators to reduce the overall density, to reduce the amount of carbon in the composite extrusions, and to provide access for the hydrogen leaching gas

All insulators were extruded using Varcum, a partially polymerized furfuryl alcohol, as the extrusion binder Durıng heat treatment, the Varcum decomposed leaving a carbon residue

As mentioned previously, three types of extrusions were made, two of which contained $\mathrm{ZrO}_{2}$ in the extrusion mix The main purpose of the $\mathrm{ZrO}_{2}$ addition was to use up free carbon during the heat-treating operation when the oxide converted to $\mathrm{ZrC}$ This allowed heat-treated extrusions to be made that contained little or no free carbon

The final insulator could not contain any free carbon Even a small amount of carbon increased the conductivity dramatically Therefore, all insulators were leached with hydrogen to remove all traces of free carbon Normal leaching conditions in LASL Group CMB-6 were $8 \mathrm{~h}$ at $2575 \mathrm{~K}$ in flowing hydrogen It proved to be quite diff - $^{-}$ cult and time consuming to leach all of the free carbon from the composite extrusions, although once the carbon was removed, these extrusions made good insulators Later extrusions concentrated on essentially stoichiometric extrusions made with mixes containing appreciable amounts of $\mathrm{ZrO}_{2}$

The following heat-treating procedure was used on the insulator extrusions

1 Cure (polymerization of the thermosetting Varcum binder) to $520 \mathrm{~K}$ for $93 \mathrm{~h}$

2 Vacuum bake to $1110 \mathrm{~K}$ for $48 \mathrm{~h}$

3 Heat treat to $2775 \mathrm{~K}$ and hold at this temperature for $2 \mathrm{~h}$

Leached insulators were evaluated in relation to density, electrical resistivity, thermal conductivity (diffusivity), and metallography Some thermal stability and strength measurements were made Unfortunately, this work had barely started when the program was terminated

A large number (well over a hundred) of insulator extrusion batches were made whose products had conductivities in the 4- to $7-\mathrm{W} / \mathrm{mK}$ range However, several extrusions using a variety of mix formulations had conductivities less than $2 \mathrm{~W} / \mathrm{mK}$ In general, the goals of the program were met Data on selected extrusion batches are tabulated in Table B-I

\section{REFERENCE}

1 R E Riley and J M Taub, " $\mathrm{MC} \cdot \mathrm{M} \mathrm{O}_{2}$ Composites A New Thermal Insulator," Los Alamos Scientific Laboratory report LA-5136 (February 1973) 
TABLE B-I

EXTRUDED ZrC INSULATORS

\begin{tabular}{|c|c|c|c|c|c|c|c|c|c|}
\hline \multirow{2}{*}{$\begin{array}{l}\text { Batch } \\
\text { No. }\end{array}$} & \multirow{2}{*}{$\begin{array}{l}\text { ZrC } \\
\text { Size }\end{array}$} & \multirow{2}{*}{$\begin{array}{c}\mathrm{ZrO}_{2} \\
\text { Size }\end{array}$} & \multirow{2}{*}{$\begin{array}{c}\mathrm{Zr}-\mathrm{C}-\mathrm{ZrO}_{2} \\
\text { Ratio }\end{array}$} & \multirow{2}{*}{$\begin{array}{c}\text { Pore Former } \\
\left(\mathrm{g} / \mathrm{cm}^{3}\right)\end{array}$} & \multirow{2}{*}{$\begin{array}{c}\text { Free Carbon } \\
\text { and Size } \\
\end{array}$} & \multirow{2}{*}{$\begin{array}{c}\% \text { Free } \\
\text { Carbon as } \\
\text { Heat Treated } \\
\end{array}$} & \multicolumn{2}{|c|}{$\begin{array}{l}\text { Leached } \\
\text { Density }\end{array}$} & \multirow{2}{*}{$\begin{array}{c}\text { Conductivity } \\
(\mathrm{W} / \mathrm{mK})\end{array}$} \\
\hline & & & & & & & $\mathrm{g} / \mathrm{cm}^{3}$ & $\%$ & \\
\hline 4575 & $-65+150$ & $5.4 \mu \mathrm{m}$ & $75-25$ & 0.10 Teflon & $-325+$ Thermax & None & 3.9 & 60 & 1.1 \\
\hline 5042 & $-65+150$ & None & & 0.10 Teflon & $8 \mu \mathrm{m}$ spherical & 17 & 3.2 & 49 & 1.7 \\
\hline 5045 & $-150+270$ & None & & 0.10 Teflon & $-200+325$ & 16 & 3.4 & 51 & 1.5 \\
\hline 5075 & $-65+150$ & None & & 0.10 Reflon & $-200+325$ & 24 & 2.6 & 40 & 1.2 \\
\hline 5201 & None & $-150+270$ & & 0.10 Teflon & $-200+325$ & 24 & 1.7 & 25 & 0.4 \\
\hline 5266 & $-150+270$ & -200 & $75-25$ & 0.70 Teflon & $0.6 \mu \mathrm{m}$ & 1 & 2.7 & 40 & 0.8 \\
\hline 5268 & $-150+270$ & -200 & $50-50$ & 0.70 Teflon & $0.6 \mu \mathrm{m}$ & 2 & 2.6 & 39 & 0.8 \\
\hline 5270 & $-150+270$ & -200 & $50-50$ & 0.40 Teflon & $0.6 \mu \mathrm{m}$ & 2 & 2.9 & 43 & 1.2 \\
\hline
\end{tabular}




\section{APPENDIX C}

\section{BRIEF SUMMARY OF NF-2 INSULATOR WORK}

by

\section{A. R. Driesner}

The NF-2 insulators were manufactured by a process developed in 1971 and early 1972 by Filmore F. Criss of LASL. This process consists of converting carbon-felt cylinders, obtained from the Y-12 Plant at Oak Ridge, to $\mathrm{ZrC}$ and then coating each fiber with $\mathrm{ZrC}$. The conversion and coating are done by a vapor deposition process utilizing zirconium tetrachloride.

The carbon felt manufactured by $\mathrm{Y}-12$ had a density of about $0.18 \mathrm{~g} / \mathrm{cm}^{3}$. The manufacture of this felt material is described in a Union Carbide Corporation document Y-1803 "Carbon-Fiber Thermal Insulation" by Z. L. Ardary and C. D. Reynolds.

Previous development work at LASL indicated that this carbon felt, when completely converted to zirconium carbide, would have a density of $\sim 1.56 \mathrm{~g} / \mathrm{cm}^{3}$ (24\% of theoretical). Although the thermal conductivity in air of this material was quite low $(0.4 \mathrm{~W} / \mathrm{m} \cdot \mathrm{K})$, there was concern that the converted-only material would not possess satisfactory strength to withstand reactor environment and the reactor compressive loads. Consequently, again based on previous development work, a $\mathrm{ZrC}$ coating was applied to each fiber to enhance its strength. Because the maximum temperature to which the material was exposed during the conversion-coating process was $\sim 1800 \mathrm{~K}$ and the reactor operating maximum temperature was to be $\sim 2750 \mathrm{~K}$, it seemed advisable to heat treat the insulators. This heat treatment was conducted in an argon atmosphere at $\sim 2770 \mathrm{~K}$ for $2 \mathrm{~h}$.

The carbon-felt pieces received from Y-12 were $\sim 1-3 / 8$-in. o.d. by 0.6 -in. i.d. by 8 -in. long. These pieces were premachined to 1.175 -in. o.d. by 0.750 -in. hex across-flats inside dimension by $\sim 7-5 / 8$ in. long. After machining, all insulator pieces were identified sequentially and were packed 12 each in a styrofoam box. Each box was numbered in the 1000 series.

Each piece was inspected by a DXT device to ascertain density variation along the length of the felt piece and also to check variations between pieces. Figure C-1 shows two typical traces of insulator densities. The calibration units shown on the upper right-hand corner of each trace is the equivalent thickness of carbon felt. In fact, Piece No. 1 was cut to various thicknesses and used as a standard.

Development work on previous carbon-felt pieces indicated that satisfactory thermal conductivity and strength values were obtained if the final density of the $\mathrm{ZrC}$ insulator was about $28 \%$ of theoretical $\left(1.9 \mathrm{~g} / \mathrm{cm}^{3}\right)$.

Approximately $50 \mathrm{~h}$ are required to convert the carbon felt to zirconium carbide. Another $10 \mathrm{~h}$ are required for the fiber-coating process.

Following the conversion-coating run, each insulator was heat treated at $\sim 2770 \mathrm{~K}$ for $2 \mathrm{~h}$ in an argon

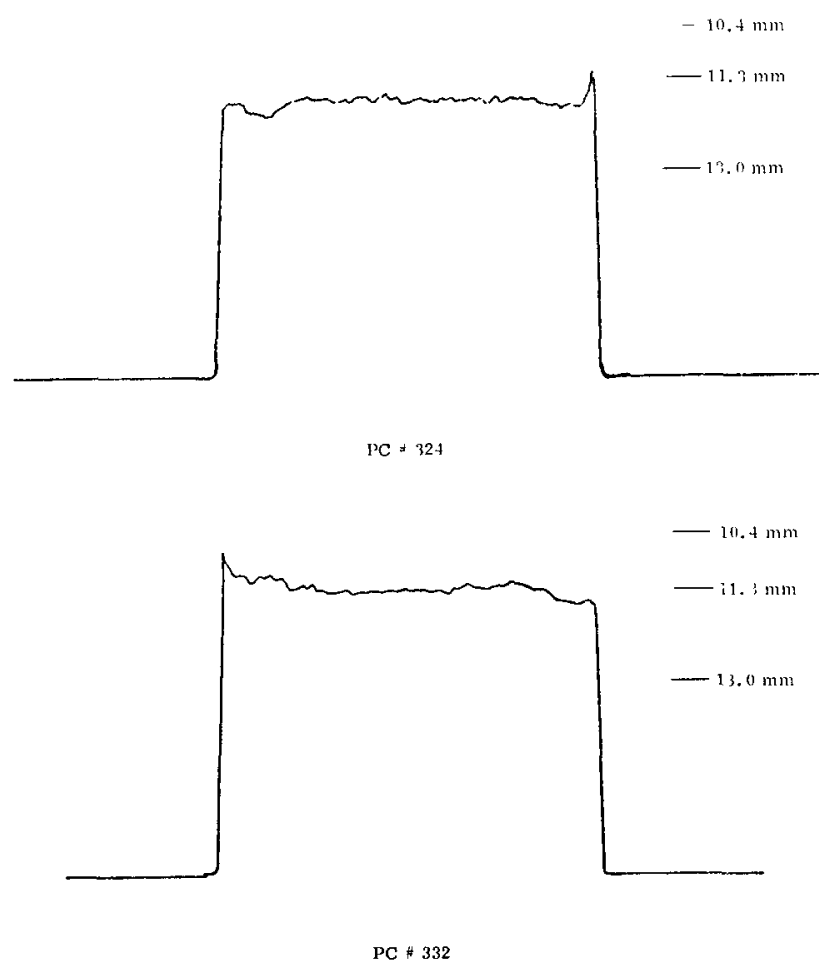

Fig. $C-1$.

Typical densities of $Y-12$ carbon felt. 
atmosphere This heat treatment was considered necessary to remove any impurities and to make the insulators dimensionally stable

Again, each insulator was inspected, nondestructively, for density vs length in a device called MULE (mass per unit length examination) An equivalent density (equivalent to zirconium metal thickness in millimeters) was recorded for each $10 \mathrm{~mm}$ of axial length The first reading is $1 \mathrm{~cm}$ from the serial number end of the insulator The densities for two typical insulators following the conversion-coatıng run and the heat treatment are shown in Table C-I

In addition to the density measurements, each insula tor was weighed before and after the conversion-coating run and after the heat-treatment run The data for Runs B3-444 and B2 122 are shown in Table C-11 for two typical insulators

Following the nondestructive testing, the insulators were to be machined to meet $\mathrm{NF}-2$ reactor requirements Unfortunately, the conversion and heat treating of the insulators had barely been finıshed when funding for the Rover Program was termınated Machınıng requirements for the NF-2 insulators were specified on LASL Drawings 43Y-151129 C2 and C3 but machining was not finished

A summary of the 11 production batches showing coating and heat-treatment batch numbers plus some technical data are shown in Table C-III

The density data for Insulator No 324 shown on Table C-I indicates that the average density was equivalent to $3104 \mathrm{~mm}$ of zirconium metal (density equal to 644 $\mathrm{g} / \mathrm{cm}^{3}$ ) Since the insulator material is $\mathrm{ZrC}$ (density equal to $661 \mathrm{~g} / \mathrm{cm}^{3}$ ), if one assumes that the ratio of densities would convert directly to insulator thickness, then the thickness of $\mathrm{ZrC}$ would be $3024 \mathrm{~mm}$ This thickness of $\mathrm{ZrC}$ would indicate a theoretical density of $38 \%$ since the entire insulator thickness is equivalent to $1080 \mathrm{~mm}$

The percent of theoretical density for Insulator No 324 is $308 \%$ in Table C Il However, this number is based

TABLE C-I

\section{EQUIVALENT Zr METAL THICKNESSES OF CONVERTED ZrC INSULATORS}

\begin{tabular}{|c|c|}
\hline $\begin{array}{c}\text { Insulator No. } 324 \\
\text { (mm) }\end{array}$ & $\begin{array}{c}\text { Insulator No. } 332 \\
(\mathrm{~mm})\end{array}$ \\
\hline 2870 & 2802 \\
\hline 2835 & 2774 \\
\hline 2955 & 2733 \\
\hline 2915 & 2774 \\
\hline 3010 & 2781 \\
\hline 3000 & 2813 \\
\hline 3065 & 2822 \\
\hline 3086 & 2869 \\
\hline 3129 & 2899 \\
\hline 3141 & 2934 \\
\hline 3191 & 2986 \\
\hline 3184 & 2949 \\
\hline 3219 & 2982 \\
\hline 3184 & 2956 \\
\hline 3274 & 2984 \\
\hline 3346 & 3011 \\
\hline 3356 & 2941 \\
\hline Av 3104 & Av 2883 \\
\hline
\end{tabular}

TABLE C-II

\section{TYPICAL PRODUCTION DATA FOR THE CONVERSION-COATING HEAT-TREAT RUNS}

NF-2 Insulators

Coat Date $\quad 11-27-72$

Heat-Treat Date 12-5-72
Boxes 1012 A, B, C, 1013A

Bertha Run No B 3-444

Bertha Run No B2-122

\begin{tabular}{|c|c|c|c|c|c|c|c|}
\hline $\begin{array}{c}\text { Insulator } \\
\text { No. } \\
\end{array}$ & $\begin{array}{r}\text { Box } \\
\text { No. }\end{array}$ & $\begin{array}{c}\text { Received } \\
\text { Wt, g }\end{array}$ & $\begin{array}{c}\text { Converted } \\
\text { Wt, g } \\
\end{array}$ & $\begin{array}{c}\text { Conversion } \\
\text { Factors } \\
\end{array}$ & $\begin{array}{l}\text { Percent } \\
\text { of T.D. } \\
\end{array}$ & $\begin{array}{c}\text { Heat Treat } \\
\text { Wt, g }\end{array}$ & $\begin{array}{c}\text { Heat Treat } \\
\text { Loss, } g \\
\end{array}$ \\
\hline 324 & $1012 \mathrm{~A}$ & 1274 & 14040 & 1102 & 308 & 13946 & 094 \\
\hline 332 & $1012 B$ & 1236 & 12416 & 1005 & 281 & 12355 & 061 \\
\hline
\end{tabular}

${ }^{\mathrm{a}}$ Theoretical Density (calculated from piece volume and weight) 
TABLE C-III

NF-2 INSULATOR SUMMARY

\begin{tabular}{|c|c|c|c|c|c|c|c|}
\hline \multirow{2}{*}{$\begin{array}{c}\text { Box } \\
\text { Number }\end{array}$} & \multirow[b]{2}{*}{ Quantity } & \multirow{2}{*}{$\begin{array}{c}\text { Conversion } \\
\text { Batch }\end{array}$} & \multirow{2}{*}{$\begin{array}{c}\text { Heat Treat } \\
\text { Batch }\end{array}$} & \multicolumn{2}{|c|}{ T. D. ${ }^{\mathrm{a}}$ Percent } & \multirow{2}{*}{$\begin{array}{c}\text { Evaluation } \\
\text { Pieces }\end{array}$} & \multirow{2}{*}{$\begin{array}{l}\text { Good } \\
\text { Pieces }\end{array}$} \\
\hline & & & & Av & Range & & \\
\hline $1003 \mathrm{ABC}$ & 36 & B 3-437 & B2-112 & 34.8 & $\begin{array}{l}32.4 \\
36.4\end{array}$ & 14 & 22 \\
\hline $1004 A B C$ & 36 & B4-598 & B2-111 & 27.5 & $\begin{array}{l}26.4 \\
29.3\end{array}$ & 12 & 24 \\
\hline $\begin{array}{l}1005 \mathrm{ABC} \\
1006 \mathrm{~A}\end{array}$ & 48 & B4-596 & B2-113 & 30.0 & $\begin{array}{l}27.2 \\
33.1\end{array}$ & 5 & 43 \\
\hline $\begin{array}{l}1006 \mathrm{BC} \\
1007 \mathrm{AB}\end{array}$ & 48 & B3-440 & B2-115 & 30.8 & $\begin{array}{l}28.9 \\
34.1\end{array}$ & 4 & 44 \\
\hline $\begin{array}{l}1007 \mathrm{C} \\
1008 \mathrm{ABC}\end{array}$ & 48 & B3-441 & B2-117 & 28.9 & $\begin{array}{l}27.2 \\
31.6\end{array}$ & 1 & 47 \\
\hline $\begin{array}{l}1009 \mathrm{ABC} \\
1010 \mathrm{~A}\end{array}$ & 48 & B3-442 & B2-119 & 29.0 & $\begin{array}{l}25.1 \\
32.6\end{array}$ & 3 & 45 \\
\hline $\begin{array}{l}1010 \mathrm{BC} \\
1011 \mathrm{BC}\end{array}$ & 48 & B3-443 & B2-120 & 27.3 & $\begin{array}{l}21.4 \\
31.1\end{array}$ & 1 & 47 \\
\hline $\begin{array}{l}1012 \mathrm{ABC} \\
1013 \mathrm{~A}\end{array}$ & 48 & B3-444 & B2-122 & 27.7 & $\begin{array}{l}24.4 \\
32.0\end{array}$ & 1 & 47 \\
\hline $\begin{array}{l}1013 \mathrm{BC} \\
1014 \mathrm{AB}\end{array}$ & 48 & B3-445 & B2-124 & 27.8 & $\begin{array}{l}22.5 \\
33.4\end{array}$ & 1 & 47 \\
\hline $\begin{array}{l}1014 \mathrm{C} \\
1015 \mathrm{ABC}\end{array}$ & 48 & B3-446 & B2-126 & 23.6 & $\begin{array}{l}19.7 \\
24.9\end{array}$ & 3 & 45 \\
\hline $\begin{array}{r}1016 \mathrm{~A} \\
\mathrm{~B}\end{array}$ & $\begin{array}{r}12 \\
6\end{array}$ & B3-45 1 & B2-129 & 30.5 & $\begin{array}{l}28.1 \\
33.5\end{array}$ & & 18 \\
\hline $\begin{array}{r}1017 \mathrm{~A}^{\mathrm{b}} \\
\mathrm{B}^{\mathrm{b}}\end{array}$ & $\begin{array}{l}12 \\
12\end{array}$ & & & 28.2 & $\begin{array}{l}26.5 \\
29.7\end{array}$ & & 24 \\
\hline $1018^{\mathrm{c}}$ & $\overline{498}$ & & & & & $\overline{45}$ & $\overline{453}$ \\
\hline
\end{tabular}


on nominal dimensions and consequently can be in error, but it was a convenient number to use during insulator production. Had the program continued, each insulator would have been machined to rather closely controlled dimensional tolerances, been weighed, and a revised percent of theoretical density would have been calculated.

\section{Evaluation Data}

Approximately 45 insulators were removed from the production pipeline for evaluation purposes, and although all the data and results produced cannot be reported here, a few of the pertinent measurements will be summarized.

Samples

One insulator was taken from each representative production conversion-coating batch and cut into evaluation samples after the heat treatment. These samples included pieces for chemistry, metallography, compressive strength and deformation, and room-temperature thermal conductivity. Unfortunately, the Rover Program termination did not permit completion of the chemistry and metallography samples. However, the strength and thermal-conductivity values were measured on the samples listed in Table C-IV.

\section{CTE}

The longitudinal coefficient of thermal expansion was measured on two NF-2 production insulators. One was Piece No. 10 from Box 1003A, which had a density of $2.36 \mathrm{~g} / \mathrm{cm}^{3}$ (35.8\% of theoretical density), and the other was Piece No. 55 from Box 1004B, which had a density of $1.76 \mathrm{~g} / \mathrm{cm}^{3}$ ( $26.7 \%$ of theoretical density).

The average coefficient of thermal expansion as measured to $2300 \mathrm{~K}$ was

$$
\begin{array}{ll}
\text { Piece 10: } & 7.72 \mu \mathrm{m} / \mathrm{m} \cdot \mathrm{K} \\
\text { Piece 55: } & 7.47 \mu \mathrm{m} / \mathrm{m} \cdot \mathrm{K}
\end{array}
$$

Time did not permit similar measurements in the transverse direction, nor on more pieces, but measurements made in both directions on development material indicated that the material was essentially isotropic.

TABLE C-IV

\section{THERMAL CONDUCTIVITY AND INSULATOR STRENGTH

\begin{tabular}{|c|c|c|c|c|c|c|}
\hline $\begin{array}{c}\text { Box } \\
\text { Number } \\
\end{array}$ & $\begin{array}{c}\text { Piece } \\
\text { Number } \\
\end{array}$ & $\begin{array}{c}\text { Batch } \\
\text { Number } \\
\end{array}$ & $\begin{array}{c}\text { Percent of } \\
\text { T.D. }{ }^{\mathbf{a}} \\
\end{array}$ & $\begin{array}{c}\text { Compressive } \\
\text { Deformation }^{b} \\
(\% \Delta 1) \\
\end{array}$ & $\begin{array}{c}\text { Compressive } \\
\text { Strength,c } \\
\text { (psi) } \\
\end{array}$ & $\begin{array}{c}\text { Thermal } \\
\text { Conductivityd } \\
\left(\mathrm{W} / \mathrm{m}^{\circ} \mathrm{K}\right) \\
\end{array}$ \\
\hline $1003 \mathrm{~B}$ & 15 & B 3-437 & 36.4 & 2.3 & 6526 & 0.79 \\
\hline $1004 \mathrm{~A}$ & 51 & B4-598 & 27.4 & 8.5 & 2450 & 0.37 \\
\hline $1005 \mathrm{~A}$ & 84 & B4-596 & 31.9 & 5.2 & 4317 & 0.90 \\
\hline $1006 \mathrm{~B}$ & 124 & B3-440 & 34.0 & & & 0.87 \\
\hline $1007 \mathrm{C}$ & 180 & B 3-441 & 30.9 & 10.0 & 3414 & 0.72 \\
\hline $1009 \mathrm{~A}$ & 225 & B 3-442 & 30.1 & & & 1.44 \\
\hline $1010 \mathrm{C}$ & 282 & B 3-443 & 25.0 & & & 1.85 \\
\hline $1012 \mathrm{~B}$ & 340 & B3-444 & 26.6 & 34. & 4568 & 1.99 \\
\hline $1013 \mathrm{C}$ & 379 & B3-445 & 22.5 & & & 1.63 \\
\hline $1015 \mathrm{~B}$ & 442 & B3-446 & 19.7 & 45 . & 2108 & 1.37 \\
\hline
\end{tabular} AS A FUNCTION OF THEORETICAL DENSITY}




\section{Chemistry and Metallography}

Chemical analyses were completed on three insulators that had also been used for compressive deformation and strength measurements (Table C-IV).

These insulators had been heat treated and then machined to remove any surface layer effects. The chemical analyses are shown in Table $\mathrm{C}-\mathrm{V}$.

TABLE C-V

CHEMICAL ANALYSES OF PRODUCTION INSULATORS

\begin{tabular}{|c|c|c|c|c|}
\hline Insulator No. & Ar wt\% & $\mathbf{C}_{\mathbf{T}} \mathbf{w t} \%$ & $\mathrm{C}_{\mathrm{F}} \mathrm{ppm}$ & C to $\mathrm{Zr}$ Ratio \\
\hline 100 & 89 & 10.58 & 490 & 0.90 \\
\hline 1005 & 88.6 & 11.18 & 630 & 0.96 \\
\hline $1007 \mathrm{C}-180$ & 88.8 & 11.04 & 410 & 0.94 \\
\hline
\end{tabular}

Chemistry results indicate that the insulators were slightly substoichiometric and this in turn contributes to the low thermal-conductivity values reported.

Metallographs of these insulators indicate that the entire carbon fiber has been converted to $\mathrm{ZrC}$; very little, if any, free carbon can be seen as substantiated by the chemical analyses. The metallographs also show that the coating process has been applied uniformly across the entire insulator cross section. Each converted fiber had received essentially the same amount of coating. The careful control during the coating process had not resulted in the coating being deposited on the insulator surface to form a "can" coat, but the coating had penetrated completely. 


\title{
APPENDIX D
}

\section{CONTRIBUTIONS FOR FINAL INSULATOR REPORT}

\author{
Design Considerations for Insulator Development
}

\section{by}

\section{T. J. Merson}

\section{Introduction}

As originally conceived, the program was to provide insulators for three separate applications

1 Flight reactor tie tube

2 Flight reactor periphery

3 NF 2 cell tubes

Each application had specific design requirements and functions A later charter was given to consider an insulator for the NF-2 hot-end washer

\section{Flight Reactor Tie Tubes}

The purposes of the tie tube insulators are to

1 Protect the tie tube from excessive temperatures,

2 Reduce heat flux from the fuel (reducing fuel thermal stress),

3 Meter the heat flow to the support system coolant such that the gas exit conditions were proper for turbine operation, and

4 Maintain structural integrity during the life of the reactor

Specific operating conditions are defined in another Los Alamos Scientific Laboratory report

\section{Flight Reactor Periphery}

The purposes of the insulator for the flight reactor periphery are to

1 Protect the metallic wrapper and beryllium slat from excessive temperatures,
2 Reduce the heat flux from the fuel to the slats, and

3 Support any bundling load that was needed external to the core

Calculations showing operating conditions are given in another Los Alamos Scientific Laboratory report

\section{NF-2 Cell}

The purposes of the insulators in the NF-2 cells are to

1 Reduce heat loss from the fuel

d To reduce fuel thermal stresses

b To keep the aluminum cell tube temperatures below redline with the limited water cooling rates avalable, and

2 Provide some radial mechanical support to the fuel element

Design calculations are presented in several LASL internal documents for effect of thermal conductivity, 19-hole carbide cluster, thermal stress, axial expansions, size calculations, and effect of thermal transients

\section{NF-2 Hot-End Washer}

The purpose of the hot-end washer is to provide a temperature transition and thermal impedance from the hot fuel and support tip to the aluminum tube bundle This insulator had a compressive strength requirement because it took the entire fuel pressure drop while at operatıng temperature 
This report has been reproduced directly from the best avarlable copy

It is avaulable to DOE and DOE contractors from the Office of Scientific and Technical Information,

PO Box 62,

Oak Ridge, TN 37831

Prices are avallable from

(615) 576-8401, FTS 626-8401

It is avalable to the public from the

National Technical Information Service,

U S Department of Commerce,

5285 Port Royal Rd,

Springfield, VA 22161 